\title{
I. Die Thoraxerkrankungen des Neugeborenen
}

\author{
Von \\ H.C. OPPERMANN \\ Mit 29 Abbildungen
}

\section{A. Einleitung}

\section{Physiologische Vorbemerkungen}

Das Neugeborene muß mit dem Moment der Geburt sehr abrupt Atmung und andere Vitalfunktionen selbsttätig übernehmen. Hierbei kommt es innerhalb kürzester Zeit zu dramatischen Veränderungen in den Lungen, am Herzen und vor allem in der pulmonalen Strombahn.

Während die Entwicklung des Tracheo-Bronchialsystems bereits am Ende der 16. Gestationswoche vollständig abgeschlossen ist (REID 1977) sind die Alveolen bei Geburt noch nicht total ausgereift. Bei einem reifen Neugeborenen sind etwa 20 Mio primitive Alveolarsäckchen ausgebildet, die bereits mit reifem Alveolarepithel ausgekleidet sind (BOYDEN 1965; DAviES u. REID 1970). Bis zur vollständigen Entfaltung dieser Alvolarsäckchen vergehen in der Regel nach der Geburt einige Stunden, obwohl bereits die ersten Atemzüge des Neugeborenen sehr intensiv sind (Berdon u. Baker 1966; FawcitT et al. 1960; Grossmann et al. 1970; Karlberg et al. 1962). In ihrer reifen, d.h. endgültigen Form entwickeln sich die Alveolen erst in der 5. Lebenswoche in der peripheren Endstrecke der Bronchioli respiratorii (BOYDEN 1965).

Die Lungen des reifen Neugeborenen enthalten bei Geburt noch residuale fetale Lungenflüssigkeit. Bei einem normalen Geburtsvorgang kann beim Durchtritt durch den Geburtskanal ein transpulmonaler Druck bis zu $100 \mathrm{~cm} \mathrm{H}_{2} \mathrm{O}$ erzeugt werden. Dadurch werden etwa 20-30 $\mathrm{ml}$ fetale Lungenflüssigkeit aus den Lungen exprimiert und über die Trachea und den Mund entleert. Neugeborene, die per Sectio caesarea geboren werden, haben daher post partum wesentlich mehr residuale fetale Lungenflüssigkeit (KARLBERG 1960; KarLBERG et al. 1962; Saunders u. Milner 1978). Der überwiegende Anteil fetaler Lungenflüssigkeit wird über das Lungeninterstitium in die Lymphgefäße abgeleitet und dann über die Kapillaren oder über die systemischen Venen in den Kreislauf drainiert (KARLBERG et al. 1962; SCARPELLI et al. 1975). Tierexperimentell ließ sich eine signifikante Zunahme des pulmonalen Lymphflusses in den ersten 6 Lebensstunden nachweisen (HUMPHREYs et al. 1967). Auch konnte eine Erhöhung des Leitungsvermögens des pulmonalen Epithels bewiesen werden.

Dieser Mechanismus wird als Adaptation zur Absorption fetaler Lungenflüssigkeit angesehen (Aherne u. Dawkins 1964; Goldman u. SCarpelli 1981; Strang 1977).

Die Entwicklung der Lungenarterien und -venen nimmt im prä- und im intraazinären Abschnitt einen unterschiedlichen Verlauf. Die präazinären Lungenarterien und -venen reifen 
gleichzeitig mit dem Bronchialbaum aus. Dagegen entwickeln sich die intraazinären Gefäßabschnitte überwiegend erst postnatal (REID 1977). -

In dem pulmonalen Gefäßbett des Neugeborenen spielen sich besonders dramatische Veränderungen $\mathrm{ab}$. Vor allem die muskularisierten präazinären Lungengefäße mit einem Durchmesser von weniger als $250 \mu \mathrm{m}$ erfahren gewaltige Strukturveränderungen. Hierbei kommt es bis zum 3. Lebenstag vornehmlich in diesen Gefäßabschnitten zu einer starken Reduktion der Gefäßmuskulatur und dadurch zu einer erheblichen Zunahme der Gefäßlumina. Dieser aktive Remodellierungsprozeß im Lungengefäßbett des Neugeborenen führt zu einer Senkung des pulmonalen Gefäßwiderstandes und gewährleistet so die Adaptation an das extrauterine Leben (HisLOP u. REID 1973; REID 1977).

Die genannten Vorgänge bestimmen die röntgenmorphologisch erfaßbare Lungenstruktur des Neugeborenen. Die Lungentransparenz hängt somit ab von dem Ausprägungsgrad der Ventilation der primitiven Alveolarsäckchen, dem Ausmaß der Resorption fetaler Lungenflüssigkeit und den Veränderungen der pulmonalen Strombahn. Im Normalfall schreitet die Lungenaufhellung postnatal in zentripetaler Richtung kontinuierlich fort, sie beginnt immer in den Oberlappen (Aherne u. Dawkins 1964; Goldman u. Scarpelli 1981; Humphreys et al. 1967; STRANG 1977).

\section{Normaler Neugeborenenthorax}

Der Neugeborenenthorax hat im Gegensatz zur ellipsoiden Form des Erwachsenenthorax nahezu eine Kreisform, da die Differenz zwischen sagittalem und transversalem Thoraxdurchmesser wesentlich kleiner ist als im Erwachsenenalter. Der Mittelwert für den sagittalen Thoraxdurchmesser in Höhe der 7. bis 8. Rippe beträgt für Mädchen 8,4 und Knaben $8,7 \mathrm{~cm}$, der Transversaldurchmesser 10,6 cm, bzw. 10,9 cm (ZseBöK 1958).

Ganz wesentlich wird die Thoraxform durch den Zwerchfellrippenwinkel beeinflußt, seine Größe ist interindividuell sehr unterschiedlich; meist beträgt der Wert des Winkels weniger als $90^{\circ}$. Die Rippen des Neugeborenen sind noch überwiegend knorpelig und dementsprechend sehr biegsam, bzw. leicht verformbar. Der Verlauf der Rippen ist im Neugeborenenalter weitgehend horizontal (OPPERMANN et al. 1982; S. 5; ZSEBÖK 1958) (Abb. $1 \mathrm{a}, \mathrm{b}$ ).

Die Weichteile des Neugeborenenthorax sind ausgesprochen locker und daher leicht verschieblich. Dadurch bedingt kann es beim Anpressen des Neugeborenen an die Filmkassette infolge von Hautfaltenverschiebungen zu Pseudobefunden kommen. Hierbei kann u.a. ein Pneumothorax vorgetäuscht werden. Umschriebene Weichteilschwellungen im Thoraxwandbereich sind besonders beachtenswert, da diese oft den ersten Hinweis auf einen entzündlichen oder tumorösen Prozeß am Thoraxskelett darstellen (OPPERManN et al. 1982, S. 5).

Das Mediastinum des Neugeborenen ist normalerweise sehr breit. In Hilushöhe entspricht die Mittelschattenbreite etwa der Hälfte des Thoraxtransversaldurchmessers, bei Erwachsenen ist die Relation zwischen Mittelschatten und Thoraxtransversaldurchmesser in Hilushöhe etwa $1: 3$ (ZsEBÖK 1958).

Die Mediastinalgrenzen sind - bedingt durch die Thymusüberlagerung - im oberen Anteil meist schlecht erkennbar. In Längsrichtung des Mediastinum erkennt man rechtsseitig parallel zur Wirbelsäule und etwas nach rechts ausladend - in gut exponierten Thoraxaufnahmen eine Verdichtungslinie, die in Höhe der Sternoklavikulargelenke beginnt und bis unter das Zwerchfell hin $\mathrm{zu}$ verfolgen ist. Diese Struktur entspricht der pleuro-mediastinalen Umschlagsfalte, die bei ausgeprägter Luftfüllung des Ösophagus auch linksseitig abgrenzbar ist (PATRIQuin et al. 1976). 

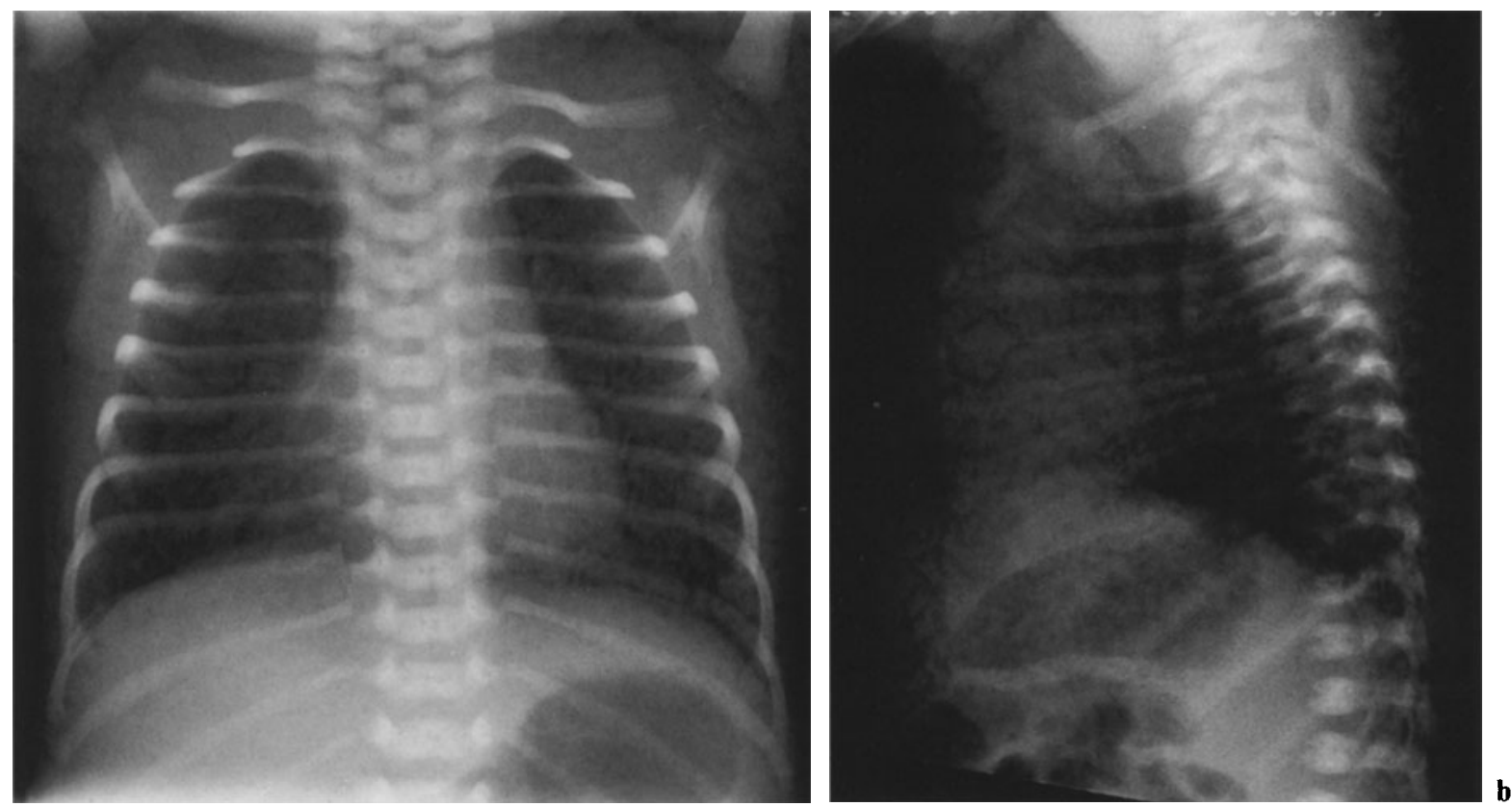

Abb. 1a, b. Zwei Tage altes Neugeborenes. Normales Thoraxskelett mit horizontalem Rippenverlauf. Mittelständiges, normal großes und unauffällig konfiguriertes Herz. Regelrechte Perihilär- und Lungengefäßzeichnung. Seitengleiche, gute Belüftung der Lungen

Die Trachea des Neugeborenen hat noch ein instabiles Knorpelgerüst und ist nur locker im Mediastinum fixiert. Hierdurch bedingt ist die Weite des Tracheakalibers in In- und Exspiration sehr unterschiedlich, zusätzlich ändert sich der Tracheaverlauf mit der jeweiligen Atemphase. In der Sagittalebene weist die Trachea eine geringe Abweichung nach rechts durch die normalerweise links verlaufende Aorta descendens auf. In der Transversalebene zeigt die Trachea beim Eintritt in den Intrathorakalraum eine geringe Ausbuckelung nach ventral, welche während der Exspiration besonders deutlich wird.

Gelegentlich sieht man in Höhe des Manubrium sterni eine umschriebene Tracheaimpression von ventral, die entweder durch eine Arteria lusoria oder durch eine anormale linksseitige Arteria carotis communis bedingt ist. Nur in Ausnahmefällen verursacht diese gefäßbedingte Tracheaimpression eine klinische Symptomatik (BERDON u. BAKER 1966; SwischuK 1971; SwischuK u. HaYden 1984).

Die Inspiration führt zu einer Streckung und Dilatation der Trachea, während die Exspiration eine Verkürzung der Trachea mit deutlicher Kaliberabnahme nach sich zieht. Diese ist in der Transversalebene wesentlich besser sichtbar als in der Sagittalebene. Bei intensivem Schreien des Neugeborenen oder Anhalten des Atems kann das Tracheakaliber in VentroDorsal-Richtung um 20-50\% variieren (WiTTENBORG et al. 1967).

Der Abstand zwischen Tracheahinterwand und Vorderkante des 6. Halswirbelkörpers beträgt im Normalfall nicht mehr als die doppelte Länge des 6. Halswirbelkörpers (ABLOW 1971).

Der Thymus besteht meistens aus zwei asymmetrischen Anteilen. Im Normalfall ist der Thymus im vorderen oberen Mediastinum, unmittelbar hinter dem Sternum und vor den großen Gefäßen, der Trachea und dem Perikard lokalisiert. Dieser Raum wird auch als Thymusloge bezeichnet (CAFFEY 1978; SONE et al. 1980).

Der Thymus zeigt in Größe und Form eine ausgesprochene Variabilität (BARTH et al. 1976; Ebel 1980; TAusend u. STERN 1965). Bei seitenbetonter Prominenz eines Thymuslap- 
pens, vornehmlich des rechten und Ausbreitung desselben bis zum kleinen Lappenspalt kann der Thymus eine segelartige Form annehmen, die in der Transversalebene noch deutlicher wird (KEMP et al. 1948). Nur in Ausnahmefällen breitet sich der Thymus bis in den unteren Halsbereich oder bis in das hintere Mediastinum aus (HINDs et al. 1970; KABELKA et al. 1977; SAADE et al. 1976).

Der Thymusrand wird häufig durch die vorderen Rippenenden imprimiert, so daß eine wellenförmige Thymuskontur resultiert. Dieser Befund ist häufiger auf der linken Seite erkennbar (Mulvey 1963; OpPermanN et al. 1982, S. 5). Oft überlagert der Thymus haubenartig die Herzsilhouette und täuscht somit eine Kardiomegalie vor. Bei gut exponierten Thoraxaufnahmen ist aber der Unterschied zwischen dem transparenteren Thymus und dem Herzen deutlich sichtbar (Abb. 2). - Auch ein großer Thymus führt nahezu nie zu einer Einengung des Tracheakalibers. Ausnahmen hierzu bilden lediglich Thymome oder Thymuszysten, besonders dann, wenn es zu einer Einblutung in dieselben kommt (OPPERMANN et al. 1982, S. 5; SHACKelford u. MCAllister 1976; Young 1973).

Das Herz des Neugeborenen ist im Vergleich zu später relativ rund konfiguriert. Der überwiegende Anteil des Herzschattens liegt im linken Hemithorax, d.h. im Normalfall besteht eine Lävokardie. Die Herzlängsachse hat - bezogen auf den Transversaldurchmesser - im Normalfall einen Neigungswinkel von $20^{\circ}$ bis höchstens $45^{\circ}$ (SCHUMACHER et al. 1978).

Insgesamt nimmt das Herz somit mehr eine horizontale Lage ein als im späteren Alter. Der Herz-Thorax-Quotient beträgt in den ersten 4 Lebenswochen im Mittel 0,55, Werte von mehr als 0,62 sind als pathologisch anzusehen (BAWKIN et BAWKIN 1935; EDWARDS et al. 1981; TAYBI 1971). Bei einer Herzvergrößerung ist die Zuordnung zu einem der beiden Ventrikel in der Neugeborenenperiode nur wenig möglich. Im Normalfall werden auch beim Neugeborenen die Herzspitze und der linke untere Herzrand vom linken Ventrikel gebildet.

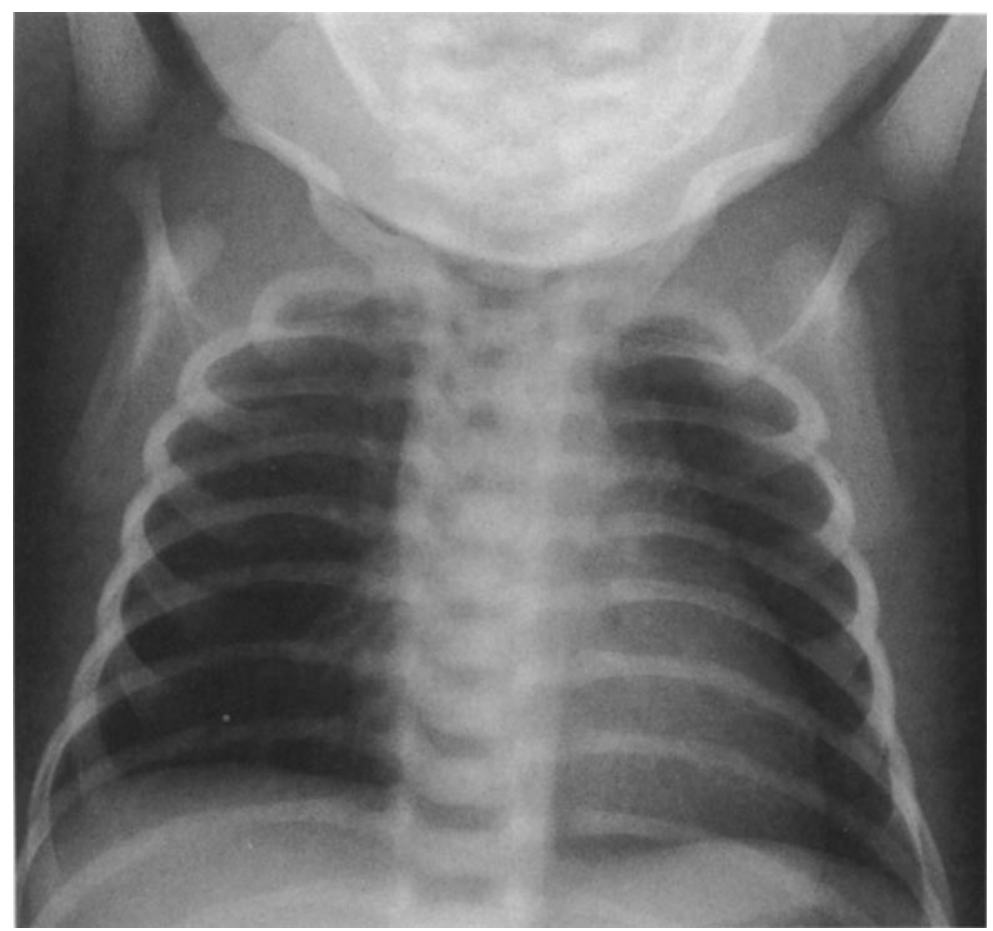

Abb. 2. Ein Tag altes Zwillings-Neugeborenes mit normalem Thoraxbefund. Links das Herz überlagernder Thymus mit wellenförmiger Kontur 
Der Hauptanteil des rechten Ventrikels liegt zentral. Die linke obere Herzkontur wird vom Ausflußtrakt des rechten Ventrikels und dem Hauptstamm der Arteria pulmonalis gebildet. Physiologischerweise besteht beim Neugeborenen eine mäßige Rechtshypertrophie, die sich im Thoraxbild durch eine Anhebung der Herzspitze zu erkennen gibt (Ulmer 1982; SCHUMACHER et al. 1978).

Die postnatale Adaptation des Lungenkreislaufes an die extrauterinen Verhältnisse unterliegt ausgeprägten, aber physiologischen Variationen. Dadurch ist die Beurteilung der Lungengefäßstruktur besonders in der Neugeborenenperiode erschwert. Zur röntgenmorphologischen Analyse und Beurteilung der Lungengefäße hat sich in der Neugeborenenzeit eine symmetrische, senkrechte Unterteilung des linken und rechten Hemithorax in jeweils drei Flächenabschnitte bewährt (MoËs et al. 1978; NADAS u. FylER 1972; UlMER 1982; SCHUMACHER et al. 1978). Die Pulmonalgefäße lassen sich so im Längs- wie im Querschnitt beurteilen. Die Lungenarterien stellen sich deutlicher abgrenzbar dar als die Lungenvenen, vor allem im Querschnitt sind die Lungenarterien scharf begrenzt. Im Bereich der Lungenbasis sind die arteriellen Gefäßquerschnitte normalerweise größer als in der Lungenspitzenregion (MOES et al. 1978).

Von den Hili ausgehend verjüngen sich die Lungengefäße zur Peripherie hin harmonisch, sie sind im Normalfall im lateralen Flächendrittel des rechten und linken Hemithorax nicht mehr nachweisbar. Im hilusnahen Flächendrittel lassen sich die orthograd getroffenen Pulmonalarterien gut von den ihnen benachbarten lufthaltigen Bronchialquerschnitten trennen.

Wenn die Gefäßquerschnitte größer als die ihnen zugeordneten Bronchusquerschnitte sind, ihre Zahl vermehrt ist und sie auch im lateralen Flächendrittel nachweisbar sind, liegt eine aktive Lungenüberdurchblutung vor.

Die Interlobärfissur ist bei etwa 30-50\% aller Neugeborenen am 1. Lebenstag sichtbar. Nach der Resorption fetaler Lungenflüssigkeit, die spätestens $72 \mathrm{~h}$ post partum abgeschlossen ist, ist das Interlobium nur noch diskret oder nicht mehr nachweisbar (AvERY et al. 1981, S. 284; Bean et al. 1969; Nadelhaft u. Ellis 1957; Peterson u. Pendleton 1955).

Das Zwerchfell liegt beim Neugeborenen in mittlerer Inspirationslage in Höhe des dorsalen Rippenanteils der 8. bis 9. Rippe, bzw. des ventralen Anteils der 6. Rippe. Links wird der mediale Anteil des Zwerchfellschenkels vornehmlich vom Herzen überlagert, so daß dieser weder im Sagittalbild noch in der Transversalebene abgrenzbar ist. Die Zwerchfellkuppe liegt vor der Zwerchfellmitte und etwas medial von dieser (OPPERMANN et al. 1982, S. 5).

\section{B. Lungenerkrankungen des Neugeborenen}

\section{Transitorische Tachypnoe}

Diese Neugeborenenerkrankung wurde erstmals 1966 von AVERY et al. als einheitliches Krankheitsbild beschrieben. Als Synonyma dieser Erkrankung sind in der Literatur respiratory distress syndrome Typ II (Sundell et al. 1971) und die wet lung disease (WeSENBERG et al. 1971) geläufig. Von einer transitorischen Tachypnoe ist erst dann zu sprechen, wenn die normale postpartale Tachypnoe über mehr als 20 Min anhält (WeSENBERG 1973).

Diesem Krankheitsbild liegt eine verzögerte Resorption fetaler Lungenflüssigkeit über das venöse System und das Lymphgefäßsystem zugrunde; zusätzlich wird eine Beeinträchtigung der Lungencompliance durch überfüllte Lymphgefäße vermutet. Möglicherweise spielt auch eine Hypoproteinämie eine pathogenetische Rolle bei diesem Krankheitsgeschehen 


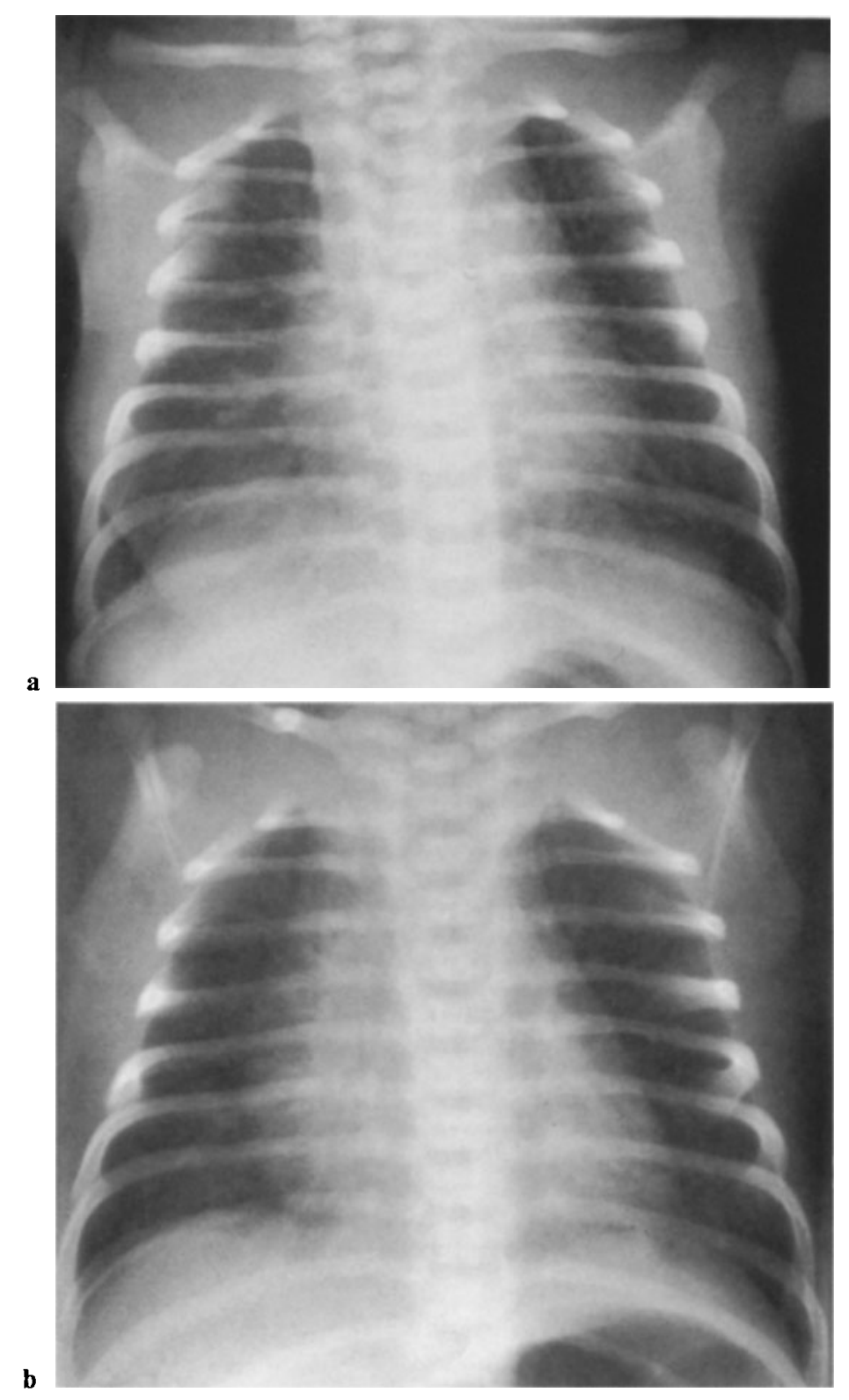

Abb. 3. a $4 \mathrm{~h}$ altes Neugeborenes nach Sektio mit transitorischer Tachypnoe. Schleierige Eintrübung beider Lungen, die erheblich überbläht sind. Grobstreifige Verdichtungen perihilär, rechts betont. Normal großes Herz. Hautfaltenüberlagerung der rechten Lunge. b Nach 14 h hat sich die fetale Lungenflüssigkeit vollständig resorbiert

(Avery et al. 1966; Avery et al. 1981, S. 312; FleTCHER et al. 1970). Neuere echokardiographische Untersuchungen lassen vermuten, daß ein passageres Linksherzversagen mitverantwortlich ist für die Entwicklung dieses Krankheitsbildes (Halliday et al. 1981).

Die transitorische Tachypnoe tritt bevorzugt bei Frühgeborenen und per Sectio caesarea geborenen Kindern auf, bei letzteren, weil bei ihnen das Exprimieren der fetalen Lungenflüssigkeit beim Durchtritt durch den Geburtskanal entfällt (Milner et al. 1978; OpPERmanN et al. 1982, S. 47; Rimmer u. FawcitT 1982). Typisch für dieses Krankheitsbild ist sein flüchtiger Charakter und die gute Korrelation zwischen klinischer und radiologischer Symptomatik (AverY et al. 1981, S. 312; SwISCHUK 1970). 
Röntgenologisch findet sich eine grobretikuläre, meistens symmetrische Zeichnungsvermehrung in der Perihilärregion, die das Korrelat interstitieller Flüssigkeitsansammlung darstellt. Im Einzelfall können auch umschriebene Flüssigkeitsansammlungen in Form grobflekkiger Eintrübungen nachweisbar sein, die allein röntgenmorphologisch nicht von pneumonischen Infiltrationen zu unterscheiden sind. Die Lungen sind - im Gegensatz zum idiopathischen Atemnotsyndrom - immer überbläht (Avery et al. 1966; KUHN et al. 1969; OPPERMANN et al. 1982, S. 47; PonHold 1981; Swischuk 1970).

Kleine Pleuraergüsse und/oder intraseptale Flüssigkeitsansammlungen sind häufig, aber nicht pathognomonisch, sie werden auch bei gesunden Neugeborenen in einer Frequenz bis zu 50\% beobachtet (BeAN et al. 1969; Harris 1981; NAdelhaft u. Ellis 1957) (Abb. 3 a, b). Im Ausnahmefall kann eine umschriebene Ansammlung fetaler Lungenflüssigkeit wie ein weichteildichter Tumor imponieren, der dann aber mit zunehmender Resorption innerhalb von 48-72 h ,,zusammenschmilzt" (Swischuk et al. 1981). Die Differentialdiagnose der transitorischen Tachypnoe umfaßt das Atemnotsyndrom Stadium I, eine perinatale Pneumonie, einen persistierenden Ductus arteriosus Botalli, eine neonatale Plethora, ein Vitium cordis (in erster Linie ein hypoplastisches Linksherz-Syndrom und eine Lungenvenenfehlmündung Typ III) und die sehr selten vorkommende kongenitale pulmonale Lymphangiektasie (OPPERMANN et al. 1982, S. 47; SAIGAL et al. 1977; WESENBERG et al. 1977).

\section{Atemnotsyndrom}

(Hyaline membrane disease - Surfactantmangel)

Das Atemnotsyndrom ist eine pulmonale Erkrankung nahezu ausschließlich des Frühgeborenen, seltener kommt sie auch bei Neugeborenen diabetischer Mütter und bei Kindern, die durch Sectio caesarea geboren werden, vor (OpPERMANN et al. 1982, S. 48; KöTELES 1982, S. 53).

Ursache dieser Lungenerkrankung ist eine funktionelle Unreife der Lungen, die mit der Entwicklung hyaliner Membranen einhergeht (BLYSTAD et al. 1961; BOMSEL et al. 1951; WOHLFELD 1965; WOLFSON et al. 1969). Infolge der Lungenunreife ist die Enzymreifung in den Alveolardeckzellen Typ II noch unvollständig. Daraus resultiert eine verminderte Phospholipidsynthese, die einen Surfactantmangel zur Folge hat. Im Normalfell senkt der pulmonale Surfactant die Oberflächenspannung an der Luft-Wasser-Grenzschicht der Alveolen und wirkt somit einem exspiratorischem Alveolarkollaps entgegen (AvERY u. Clemens 1963; Howatt et al. 1965; Obladen 1979; Reynolds 1970; Rudolph u. Smith 1960). Mangel an Surfactant oder sein Fehlen führt zu einer verminderten Alveolarstabilität mit Neigung zum Alveolarkollaps. Auf diese Weise entwickeln sich beim Atemnotsyndrom diffuse Mikroatelektasen (Alveolaratelektasen), die einen normalen Gasaustausch in den Lungen weitgehend verhindern (ReYNOLDS 1968; STRANG 1963; TAYLOR u. Abrams 1966).

Somit ist das histomorphologische Bild des Atemnotsyndroms charakterisiert durch diffuse Alveolaratelektasen, belüftete Ductuli alveolares und mit Fibrinbelegen (hyaline Membranen) gefüllten Bronchioli terminales (Abb. 4e). Hyaline Membranen können aber auch im Rahmen einer Mekoniumaspiration, einer perinatalen Pneumonie und bei einer bronchopulmonalen Dysplasie nachgewiesen werden (BaUmanN u. NAdelhaft 1958; Ellis u. NadelHaFT 1957; GregG u. Bernstein 1961; Gruenwald 1958; OpPermann et al. 1982, S. 52; SinGLETON 1967) (Abb. 4).

Röntgenologisch zeigt das Atemnotsyndrom in den meisten Fällen ein charakteristisches Bild. Es besteht eine generelle Hypoventilation beider Lungen. Neben einer diffusen schleierigen Grundeintrübung finden sich klein-granuläre Verdichtungen in diffuser Verteilung; sie 


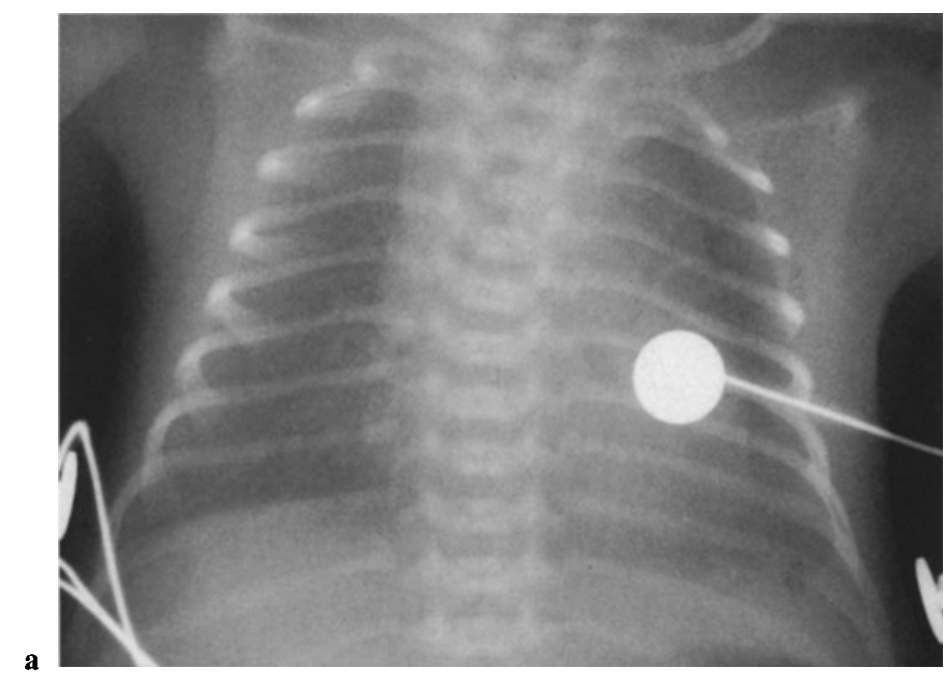

b

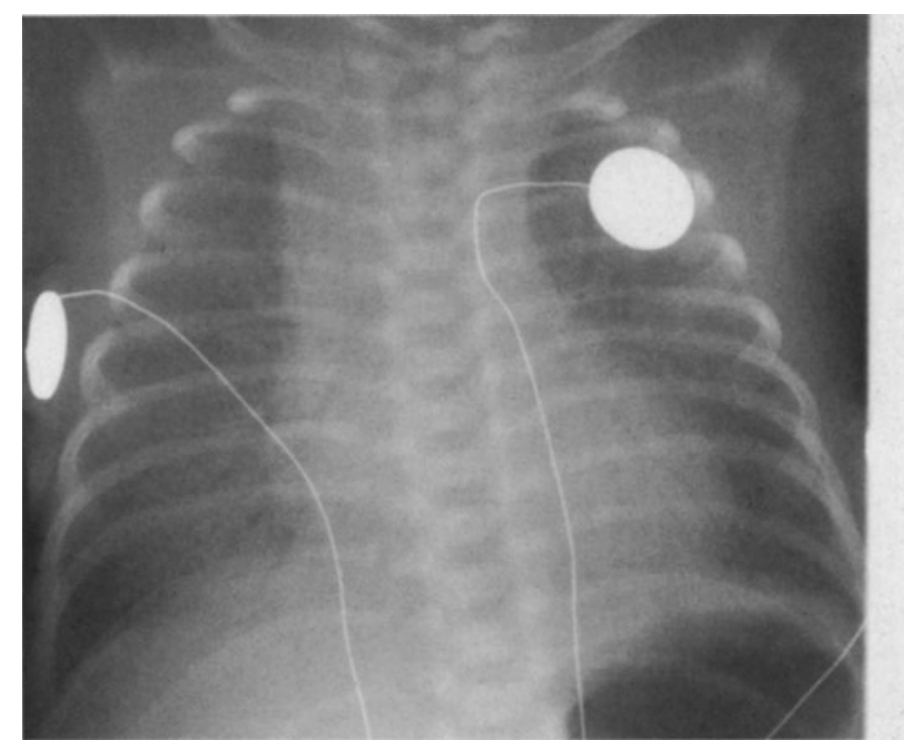

Abb. 4. a Frühgeborenes mit Atemnotsyndrom Stadium I. Diffus schleierige Lungeneintrübung mit retikulogranulärem Lungenmuster. b Frühgeborenes mit Atemnotsyndrom Stadium II. Schleierige, diffuse Lungeneintrübung; diffus retikulo-granuläres Lungenmuster, ausgeprägtes Aerobronchogramm, welches die Herzgrenzen überschreitet. c Frühgeborenes mit Atemnotsyndrom Stadium III. Ausgeprägte diffuse Lungeneintrübung, Unschärfe der Herz- und Zwerchfellgrenzen, besonders rechts. d Frühgeborenes mit Atemnotsyndrom Stadium IV. - Beide Lungen sind total verschattet, Herz und Zwerchfell sind nicht mehr gegeneinander abgrenzbar (Sog. ,weiße Lunge“)

stellen das Korrelat ausgedehnter alveolärer Atelektasen dar. Weiter kennzeichnend für das Atemnotsyndrom ist ein positives Ärobronchogramm, das die Herzgrenzen überschreitet und weit bis in die Peripherie hin zu verfolgen ist. Dieses entspricht den belüfteten Bronchioli terminales und Ductuli alveolares. Das Verhältnis der Alveolarbelüftung zum Luftgehalt der terminalen Luftwege bestimmt das Ausmaß der röntgenmorphologischen nachweisbaren Veränderungen. Zwischen röntgenologisch erfaßbaren Strukturalterationen und klinischer Symptomatik besteht in der Regel eine gute Korrelation.

Die charakteristischen Röntgensymptome des Atemnotsyndroms wurden erstmalig 1953 von Donald u. Steiner beschrieben, sie unterschieden drei Schweregrade. 

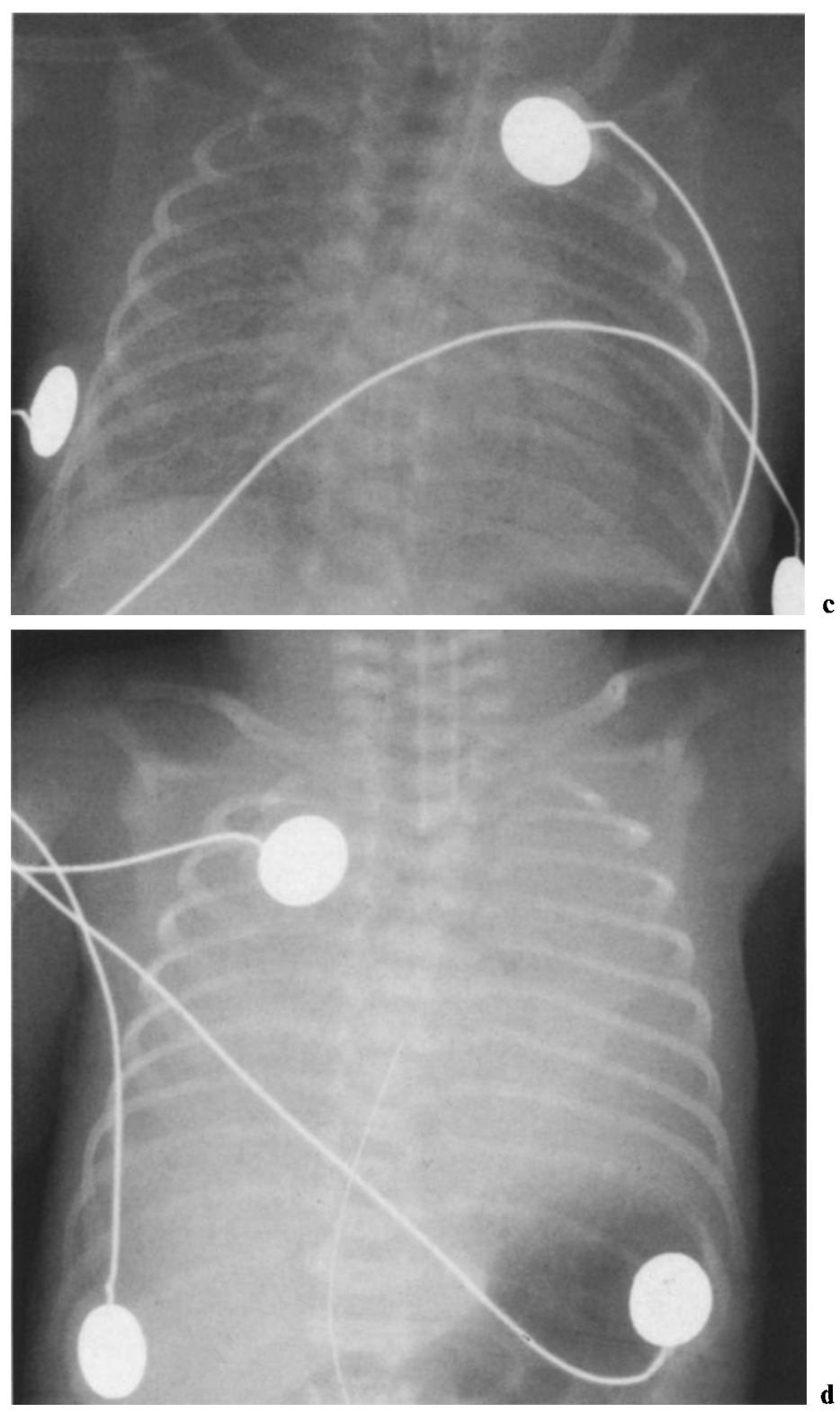

Abb. 4c, d

Heute wird das Atemnotsyndrom in Abhängigkeit von dem Ausprägungsgrad der pulmonalen Strukturveränderungen in vier Stadien unterteilt (CouCHARD et al. 1974; GiEdion et al. 1973; TCHOU et al. 1972; Wolfson et al. 1969). Das Stadium I ist durch eine schleierige Lungeneintrübung mit retikulo-granulärer Lungenstruktur gekennzeichnet (Abb. 4a).

Im Stadium II ist darüberhinaus ein Ärobronchogramm nachweisbar, welches die Herzgrenzen überschreitet (Abb. 4b).

Im Stadium III werden Herz- und Zwerchfellkonturen nur noch unscharf gegeneinander abgrenzbar (Abb. 4c). Im Stadium IV findet sich eine totale homogene Verschattung beider unbelüfteter Lungen. Dieser Schweregrad entspricht der sog. ,weißen Lunge“ (Couchard et al. 1974; Giedion et al. 1973; Peterson u. Pendleton 1955; Wolfson et al. 1969) (Abb. 4d). - Die Röntgensymptome des Atemnotsyndroms sind in der Regel in den basalen 


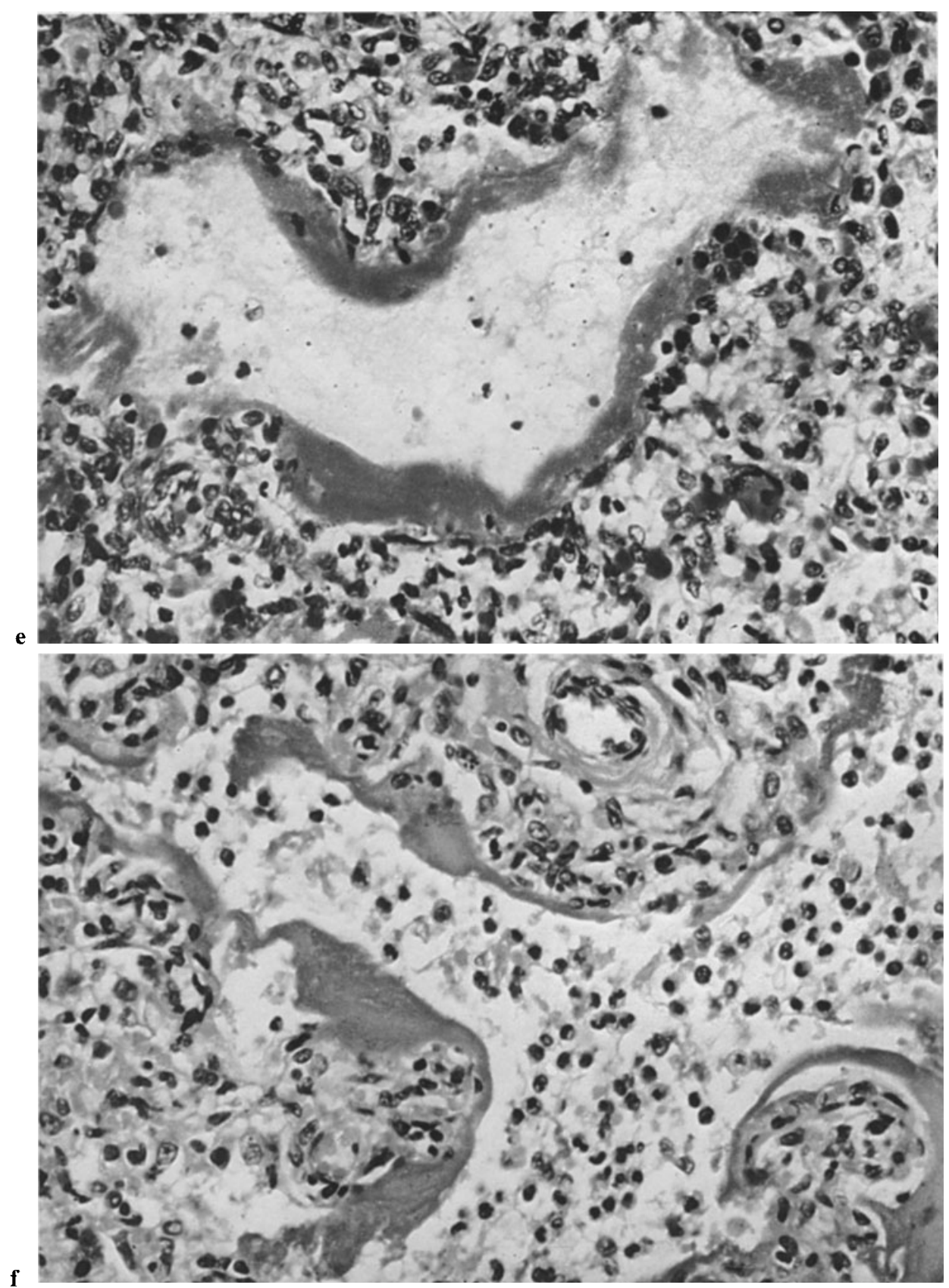

Abb. 4e, f. e Histologischer Befund beim Atemnotsyndrom (Hyaline Membranen). Im Alter von $22 \mathrm{~h}$ verstorbenes Neugeborenes mit ausgeprägtem Atemnotsyndrom. HE $\times 350$. Im zentral gelegenen Alveolargang werden die ausgeprägten hyalinen Membranen sichtbar. $f$ Histomorphologischer Befund bei einem im Alter von 2 Tagen verstorbenen Neugeborenen mit konnataler Pneumonie und hyalinen Membranen. HE $\times 350$. In den Lichtungen der zentral sichtbaren Alveolargängen finden sich neben hyalinen Membranen reichlich Granulozytenansammlungen. (Die Abbildungen wurden mir freundlicherweise von Herrn Professor Dr. D. Harms, Direktor der Abtlg. für Paido-Pathologie der Christian-Albrechts-Universität Kiel zur Verfügung gestellt)

Lungenabschnitten besonders ausgeprägt, weil die Reifung der Lungenoberlappen der der Unterlappen vorausgeht (ABLOw u. OrZALESI 1971; TCHOU et al. 1972). Darüberhinaus können die Lungenstrukturveränderungen eine seitendifferente Ausprägung haben. Dieser 
Befund kann aber auch durch eine längerfristige einseitige Lagerung des Patienten vorgetäuscht werden, da die Resorption der fetalen Lungenflüssigkeit auf der abhängigen Seite verzögert ist.

Unter mechanischer Ventilationsbehandlung ändert sich das röntgenmorphologische Bild des Atemnotsyndroms. Hierbei wird durch Überdehnung der terminalen Luftwege und Alveolen eine Befundbesserung vorgetäuscht, die sich in einer progredienten Lungenaufhellung äußert. Ferner kann eine erneute Lungeneintrübung nach bereits erfolgter zwischenzeitlicher Lungenaufhellung eintreten. Dieses Symptom ist Ausdruck eines passageren Lungenödems. - Das letztere gibt oft - auch ohne gleichzeitige klinische Verdachtsmomente - den ersten Hinweis auf das Vorliegen eines persistierenden Ductus arteriosus Botalli, kann sich aber auch ohne therapeutische Maßnahmen zurückbilden (RHODEs et al. 1975; OPPERMANN et al. 1980, 1983). Eine totale Lungeneintrübung kann mit Reduktion des Inspirationsdruckes während der Heilungsphase des Atemnotsyndroms auftreten. Dieser Befund wird durch eine Exposition der Thoraxaufnahme während der Exspirationsphase oft vorgetäuscht (CLEVELAND u. TODRES 1981).

Bei der Differentialdiagnose des Atemnotsyndroms müssen die Schweregrade, bzw. Stadien, berücksichtigt werden. Im Stadium I und II sind die wichtigsten Differentialdiagnosen transitorische Tachypnoe, die perinatale Pneumonie, insbesondere die B-Streptokokkenpneumonie mit atemnotsyndromähnlichem Bild und die äußerst seltene kongenitale pulmonale Lymphangiektasie. - Beim Atemnotsyndrom Stadium III sind abzugrenzen die Lungenvenenfehlmündung mit venöser Obstruktion (Typ III vornehmlich), die Pulmonalvenenatresie, eine pulmonale Hämorrhagie und das hypoplastische Linksherz-Syndrom. Bei dem Atemnotsyndrom Stadium IV kommen differentialdiagnostisch in Frage eine massive bilaterale Lungenblutung, eine bilaterale Lungenagenesie, eine bronchopulmonale Dysplasie im Stadium II und eine Thoraxaufnahme in maximaler Exspiration.

\section{Persistierender Ductus arteriosus Botalli beim Atemnotsyndrom}

Der persistierende Ductus arteriosus Botalli ist eine häufige und ernsthafte Komplikation bei Frühgeborenen mit und ohne Atemnotsyndrom. Die Größe des Links-Rechts-Shuntes bestimmt hierbei die hämodynamische Bedeutung des Ductus Botalli (JoNES u. Pickering 1977; Oppermann et al. 1980, 1983; Thibeault et al. 1975). Mit dem Persistieren des Ductus arteriosus Botalli ist um so eher zu rechnen, je unreifer das Frühgeborene ist. Etwa 77\% aller Frühgeborenen mit einem Gestationsalter von 28-30 Wochen haben einen persistierenden Ductus Botalli, die Frequenz sinkt auf etwa $21 \%$ bei Frühgeborenen mit einem Gestationsalter von 34 Wochen (SIASSI et al. 1976). Nach den Untersuchungen von Ellison et al. (1983) in einer amerikanischen multizentrischen Studie zeigt sich bei etwa $40 \%$ aller Frühgeborenen mit einem Geburtsgewicht von weniger als $1500 \mathrm{~g}$ ein offener Ductus Botalli.

Im Normalfall kommt es postnatal mit dem Anstieg des arteriellen Sauerstoffpartialdrukkes ( $\mathrm{pa}_{2}$ ) zur Kontraktion der glatten Muskulatur im Ductus arteriosus Botalli. Als Ursache des Persistieren dieser Gefäßverbindung zwischen Lungen- und Körperkreislauf wird eine hohe Syntheserate von Prostaglandin $\mathrm{E}_{2}$ und Prostaglandin $\mathrm{I}_{2}$ angenommen (COCEANI et al. 1980; Jones u. Pickering 1977; Olley u. Coceani 1981; Seyberth 1986; Thibeault et al. 1975). Die vermehrte Aktivität von Prostaglandin $E_{2}$ und Prostaglandin $I_{2}$ ist bei etwa $80 \%$ aller Frühgeborenen mit Atemnotsyndrom nachweisbar (SEYBERTH 1986).

Röntgensymptome, die auf einen persistierenden Ductus Botalli hinweisen, sind ein pulmonales Ödem, eine pulmonale Plethora und eine Veränderung der Herzgröße, entweder in Form einer kontinuierlichen Größenzunahme des Herzens oder einer wechselnden Herzgröße. Bei gleichzeitig vorliegendem Atemnotsyndrom ist eine ausbleibende Lungenaufhellung nach 
spätestens 4-5 Tagen oder eine wieder einsetzende Lungeneintrübung verdächtig auf die Persistenz eines Ductus arteriosus Botalli (Burney et al. 1978; HigGins et al. 1977; OpPerManN et al. 1983; Slovis u. Shankaran 1980). Der Manifestationszeitpunkt für die pulmonale Plethora liegt im Mittel bei etwa 3 Lebenstagen, für die Herzgrößenänderung und das pulmonale Ödem bei etwa 4 Tagen. In einer größeren retrospektiven Studie an Frühgeborenen mit persistierendem Ductus Botalli fanden OPPERMANN et al. (1983) in $75 \%$ dieser Patienten ein pulmonales Ödem, in $78 \%$ eine pulmonale Plethora und in $75 \%$ eine wechselnde Herzgröße (Abb. 5a-c).

Beim pulmonalen Ödem im Rahmen des persistierenden Ductus Botalli sind differentialdiagnostisch abzugrenzen Lungenödeme anderer Genese, die bronchopulmonale Dysplasie im Stadium II, eine Hyperinfusion, ein bilateraler Hydrothorax, eine bilaterale diffuse Pneumonie und eine massive Lungenblutung. - Eine wechselnde Herzgröße oder kontinuierliche Größenzunahme muß zudem die Möglichkeit anderer Shunt-Vitien und das Vorliegen einer septischen Kardiomegalie berücksichtigen.

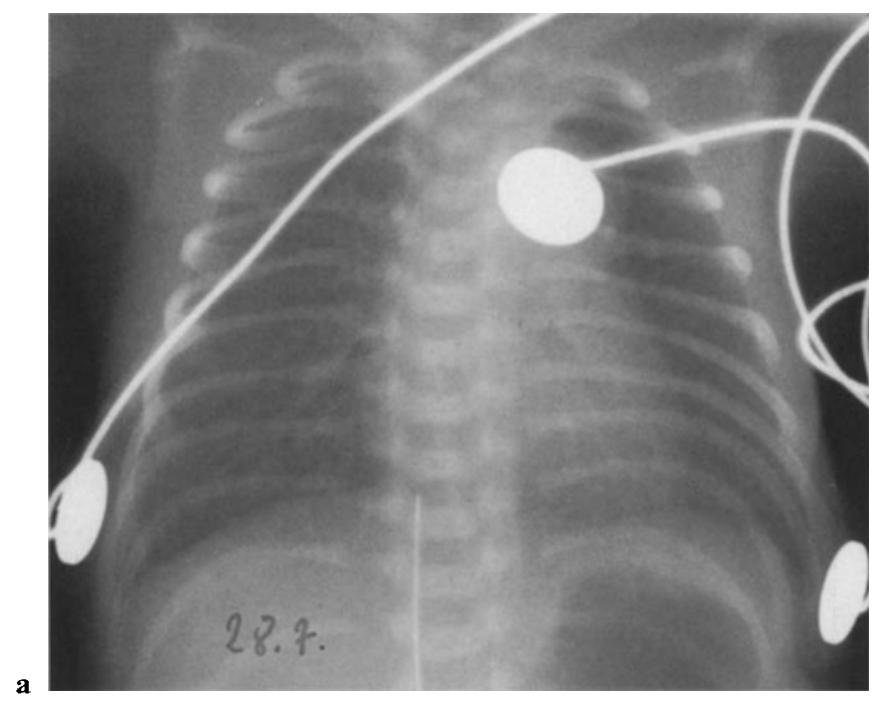

Abb. 5a-c. Frühgeborenes mit Atemnotsyndrom und persistierendem Ductus arteriosus Botalli. a Atemnotsyndrom Stadium I. b Am 8. Lebenstag zunehmende, diffuse Lungeneintrübung und deutliche Herzgrößenzunahme. Rechts zentral vermehrte Gefäßzeichnung. c Am 13. Lebenstag Rückbildung der diffusen Lungeneintrübung, Normalisierung der Herzgröße. In beiden Lungen noch etwas fleckigstreifige Zeichnung (Status nach medikamentösem Ductusverschluß)

\section{Ductus Bump}

In der Fetalzeit stellt der Ductus arteriosus Botalli eine physiologische Verbindung zwischen dem Hauptstamm der Arteria pulmonalis und dem Aortenbogen dar. Hierbei fließt etwa $84 \%$ des Blutvolumens aus dem Pulmonalis-Hauptstamm in die Aorta descendens ab, während nur etwa 16\% in die rechte und linke Pulmonalarterie gelangt (Moss et al. 1963).

Im Normalfall ist beim reifen Neugeborenen der Ductus arteriosus Botalli bereits innerhalb der ersten 10-15 Lebensstunden post partum funktionell geschlossen (HeymanN u. RudolPH 1972). Sein endgültiger Verschluß ist mit kontinuierlichem Absinken des pulmonalen Gefäßwiderstandes nach etwa 1 Woche erreicht (Cronan u. Ablow 1981; Heyman u. RUDOLPH 1972). 

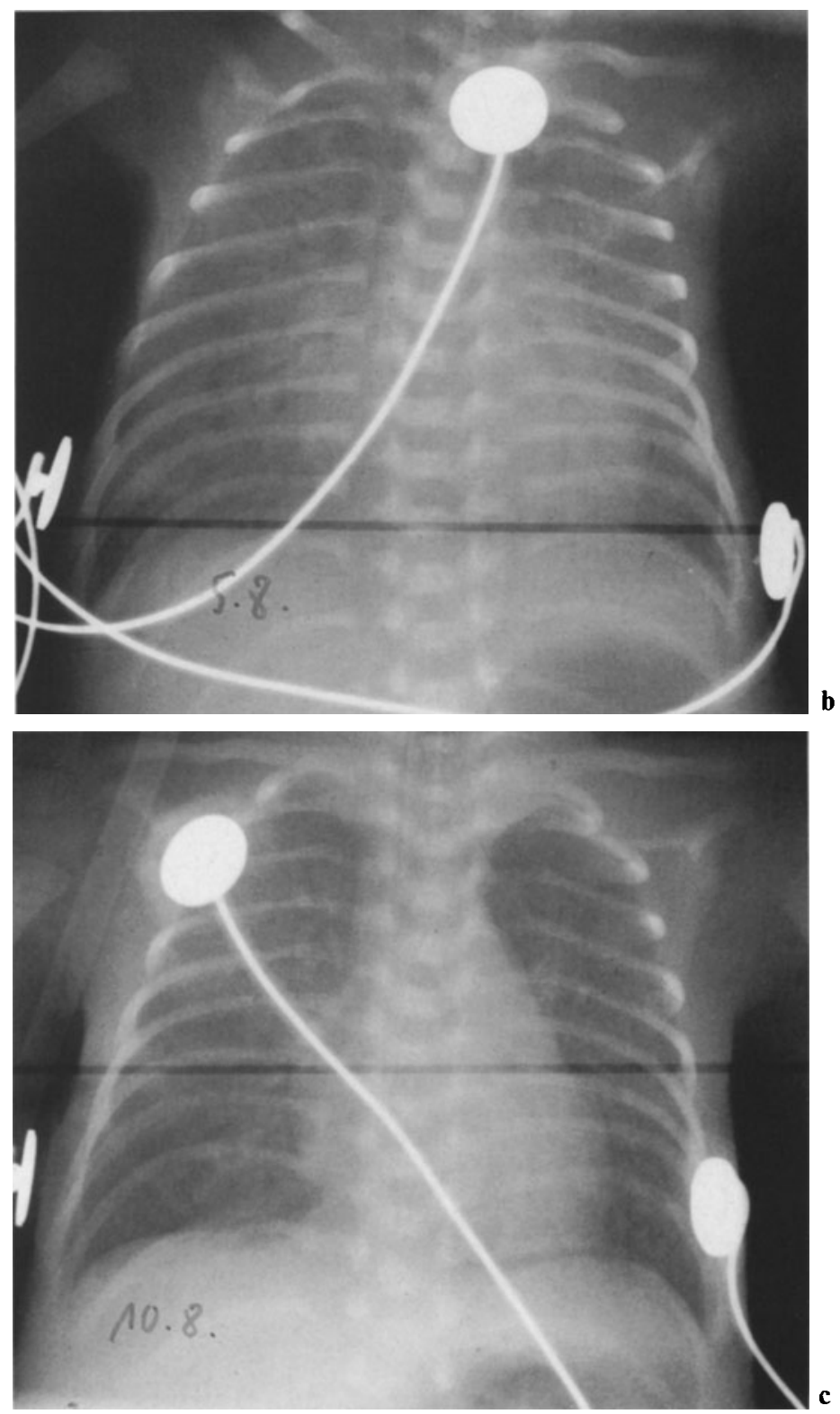

Abb. 5b, c

Bei einigen Neugeborenen bleibt das dilatierte, infundibuläre Segment des PulmonalisHauptstammes und der Ductus arteriosus Botalli als „Ductus Bump“ über die ersten 48-72 Lebensstunden erhalten. Dieser imponiert im ap-Thorax-Bild als linksseitige, umschriebene, konvexbogig begrenzte „Mediastinalbeule“ in Höhe des Aortenbogens (BERDON et al. 1965; Cronan u. Ablow 1981; Knapp 1967) (Abb. 6).

Der Ductus Bump ist somit als physiologische Normvariante beim Neugeborenen aufzufassen. Wenn dieser länger als $72 \mathrm{~h}$ post partum nachweisbar ist und eine progrediente VergröBerung zeigt, ist differentialdiagnostisch ein Ductusaneurysma zu berücksichtigen. Das Ductusaneurysma kommt sehr selten vor, es ist aber wegen seiner thromboembolischen Komplikation sehr gefürchtet (KERSTAN u. SCHMIDT 1977; KIRKS et al. 1980; RUTISHAUSER et al. 1977). 


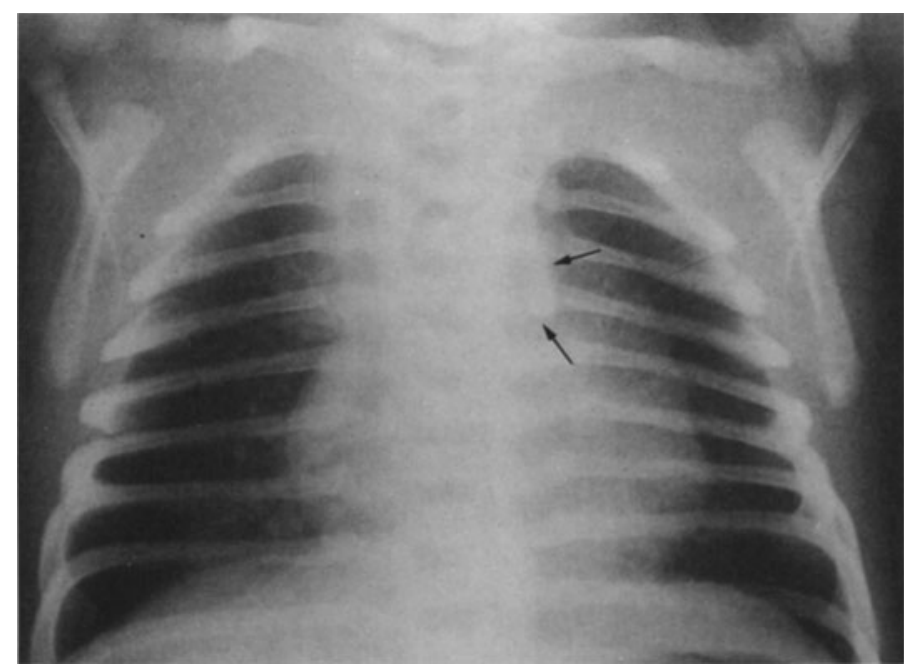

Abb. 6. Ductus Bump, 16 h altes Neugeborenes mit Ductus Bump. - Linksseitige „Mediastinalbeule“ suprahilär (Pfeile). Asymmetrischer Thymus. (Für die freundliche Überlassung des Bildes danke ich Herrn Professor Dr. E. Willich, Heidelberg)

\section{Aspirationssyndrom}

Das Aspirationssyndrom ist nach dem Atemnotsyndrom die häufigste Form der neonatalen Atemstörung. Betroffen hiervon sind im Gegensatz zum Atemnotsyndrom vorwiegend reife und übertragene Neugeborene. Wesentliche Ursache für eine fetale Aspiration ist eine intra-uterine Hypoxie. Diese führt über eine Vagusstimulation zu einer vermehrten Persistaltik im Magen-Darm-Kanal und auf diese Weise zu einer vorzeitigen Mekoniumentleerung in das Fruchtwasser (BACSIK 1977; DeSMOND et al. 1957; Fox et al. 1977; HoFFMAN et al. 1974; Köteles 1982, S. 64; OpPermanN u. Wille 1977; Wesenberg 1973, S. 119). Durch forcierte intra-uterine Atemexkursionen gelangen das Fruchtwasser und/oder Mekonium in die Bronchioli terminales und Ductuli alveolares. Das aspirierte Material verstopft die terminalen Luftwege und führt zur Entwicklung multipler kleiner Atelektasen. Nahezu immer besteht ein Ventilmechanismus, der eine mehr oder weniger ausgeprägte, diffuse Lungenüberblähung nach sich zieht.

Mit einer Mekoniumpassage in das Fruchtwasser ist in etwa 10-20\% aller Geburten zu rechnen. Die Häufigkeit der Mekoniumaspiration liegt aber nur bei ca. 0,09\% aller Geburten (Gooding u. Gregory 1971; Peterson u. Pendleton 1955).

Als Folge einer Aspiration kann sich innerhalb von 24-48 h eine chemische Pneumonitis entwickeln, darüber hinaus kann sekundär eine Pneumonie entstehen (SCHAFFER u. AvERY 1977; TYLER et al. 1978). Ausgeprägte Aspirationen sind kompliziert durch Alveolarruptur in den aspiratfreien Lungenabschnitten, da diese Areale kompensatorisch überdehnt sind. Über ein pulmonales interstitielles Emphysem nach Alveolarruptur entstehen leicht ein Pneumomediastinum und/oder Pneumothorax. Eine besonders gefürchtete Komplikation einer Aspiration ist die Entwicklung einer pulmonalen Hypertonie (Fox et al. 1977; Gooding u. Gregory 1971; Peterson u. Pendleton 1955; Taylor et al. 1971).

Die Röntgensymptomatologie des Aspirationssyndroms ist abhängig vom Ausprägungsgrad der Aspiration, insbesondere vom Zellgehalt und der Mekoniummenge im Aspirat. 
Bei nur geringer Fruchtwasseraspiration kann das Thoraxbild normal aussehen (OPPERMANN et al. 1982, S 87; WeISENBACH et al. 1982). - Nach massiver Aspiration finden sich meistens dichte, grobfleckige, teilweise konfluierende Eintrübungen, die von zystoiden, fokalen Emphysembezirken umgeben sind. Generell findet sich eine erhebliche Lungenüberblähung (GoOding u. Gregory 1971; Gregory et al. 1974; WeIsENBaCH et al. 1982) (Abb. $7 \mathrm{a}-\mathrm{c}$ ).

Aus der zeitlichen Sequenz der Rückbildung der Verschattungsbezirke läßt sich auf den Inhalt des Aspirates schließen. Sind die pulmonalen Verdichtungsbezirke bereits wenige Stunden post partum nicht mehr nachweisbar, ist davon auszugehen, daß die Aspirationsherde überwiegend aus Amnionflüssigkeit bestanden. In der Regel bilden sich aspirationsbedingte Lungenveränderungen innerhalb von 3 Tagen zurück. Bei sekundärer Infektion der Aspirationsherde sind diese aber noch nach mehreren Tagen nachweisbar (AvERY u. Fletcher 1974; Hoffmann et al. 1974; Neuhauser u. Griscom 1967; Weisenbach et al. 1982; SwiSCHUK 1980, S. 64). Differentialdiagnostisch ist beim Aspirationssyndrom in erster Linie an eine perinatale Pneumonie zu denken. Ferner sind zu berücksichtigen eine Lungenblutung, die sehr seltene kongenitale pulmonale Lymphangiektasie und eine Lungenvenenfehlmündung mit venöser Obstruktion.

\section{Perinatale Pneumonien}

Intra-uterin erworbene sowie sub partu und post partum entstandene Lungeninfektionen sind unter dem Begriff der perinatalen Pneumonien zusammenzufassen. Die intra-uterinen Pneumonien entstehen entweder durch eine dia-placentare Übertragung von Krankheitserregern - wie z.B. die Listerienpneumonie und Pneumonie bei Zytomegalieinfektion - oder nach Aspiration infizierten Fruchtwassers.

Unmittelbar unter der Geburt, d.h. bei der Passage durch den Geburtskanal und post partum, entwickeln sich die Pneumonien ebenfalls durch Aspiration. Darüberhinaus treten sie im Rahmen einer Sepsis auf oder entstehen durch eine Infektion mit Viren, Bakterien, Protozoen und Pilzen. Prädisponierende Faktoren für perinatale Pneumonien sind verlängerte Wehen, ein vorzeitiger Blasensprung und eine aszendierende Infektion via vagina (BENIRSCHKE 1960). Im Neugeborenenalter dominieren die bakteriellen Pneumonien gegenüber den viralen Infektionen, wenngleich die letzteren nicht ungewöhnlich in dieser Altersgruppe sind. Die Symptome bei den unter der Geburt erworbenen perinatalen Pneumonien treten gegenüber den intra-uterinen Pneumonien verzögert auf (AVERY et al. 1981, S. 203; BENIRSCHKE 1960; Cheeseman et al. 1977; Cramblett et al. 1973; Hilton et al. 1984; Joshi et al. 1973; Köteles 1982, S. 64; Krous et al. 1973; OppermanN u. Wille 1977; Oppermann et al. 1982, S. 80; PhILIP u. LARSON 1973).

Beim Neugeborenen sind die Abwehrmechanismen physiologischerweise noch nicht vollständig ausgereift, zudem besteht ein relatives Überwiegen des Lungeninterstitium gegenüber dem Lungenparenchym. Daher reagiert die Neugeborenenlunge auf unterschiedliche Noxen überwiegend mit einer Strukturveränderung im Lungeninterstitium. Darüberhinaus disponieren die kleinen Bronchiallumina der Neugeborenenlunge zum raschen Kollabieren, so daß sich im Rahmen einer bronchopulmonalen Infektion sehr schnell ein obstruktiver Ventilmechanismus entwickeln kann. Dieser und die kompensatorische Ventilation der nicht - infiltrierten Lungenareale via Kohnsche Poren und Lambertsche Kanäle führt zu einer meistens erheblichen Lungenüberblähung (Griscom et al. 1978; KöTELES 1982, S. 64).

Die Röntgensymptome der perinatalen Pneumonien sind polymorph. - Das Spektrum der röntgenmorphologischen Veränderungen einer perinatalen Pneumonie reicht von parahi- 


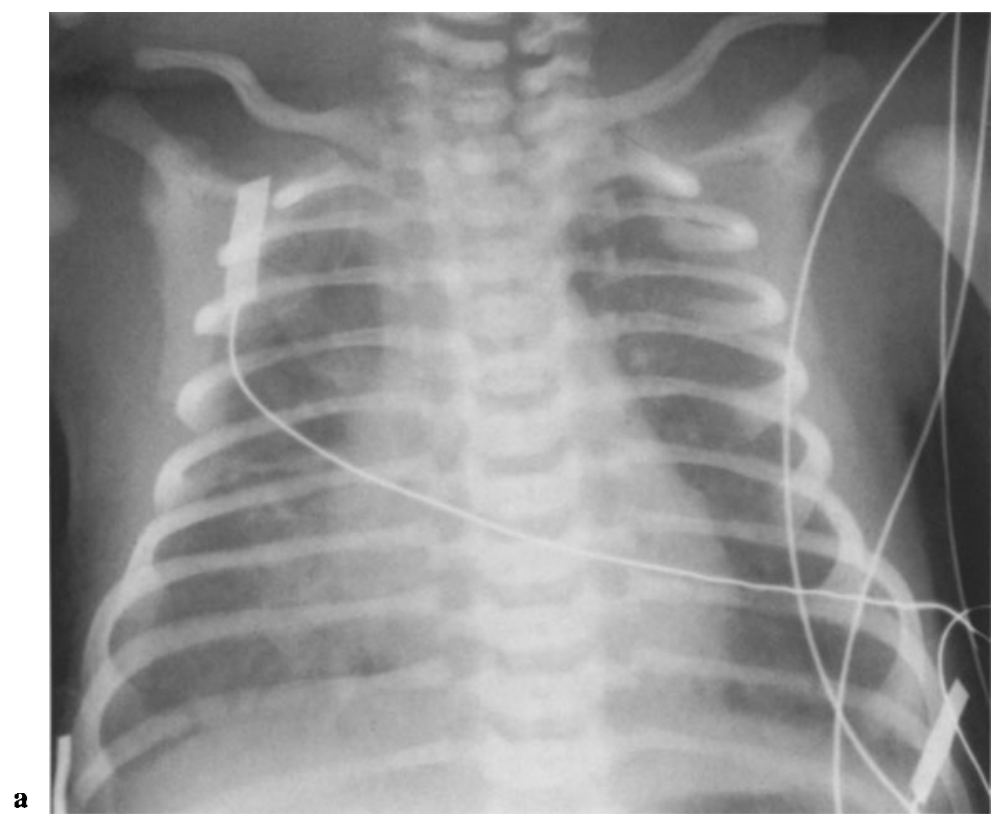

Abb. 7. a 3 h altes Neugeborenes mit massiver Mekoniumaspiration. Grobfleckige, z.T. konfluierende Verdichtungsherde, vornehmlich rechts. Schmaler Pleurabegleitsaum rechts. b Das Kontrollbild desselben Patienten nach 3 Tagen zeigt einen normalen Thoraxbefund. $\mathbf{c} 6$ h altes Neugeborenes mit anamnestischer Fruchtwasseraspiration. Der röntgenologische Thoraxbefund ist normal

lärer interstitieller Streifenzeichnung über kleinnoduläre Verdichtungen und großfleckige Eintrübungen bis hin zu einer diffus schleierigen Eintrübung. Im Einzelfall läßt sich auf Grund der morphologischen Veränderungen im Röntgenbild allein nicht entscheiden, ob den Veränderungen eine virale oder bakterielle Lungeninfektion zugrunde liegt (GRISCOM et al. 1978; Köteles 1981, S. 64; Oppermann et al. 1982, S. 80; Swischuk 1980, S. 167). Die wichtigsten bakteriellen Pneumonieerreger in der Neonatalperiode sind die nicht - haemolysierenden B-Streptokokken, Staphylokokken (Staphylococcus aureus) und Escherichia coli. Als weitere Erreger sind Klebsiella aerobacter, Pseudomonas aeruginosa, Streptococcus pneumoniae und Hämophilus influenzae bekannt. Eine heute nur noch untergeordnete Rolle unter den bakteriellen neonatalen Pneumonien spielt die konnatale Tuberkulose, zumindest innerhalb des europäischen Raumes (Ablow et al. 1976; AVERY et al. 1981, S. 203; BALE u. Walkins 1978; Baumgärtner et al. 1980; Hammersen et al. 1977; Kuhn u. Lee 1973; Leonidas et al. 1977; Lilien et al. 1978; Oppermann u. Wille 1977; Oppermann et al. 1982, S. 80; Polansky et al. 1978; Schröder u. Paust 1979; Siegel u. McCracken 1979; Speer et al. 1978).

Virale Pneumonieerreger in der Neonatalperiode sind vor allem Zytomegalieviren, Coxsackie- und Echo-Viren, aber auch Herpes simplex und Varizellen (CHEESEMAN et al. 1977; Joshi et al. 1973; Opermann et al. 1982, S. 80; Swischuk 1980, s. 167; WeSENBERg 1973, S. 71).

Unter den Pilzinfektionen ist die Candidainfektion besonders gefürchtet. Sie kann zu einer fulminanten Pneumonie führen (Dixon u. Houston 1978).

Seltene Erreger neonataler Pneumonien sind Listerien (Listeria monocytogenes), Pneumocystis carinii und Chlamydien (Ebel u. Fendel 1967; Frommell et al. 1979; Peuckert 

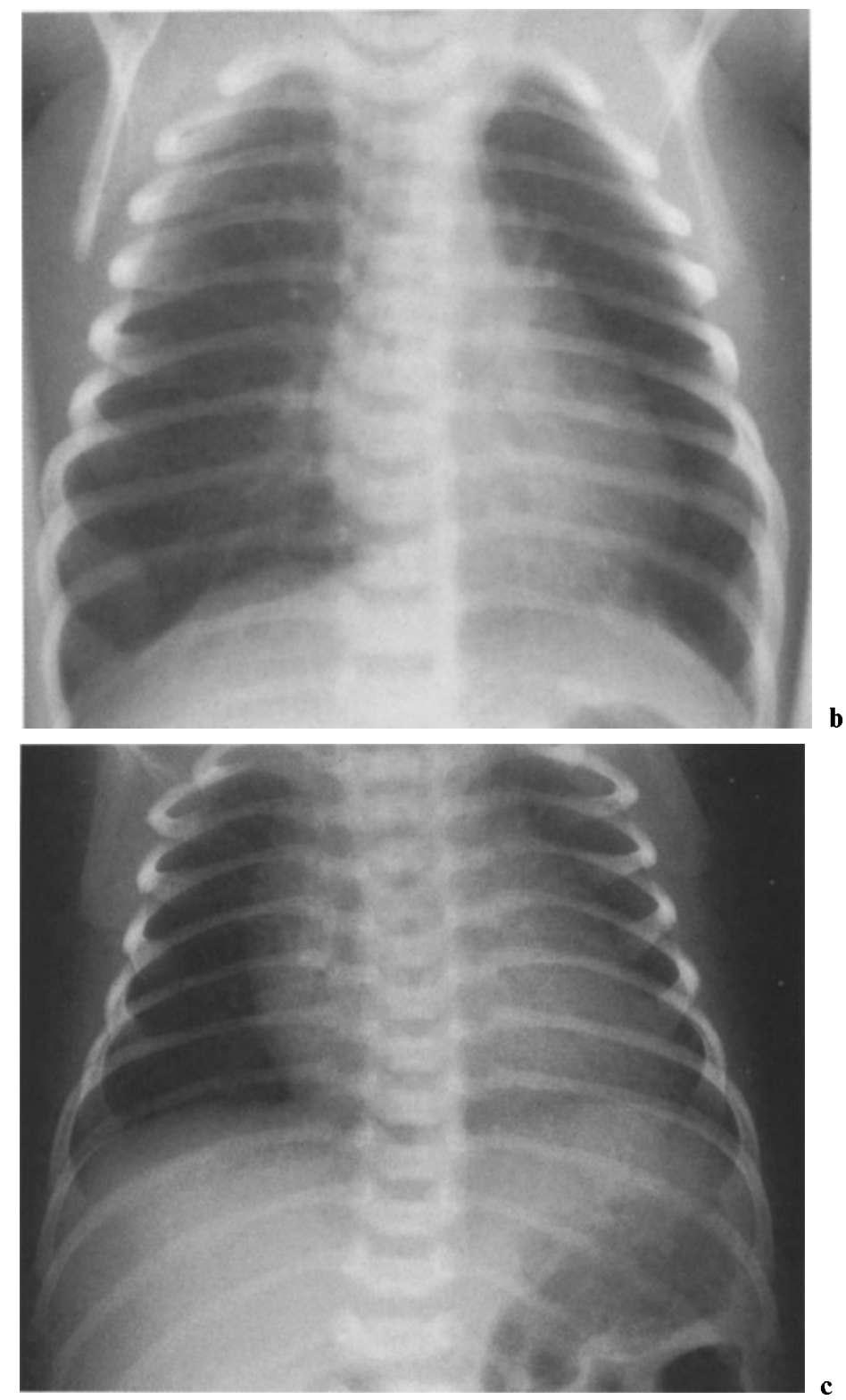

Abb. 7 b, c

et al. 1981; TiPPLE et al. 1979; RADKowsKi et al. 1981; Willich 1967a; ZaCH u. RitsCHL 1982).

Eine Pneumonie im Rahmen einer konnatalen Lues gilt heute als Rarität. Ihre Röntgensymptomatik ist unspezifisch. Richtungsweisend für die Diagnose sind luestypische Skelettveränderungen und spezifische immunfluoreszierende Phänomene bei Untersuchung des Trachealsekretes (Avery et al. 1981, s. 203; Macias et al. 1974; OpPermann u. Wille 1977; Wesenberg 1973, S. 71). Die Lues-Pneumonie wird wegen des Aussehen der Lungen im makroskopischen Lungenpräparat infizierter Lungen auch als Pneumonia alba bezeichnet. 


\section{B-Streptokokkenpneumonie}

Die B-Streptokokkenpneumonie ist die häufigste bakterielle Pneumonie in der Neugeborenenperiode (HAMmersen et al. 1977; OPPERMANN u. Wille 1977; Roos et al. 1979; SCHRöDER u. PAust 1977).

Das röntgenmorphologische Erscheinungsbild der B-Streptokokkenpneumonie ist ausgesprochen variabel. In der Regel findet man bei den Frühgeborenen eine andere Röntgensym-
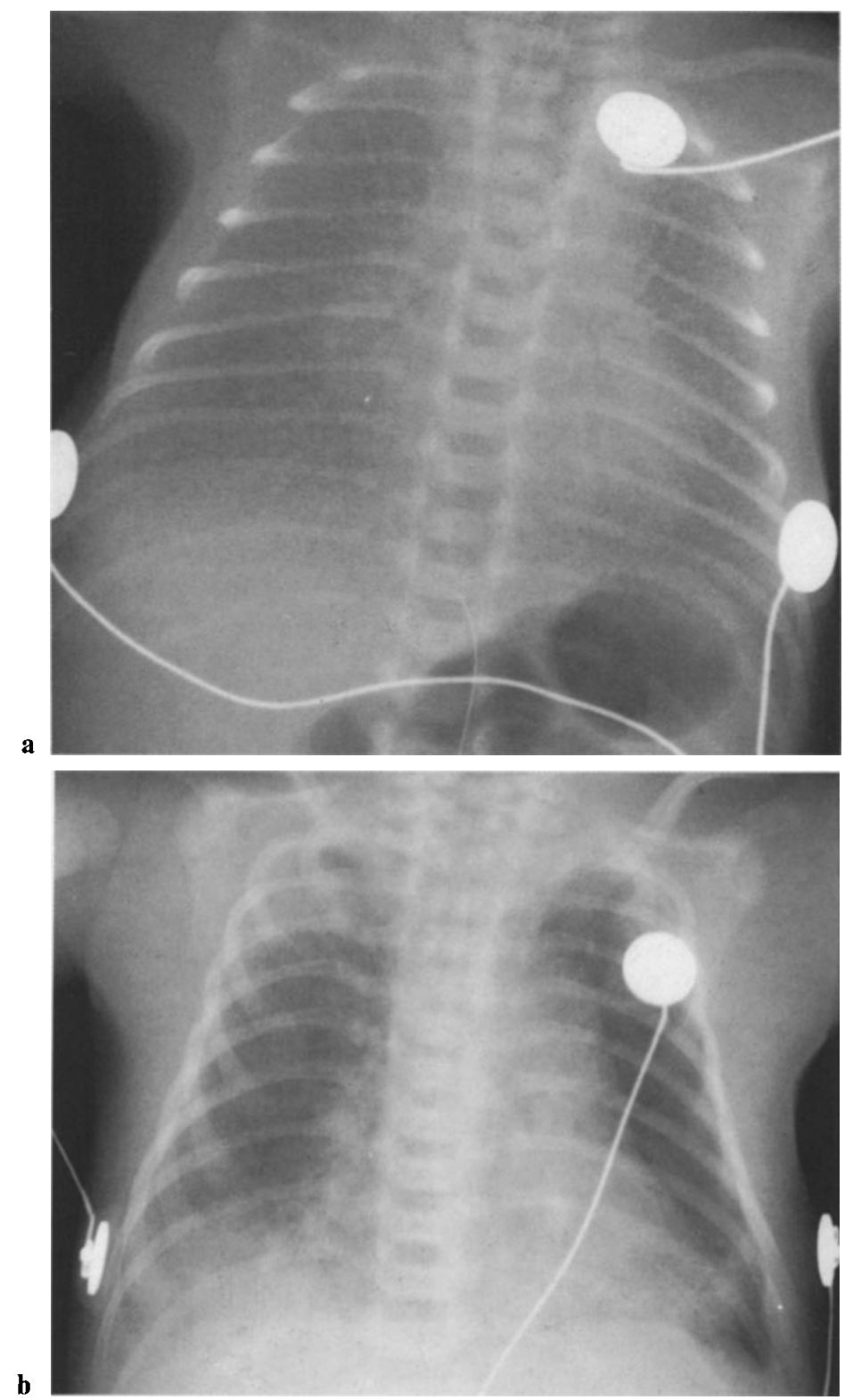

Abb. 8. a 10 h altes Frühgeborenes mit bakteriologisch gesicherter B-Streptokokkenpneumonie. Das Röntgenbild täuscht ein idiopathisches Atemnotsyndrom mit retikulogranulärem Lungenmuster vor. Beachte die Seitendifferenz der Lungenveränderungen. b $8 \mathrm{~h}$ altes Neugeborenes mit bakteriologisch gesicherter B-Streptokokkenpneumonie. Grobfleckige, teilweise konfluierende pulmonale Verdichtungen, besonders rechts 
ptomatologie als bei Neugeborenen. Bei Frühgeborenen kann die B-Streptokokkenpneumonie das Röntgenbild eines idiopathischen Atemnotsyndrom im Stadium II und III imitieren. Typischerweise finden sich kleinfleckige, bzw. noduläre, pulmonale Eintrübungen, die oft mit kleineren Pleuraergußbildungen einhergehen. Die Begleitpleuritis ist aber nicht pathognomonisch für eine B-Streptokokkenpneumonie (Abb. 8a).

Beim reifen Neugeborenen ruft die B-Streptokkenpneumonie meistens grobfleckige, z.T. konfluierende Eintrübungen hervor oder sie stellt sich in Form lobärer oder segmentaler Infiltrationen mit Überblähung der nicht infiltrierten Lungenbezirke dar. Darüberhinaus kann eine Kardiomegalie bestehen, die wahrscheinlich Ausdruck einer toxischen Myokardschädigung ist (ABLOW et al. 1976; HAMMERSEN et al. 1977; Roos et al. 1979; SCHRÖDER u. Paust 1979; Wille u. OpPermann 1979) (Abb. 8b). Ablow et al. (1977) unterscheiden bei der B-Streptokokken-Pneumonie nach röntgenmorphologischen Kriterien 4 verschiedene Typen, bzw. Gruppen von Patienten, die offenbar auch eine unterschiedliche Prognose aufweisen. Danach gilt als prognostisch ungünstigte Form der Nachweis eines retikulo-granulären Lungenmusters, welches dem idiopathischen Atemnotsyndrom täuschend ähnlich sieht. Eine weitere Form ist durch ausgedehnte alveoläre Infiltrationen gekennzeichnet. Die 3. Variante zeigt mehrere kleinfleckige Herdbildungen. Als 4. Form geben ABLow et al. (1974) eine Gruppen von Patienten an, bei denen eine bakteriologisch gesicherte B-Streptokokkenpneumonie besteht, die aber im Röntgenbild einen Normalbefund zeigt oder das Bild einer verzögerten Resorption fetaler Lungenflüssigkeit hat. - In seltenen Fällen kann die B-Streptokokkenpneumonie einhergehen mit dem verspäteten Auftreten einer kongenitalen Zwerchfellhernie. Eine Erklärung hierfür ist nicht bekannt (MCCARTEN et al. 1981).

Die wichtigste Differentialdiagnose zur B-Streptokokkenpneumonie stellen das Atemnotsyndrom im Stadium II bis III und die transitorische Tachypnoe dar. Bei mehr umschriebenen, vornehmlich basal gelegenen Eintrübungen ist an ein Aspirationssyndrom zu denken.

\section{Staphylokokkenpneumonie}

Im Vergleich zur B-Streptokokkenpneumonie ist die Staphylokokkenpneumonie als Ursache einer bakteriellen Lungenentzündung im Neugeborenenalter heute wesentlich seltener. Diese Pneumonieform ist dennoch gefürchtet, weil sie in der Regel einen fulminanten Verlauf nimmt.

Die Röntgensymptome der Staphylokokkenpneumonie sind gekennzeichnet durch grobfleckige alveoläre Verdichtungen, welche innerhalb von Stunden konfluieren können (AVERY et al. 1981, S. 203; Huxtable et al. 1964; Köteles 1982, S. 64; Miller et al. 1947). Die interstitielle Lungenzeichnung kann verstärkt sein. Oft besteht gleichzeitig ein Pleuraerguß (BoISSET 1972; HIGHMAN 1969). - Die pneumonischen Infiltrationen sind meistens einseitig lokalisiert, sekundär kommt es zur kompensatorischen Überblähung der gesunden Lungenseite. Die Infiltrationen können innerhalb weniger Tage einschmelzen und sich dann in Form von intra-parenchymatösen oder subpleuralen zystenähnlichen Gebilden, sog. Pneumatozelen, darstellen (DUNKEn 1927; Miller et al. 1947; OPPERMANn et al. 1982, S. 80; SwisCHUK 1980, S. 167) (Abb. 9).

Durch Ruptur der Pneumatozelen können extra-alveoläre Luftansammlungen, wie z.B. ein Pneumothorax, entstehen. Andererseits persistieren die Pneumatozelen oft wochenlang, zeigen letztendlich aber eine gute Rückbildungstendenz. Auch im Rahmen anderer bakterieller Pneumonien können sich Pneumatozelen entwickeln, sie sind somit keineswegs pathognomonisch für eine Staphylokokkenpneumonie (Boisset 1972; Highman 1969; KuhN u. LeE 1973; Siegel u. MCCracken 1979; SWischuk 1980; S. 167; WeSEnBerg 1973). 


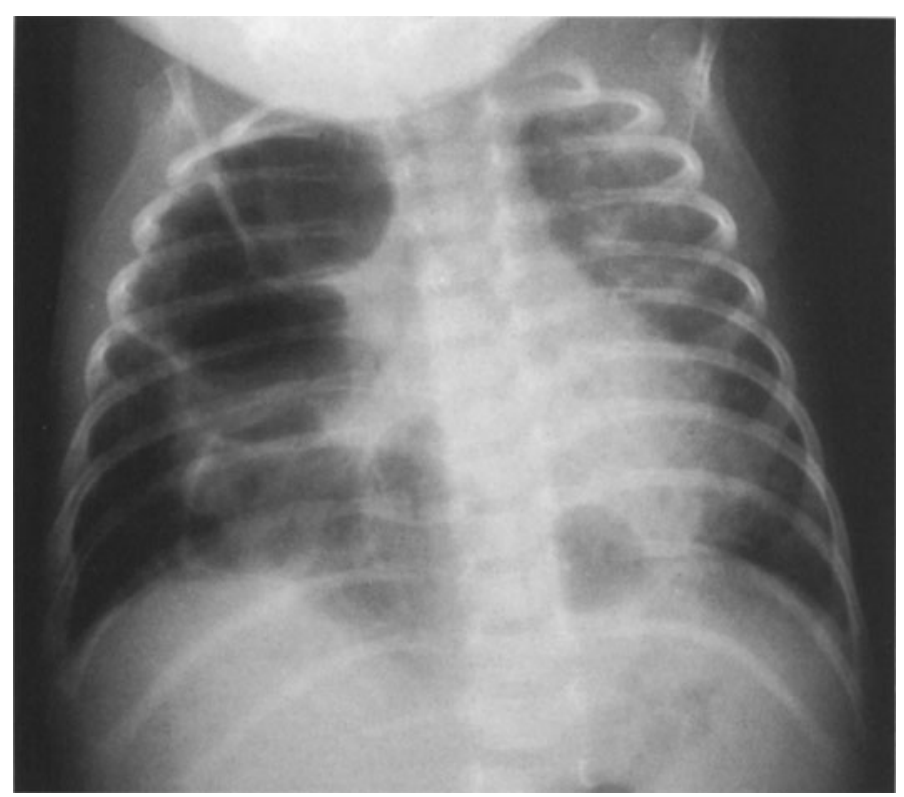

Abb. 9. Wenige Tage altes Neugeborenes mit Staphylokokkenpneumonie. Grobstreifige Infiltrationen retrokardial bds. Multiple, zystoide Aufhellungszonen in der rechten Lunge und links in Überprojektion mit dem Herzen (Pneumatozelen)

In seltenen Fällen ist die Staphylokokkenpneumonie der Perinatalperiode durch ein Pleuraempyem kompliziert. Es sollte dann unbedingt nach einer Rippenosteomyelitis gesucht werden (Avery et al. 1981, S. 203; Oppermann et al. 1982, S. 80; Siegel u. MCCracken 1979).

Die Differentialdiagnose der Staphylokokkenpneumonie umfaßt andere bakterielle Pneumonie, besonders solche, die durch Kolibakterien und Klebsiellen ausgelöst sind.

\section{Chlamydienpneumonie}

Die durch Chlamydia trachomatis hervorgerufene Pneumonie hat in den letzten 10 Jahren zunehmend an Bedeutung gewonnen (Arth et al. 1978; BeEm u. SaXon 1977; Frommell et al. 1979; ZACH u. RitsCHL 1982). Der Krankheitserreger dieser Pneumonieform ist ein intrazellulärer Organismus, der sowohl bakterielle wie auch virale Eigenschaften aufweist (BeEM u. SaXon 1977; Hobson u. Rees 1977).

Die Chlamydienpneumonie unterscheidet sich von den anderen Formen perinataler Pneumonien durch eine weitgehend charakteristische Trias der klinischen Symptomatik mit Stakkatohusten, Eosinophilie und Afebrilität (Hobson u. Rees 1977; Peuckert et al. 1981; StickNEY et al. 1978; TIPPLE et al. 1979; ZACH u. RitsCHL 1982). Serologisch läßt sich ein erhöhter Serumimmunglobulinspiegel nachweisen (RADKowski et al. 1981). Von Oetgen wird ein Zusammenhang zwischen einer Chlamydienpneumonie und dem Wilson-Mikity-Syndrom diskutiert. Er fand bei 5 von WILSON und MikiTY 1965 beschriebenen Patienten eine der Chlamydienpneumonie ähnliche klinische und röntgenmorphologische Symptomatik (OETGEN 1979).

Die Chlamydienpneumonie manifestiert sich bei Kindern vornehmlich in einem Alter von 2 Lebenswochen bis zu 6 Monaten (PeUCKert et al. 1981; RADKowski et al. 1981; WoOD 1979). 
Die Röntgensymptomatologie der Chlamydienpneumonie ist nicht spezifisch. Es finden sich vornehmlich interstitielle Lungenveränderungen mit retikulo-nodulären Verdichtungen, aber auch Atelektasen und konfluierende Verschattungsbezirke. Nahezu immer sind die Lungen erheblich überbläht, eine Begleitpleuritis wird im Rahmen einer Chlamydieninfektion nicht beobachtet (Pluckert et al. 1981; RADKOWSKI et al. 1981; TIPPLE et al. 1979; WoOd 1978; ZaCH u. RitsChl 1982) (Abb. 10).

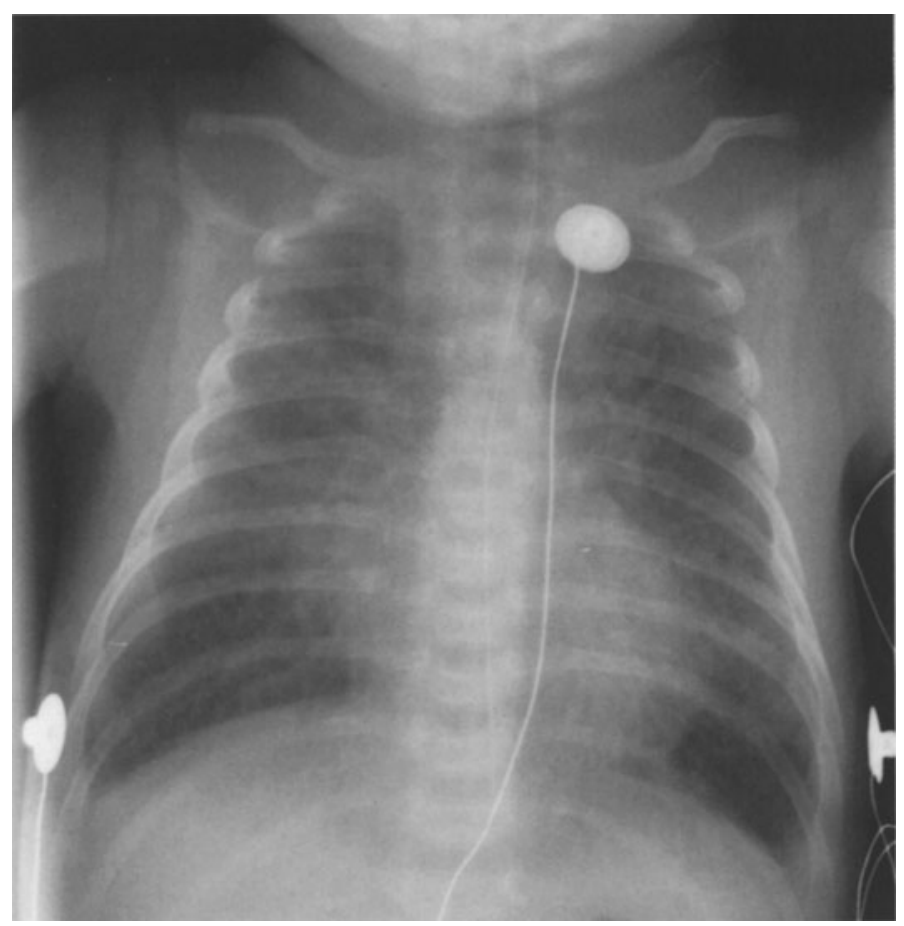

Abb. 10. 3 Wochen alter Säugling mit bakteriologisch gesicherter Chlamydienpneumonie. Grobnetzige, zum Teil fleckig-konfluierende Verschattungen parahilär beiderseits. Erhebliche, bilaterale Lungenüberblähung

\section{Listerienpneumonie}

Die Infektion mit Listeria monocytogenes ist selten. Sie erfolgt beim Neugeborenen entweder dia-plazentar über die Nabelvene oder durch Aspiration infizierter Amnionflüssigkeit.

Die Röntgensymptomatologie der Listerienpneumonie ist sehr variabel. Nach WILLICH (1967) lassen sich drei Grundmuster unterscheiden. Es finden sich 1. bilateral miliariforme Lungenverdichtungen, 2. streifig-fleckige Verschattungen (dystelektatisch-bronchopneumonische Form) oder 3. feinstreifige interstitielle Verdichtungen (interstitielle Pneumopathie) (MoOre u. Brogdon 1962; OpermanN u. Wille 1977; Willich 1967 b) (Abb. 11).

In seltenen Fällen kann die Listerienpneumonie röntgenologisch das Bild eines idiopathischen Atemnotsyndrom imitieren (OpPermanN u. Wille 1977; SwischuK 1980, S. 71). Die Rückbildung der pneumonischen Lungenveränderungen durch Listerien kann sich über mehrere Wochen erstrecken (AVERY et al. 1981, S. 203; VisinTINE et al. 1977; WILLICH 1967). Differentialdiagnostisch ist die Listerienpneumonie abzugrenzen gegen ein Atemnotsyndrom Stadium II bis III, bei diesem findet sich aber nahezu nie eine Hepatomegalie. Weiterhin ist zu berücksichtigen eine interstitielle Lungenhämorrhagie und die B-Streptokokkenpneumonie. 


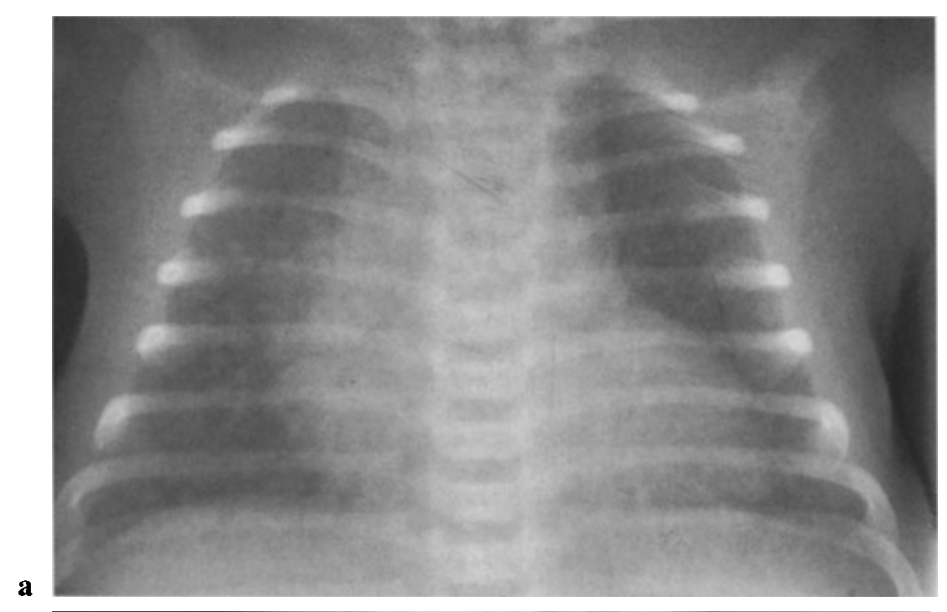

b

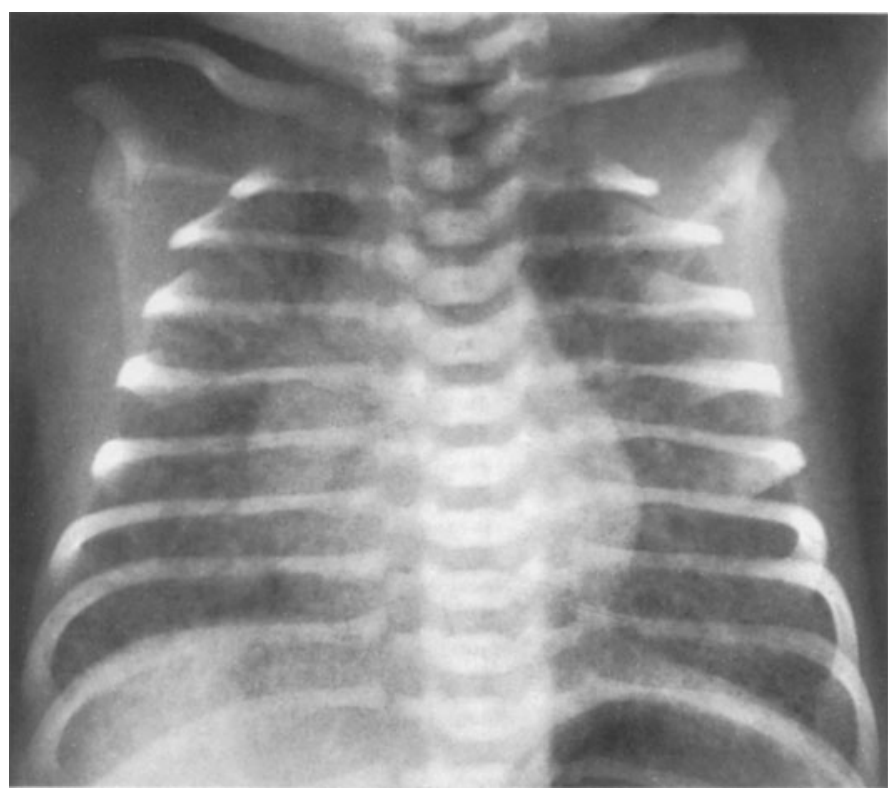

Abb. 11. a 2 Tage altes Neugeborenes mit Listerienpneumonie. Noduläre Infiltrate in der rechten Lunge, diskrete Infiltrationen links. b 2 Tage altes Neugeborenes mit histologisch gesicherter Listeriosepneumonie. In beiden Lungen disseminierte Listeriose-Granulome. (Für die Überlassung des Bildes danke ich Herrn Professor Dr. med. E. WiLlich, Heidelberg)

\section{Pneumozystis carinii-Pneumonie (Plasmazellpneumonie)}

Die durch Pneumozystis carinii -- einem Protozoon - hervorgerufene Pneumonie hat in der Perinatalzeit heute an Bedeutung verloren und wird nur noch vereinzelt beobachtet. Sie betrifft nahezu ausschließlich Frühgeborene und manifestiert sich erst jenseits der ersten 4 Lebenswochen (CAPITANIO u. KirKPatrick 1966; FalKenbaCH et al. 1961; Köteles 1982; OPPERMANN et al. 1982, S 84).

Röntgenologisch finden sich parahilär interstitielle, streifige Infiltrationen mit fehlender oder nur schwach ausgeprägter Hiluslymphknotenreaktion. Seltener sind auch noduläre Infiltrate, umgeben von einem Emphysemhof, nachweisbar (EBEL u. FENDEL 1967) (Abb. 12).

Als Komplikationen dieser Pneumonie können sich ein interstitielles Lungenemphysem, ein Pneumomediastinum und/oder Pneumothorax entwickeln (DOPPMAN et al. 1975; EBeL u. Fendel 1967; Luddy et al. 1977; ThOMAs et al. 1966; VesSAL et al. 1974). 
Darüberhinaus kann die Pneumozystis carinii-Pneumonie durch die sekundäre Entstehung von Pneumatozelen kompliziert werden (DopPMan et al. 1975; Ebel u. Fendel 1967).

Die Differentialdiagnose bei der Pneumozystis carinii-Pneumonie muß vornehmlich eine neonatale pulmonale Hämorrhagie und ein Atemnotsyndrom Stadium II und III berücksichtigen. Weiterhin sind virale und bakterielle Pneumonien auszuschließen.

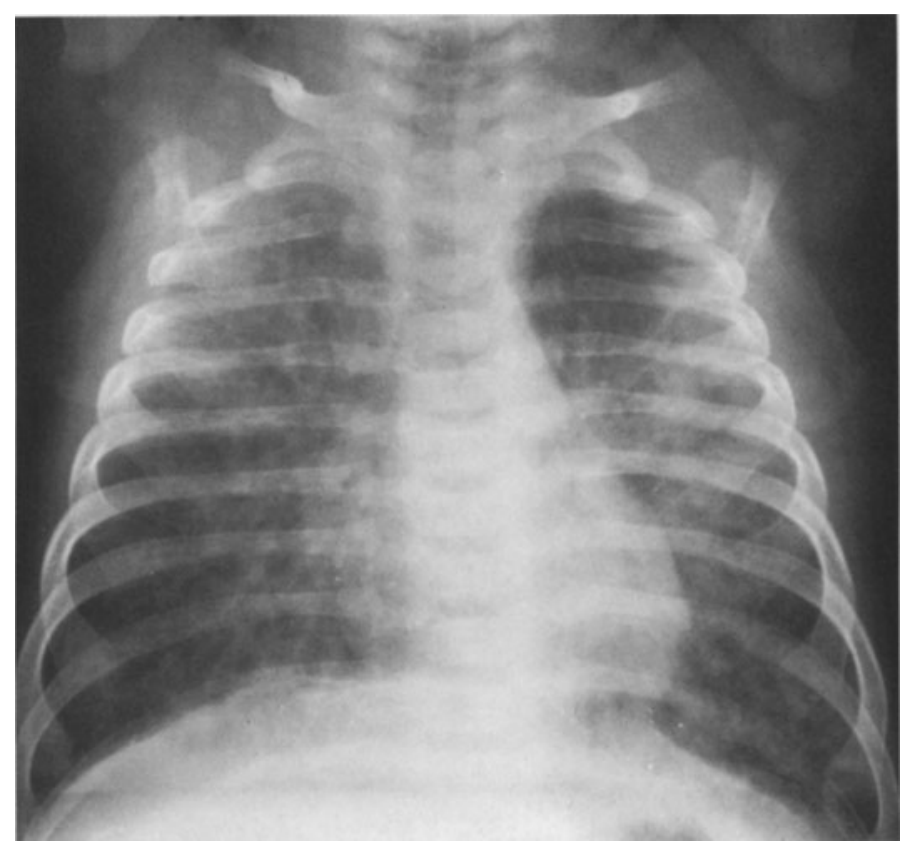

Abb. 12. 4 Monate alter Säugling mit Pneumocystis-Carinii-Pneumonie. Perihilär grobnetzige Zeichnungsvermehrung, peripher vereinzelt noduläre Verdichtungen mit kleinen Emphysemhöfen. (Für die Überlassung des Bildes danke ich Herrn Professor Dr. med. E. Willich, Heidelberg)

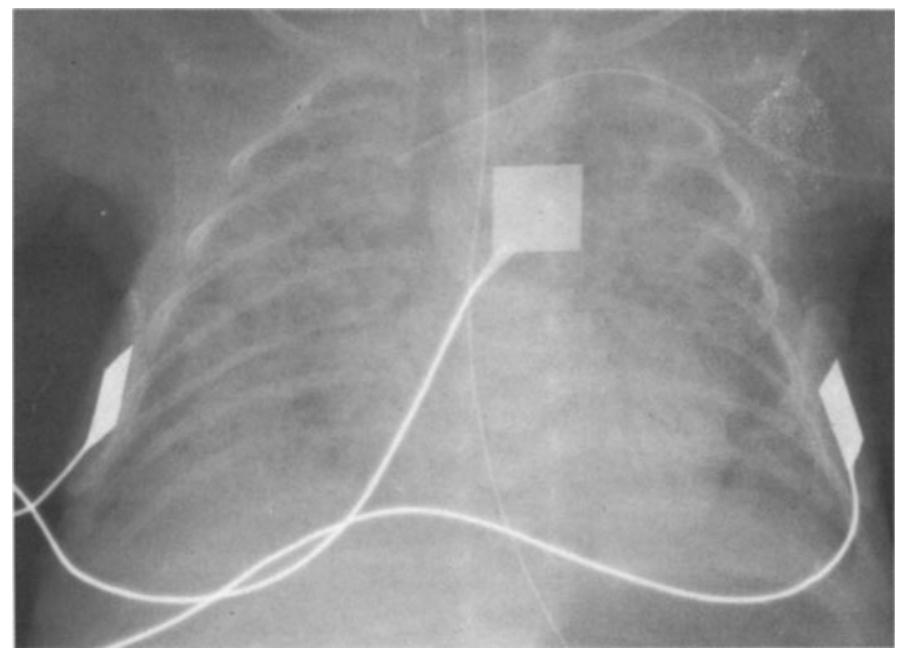

Abb. 13. 8 Tage altes Frühgeborenes mit primär idiopathischem Atemnotsyndrom. Bakteriologisch gesicherte pulmonale Candidiasis. Subtotale Eintrübung beider Lungen mit konfluierenden Verdichtungen, rechts ausgeprägter als links 


\section{Candidapneumonie}

Die Pneumonie nach Infektion mit Candida albicans ist in der Perinatalperiode selten, gilt aber als sehr gefürchtet, da sie einen fulminanten Verlauf nehmen kann (DIXON u. HousTON 1978).

Röntgenologisch sind bei Beginn der Erkrankung grobfleckige alveoläre Infiltrate und meistens eine erhebliche Lungenüberblähung nachweisbar. Im weiteren Verlauf können die Infiltrate zu großflächigen Verschattungsbezirken konfluieren. Diese Entwicklung geht einher mit einer rapiden Befundverschlechterung der klinischen Symptomatik (PATRIQuin et al. 1980) (Abb. 13).

Differentialdiagnostisch kommen bei der Candidapneumonie alle anderen bakteriellen Pneumonien in Frage.

\section{Lungenhämorrhagie}

Die pulmonale Hämorrhagie als Ursache einer neonatalen Atemstörung ist ausgesprochen selten. Dagegen ist der mikroskopische Nachweis pulmonaler Blutungen bei verstorbenen Neugeborenen - und besonders bei Frühgeborenen - nicht ungewöhnlich (AVERY 1968; Esterly u. OpPenheimer 1966; PARKer et al. 1968). Nach AdAmson ist eine massive pulmonale Blutung in zwei und mehrere Lungenlappen ohne Nachweis anderer pulmonaler Erkrankungen in etwa 5-20\% aller Autopsien von Früh- und Neugeborenen die Todesursache. In nahezu 50\% dieser Patienten ist auch eine Blutung aus den oberen Luftwegen nachweisbar (ADAMSON et al. 1969; AVERY 1968).

Als ursächliche Faktoren für die Entwicklung einer pulmonalen Hämorrhagie werden diskutiert eine perinatale Asphyxie (AHVEnainen u. CALl 1952; LoHER u. Giedion 1971; Rowe u. Avery 1966), eine perinatale Gerinnungsstörung (Cole et al. 1973; EASA 1978; HathaWAY 1970) oder eine Linksherzinsuffizienz, die der Entwicklung einer pulmonalen Blutung Vorschub leisten kann (Adamson et al. 1969; EsTERly u. OPPENHEIMER 1966; Rowe u. AVERy 1966).

Von Shanklin u. Wolfson (1967) wird eine therapeutisch induzierte $\mathrm{O}_{2}$-Zufuhr als ein möglicher pathogenetischer Faktor für die Lungenblutung angenommen. Im übrigen können Lungenblutungen auch in Verbindung mit dem idiopathischen Atemnotsyndrom, einer Mekoniumaspiration, neonatalen Pneumonien und einer bronchopulmonalen Dysplasie entstehen (PARKer et al. 1968; Ponhold 1981 b; Trompeter 1975).

Die pulmonale Blutung macht röntgenmorphologisch kein pathognomonisches Muster (Bоothby u. De Sa 1973; Ponhold 1981 b). Sie kann als alveoläre, interstitielle oder als gemischt alveolo-interstitielle Verdichtung imponieren. Bei Auftreten der Lungenblutung innerhalb der ersten Lebensstunden kann das Bild eines idiopathischen Atemnotsyndroms imitiert werden (BOMSEL et al. 1975; PARKER et al. 1968) (Abb. 14).

Prinzipiell läßt sich die Diagnose einer Lungenblutung auf Grund des Thoraxbildes nur dann stellen, wenn gleichzeitig blutiges Trachealsekret nachweisbar ist. Es ist besonders auf eine plötzlich auftretende homogene Eintrübung einer oder beider Lungenseiten zu achten, bei der man immer an eine Lungenblutung denken muß (OPPERMANN et al. 1982, S. 91; Parker et al. 1968; Rowe u. Avery 1966).

Die Differentialdiagnose hat zu berücksichtigen ein Atemnotsyndrom Stadium III und IV, eine perinatale Pneumonie, ein pulmonales Ödem und einen persistierenden Ductus Botalli bei Atemnotsyndrom. Bei massiver Verschattung ist auch an einen Pleuraerguß (evtl. Hämothorax) zu denken (OPPERManN u. WiLle 1980; OPPERMANn et al. 1982, S., 91). 


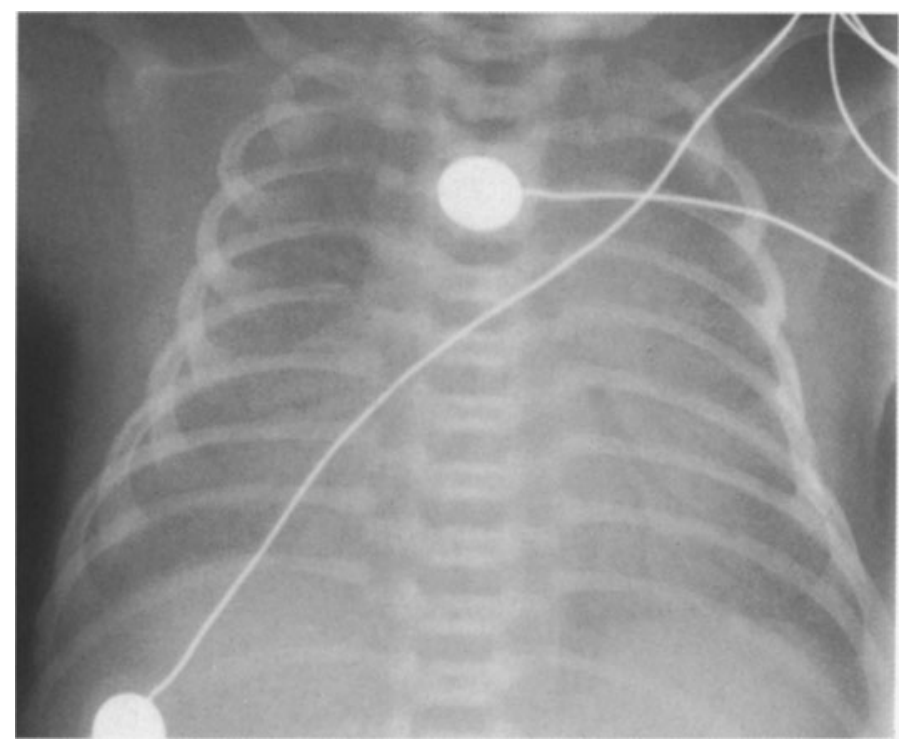

Abb. 14. Lungenhämorrhagie. Wenige Stunden altes Neugeborenes mit respiratorischer Insuffizienz und blutigem Trachealsekret bei diffuser Lungenblutung. Diffuse, überwiegend homogene bilaterale Lungeneintrübung

\section{Wilson-Mikity-Syndrom}

Diese heute nur noch sehr selten anzutreffende Lungenerkrankung wurde erstmalig 1960 von WILSON u. MikiTY beschrieben. Ätiologisch ist diese pulmonale Erkrankung noch nicht endgültig geklärt. Sie beruht vermutlich auf einer verzögert und dissoziiert verlaufenden Lungenreifung und wird nahezu ausnahmslos bei Frühgeborenen mit einem Gewicht von weniger als $1500 \mathrm{~g}$ beobachtet (AvERY et al. 1981, S. 271; KAUfMANN 1962; Mithal u. EMERY 1961; WeingärTner et al. 1968; Wilson u. Mikity 1960). Bei etwa 50\% aller Patienten mit Wilson-Mikity-Syndrom ist die Prognose durch die Entwicklung einer Rechtsherzinsuffizienz als infaust anzusehen (Avery et al. 1981, S. 271; KAUfMAnN 1962).

Autoptisch imponieren diese Lungen durch ein generelles Emphysem, Atelektasen und Bindegewebsproliferation. Mikroskopisch ist das Wilson-Mikity-Syndrom durch eine lymphozytäre Infiltration und Degeneration des elastischen Gewebes in den erweiterten Alveolarsepten charakterisiert (KAUfMANN 1962; KöTEles 1982, S. 52; WeINGärTNER et al. 1968).

Das Wilson-Mikity-Syndrom manifestiert sich als Atemstörung ohne vorangegangenes Atemnotsyndrom und ohne stattgehabte Respiratortherapie frühestens nach der 1. Lebenswoche, meistens jedoch erst jenseits der 3. Lebenswoche (BURNARD et al. 1965; WeINGÄRTNER et al. 1968; WiLSON u. Mikity 1960).

Die Röntgensymptomatologie des Wilson-Mikity-Syndroms variiert, sie hängt vom Zeitpunkt der Manifestation ab. Wesentliche Charakteristika sind eine netzartige, fast immer symmetrische Verdichtung des Lungeninterstitium und ein generelles, basal besonders ausgeprägtes Emphysem (KAUfMANN 1962; Mikity et al. 1967; WeINGärTNER et al. 1968).

Hodgman hat die Röntgensymptome des Wilson-Mikity-Syndroms in drei Stadien unterteilt. 
In der Frühphase des Stadium I, die einen Zeitraum von 6 bis 35 Tagen umfaßt, finden sich perihilär streifige Verdichtungen (Abb. 15a).

Die Spätphase des Stadium I in einem Zeitraum von 30 Tagen bis 4 Monaten ist charakterisiert durch ein generelles Emphysem, grobstreifige Verdichtungen und Pseudozystenbildungen (sog. ,Bubble lung“") (Abb. 15b).

Im Stadium II kommt es zur Verschmelzung der pseudozystischen Herde, besonders in den Unterlappen, dieser Zeitraum dauert etwa bis zu $5^{1 / 2}$ Monaten an.

Das Stadium III, die sog. Regenerationsphase, umfaßt einen Zeitraum von 6 Monaten bis zu 2 Jahren. In diesem Stadium kommt es zu einer allmählichen Normalisierung der Lungenstrukturveränderungen. Die wichtigste Differentialdiagnose zum Wilson-Mikity-

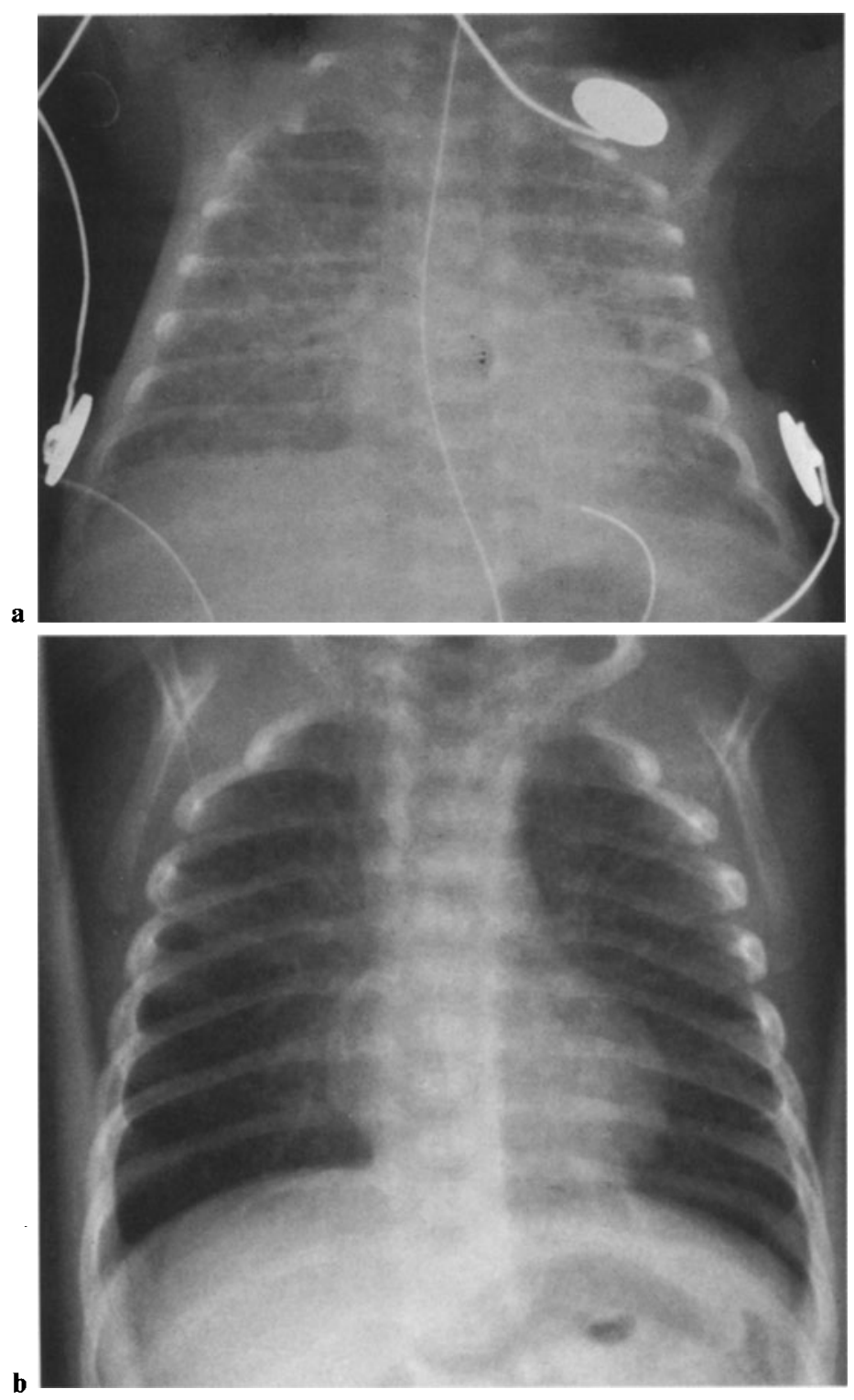

Abb. 15a, b. Wilson-Mikity-Syndrom. a 6 Tage altes Frühgeborenes mit Wilson-Mikity-Syndrom (Frühphase). Grobnetzige, perihiläre Verdichtungen bds. b 4 Wochen altes Frühgeborenes mit Wilson-Mikity-Syndrom (Spätphase). Perihiläre Restinfiltrate und erhebliche, diffuse bilaterale Lungenüberblähung 
Syndrom ist die bronchopulmonale Dysplasie im Stadium III und IV. Die Differenzierung ist leicht durch die Anamnese möglich. Des weiteren müssen berücksichtigt werden eine perinatale interstitielle Pneumonie, eine kongenitale pulmonale Lymphangiektasie und die heute extrem seltene konnatale Tuberkulose.

\section{Bronchopulmonale Dysplasie}

Das Krankheitsbild der bronchopulmonalen Dysplasie (BPD) wurde erstmalig 1967 von NorTHWAY et al. beschrieben. Diese Autoren faßten die röntgenmorphologischen und histologisch nachweisbaren pulmonalen Strukturveränderungen von Neugeborenen mit schwerem Atemnotsyndrom, die über mindestens $24 \mathrm{~h}$ mit intermittierend positivem Druck und einer Sauerstoffkonzentration von $80-100 \%$ beatmet worden waren, unter dem Begriff ,Bronchopulmonale Dysplasie“" zusammen.

Nach heutigen Erkenntnissen ist die bronchopulmonale Dysplasie als eine sekundäre pulmonale Erkrankung aufzufassen, die sowohl im Gefolge eines Atemnotsyndroms wie auch nach anderen neonatalen Atemstörungen, die eine mechanische Ventilation über mindestens $24 \mathrm{~h}$ erforderlich machen, auftreten kann (BARNES et al. 1969; EDWARDS et al. 1977; EdWards 1979; EdWards et al. 1979; NorThWay et al. 1967; NorThWay u. Rosan 1968; OPPERMANn et al. 1977; OpPERMANn u. Wille 1982; SHEPARD et al. 1968).

Die wesentlichen pathogenetischen Faktoren für die Entstehung dieser Erkrankung sind die Applikation hoher Sauerstoffkonzentrationen über mehrere Tage (ANDERSON u. STRICKLAND 1971; BanerJee et al. 1972; Clark u. LAMBERTSON 1971; EhrenKranz et al. 1978; PhILIP 1975), die Ventilation mit intermittierend positivem Druck (BARNes et al. 1969; BerG et al. 1975; Northway u. Rosan 1968; Stocks u. Godfrey 1976) und die Dauer der Beatmung (NASH et al. 1967; OpPermann et al. 1977; Pusey et al. 1969; Stocks u. Godfrey 1976).

Die Inzidenz der bronchopulmonalen Dysplasie variiert in Abhängigkeit vom Geburtsgewicht bzw. Gestationsalter der Früh- und Neugeborenen, dem individuellen Sauerstoffbedarf und der Atmungsdauer. Sie liegt zwischen 5 und 20\% der beatmeten Früh- und Neugeborenen (BanCalari 1979; Harrod et al. 1974; Moylan et al. 1976; Outerbridge u. STern 1972; WuNG et al. 1979).

Röntgenmorphologisch wurden ursprünglich nach dem Zeitpunkt des Auftretens und dem Schweregrad der nachweisbaren Lungenveränderungen vier Krankheitsstadien unterschieden (Northway et al. 1967; NorthWAy u. Rosan 1968). Neuere Untersuchungen zeigen, daß die Stadien der bronchopulmonalen Dysplasie nicht mehr in so ausgeprägter Form vorkommen wie früher beschrieben wurde und die Krankheitsstadien in den meisten Fällen der beatmeten Früh- und Neugeborenen nicht mehr in der ursprünglich beschriebenen Sequenz auftreten (EdWARds et al. 1977; OpPermanN u. Wille 1982; OpPermanN et al. 1986). Das Stadium I der BPD entspricht meistens einem Atemnotsyndrom (s. Abschnitt B.II.).

Das Stadium II stellt sich in der Regel zwischen dem 4. und 10. Lebenstag ein. Es ist charakterisiert durch eine subtotale Lungeneintrübung, welche die Regenerationsphase des Atemnotsyndroms darstellt und zugleich oft Ausdruck eines persistierenden Ductus arteriosus Botalli ist (Brown et al. 1978; OpPERMANN u. Wille 1982) (Abb. 16a).

Das Stadium III - etwa vom 10. bis 30. Lebenstag - repräsentiert den Übergang in einen chronischen Krankheitszustand. Röntgenmorphologisch imponieren unterschiedlich große multiple zystoide Strukturveränderungen, die meistens beiden Lungen einen grobnetzigen-wabigen Charakter verleihen (sog. ,Schwammuster“ der Lungen) (Abb.16b). 
a

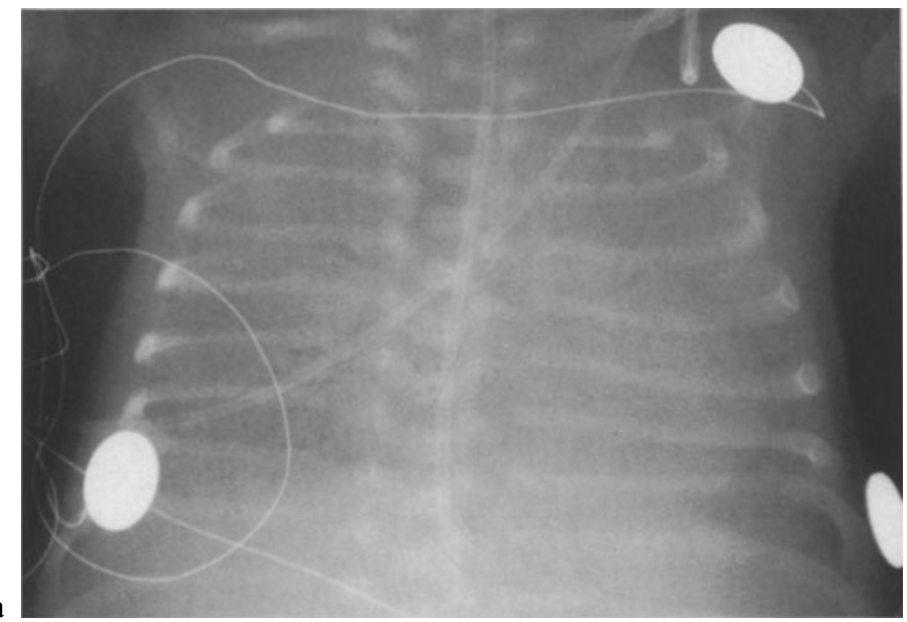

b
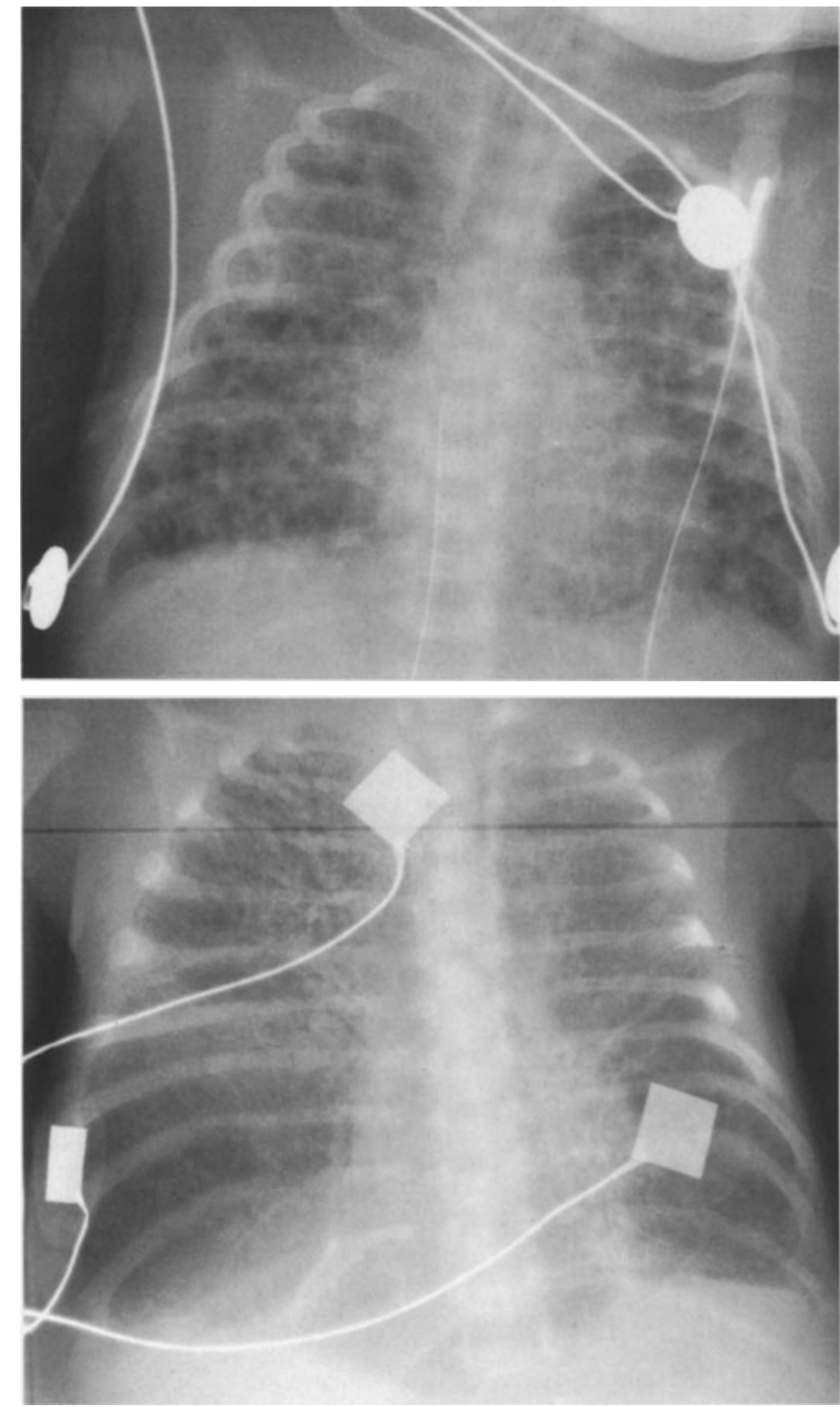

Abb. 16a-c 


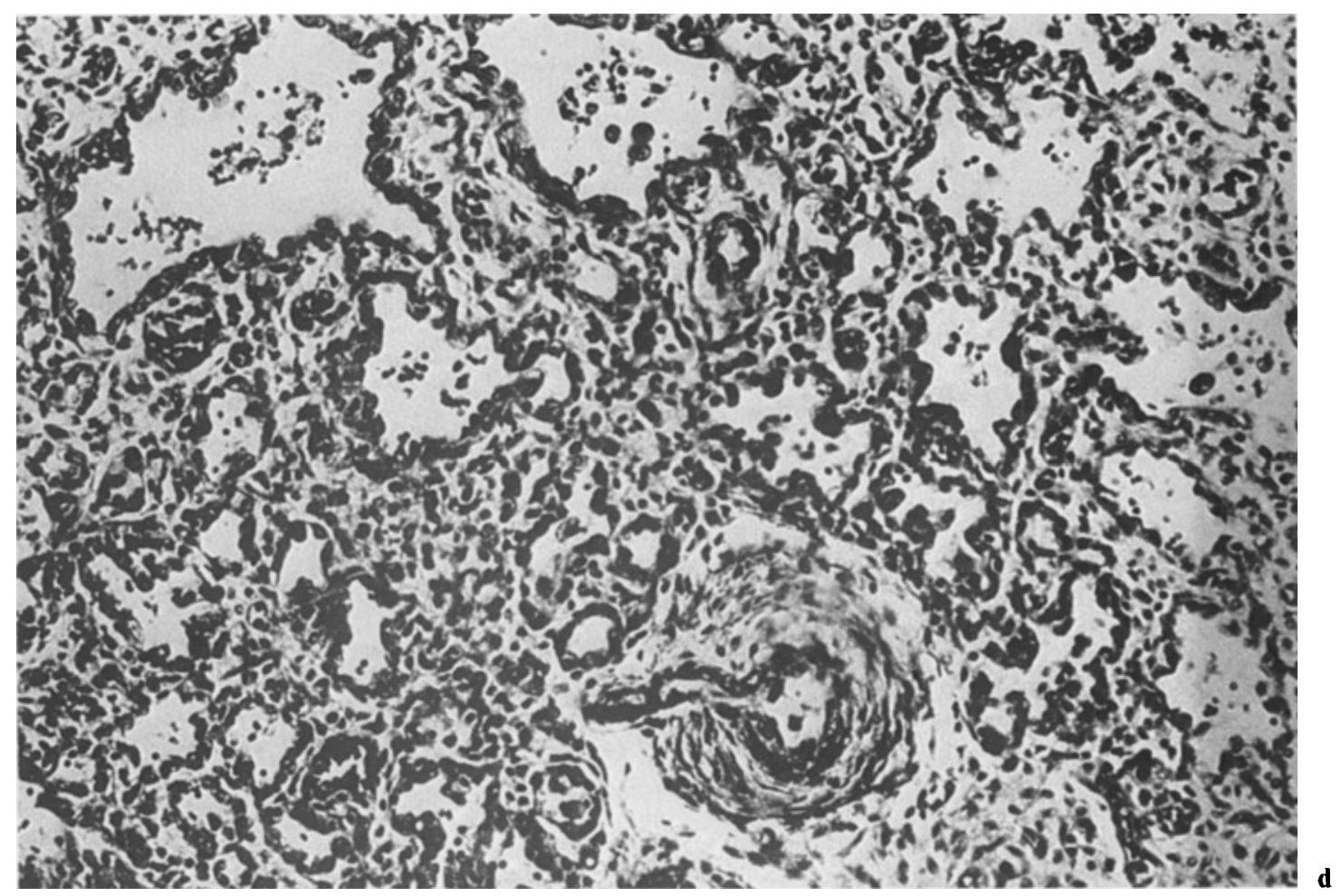

Abb. 16. a Bronchopulmonale Dysplasie Stadium II. Dicht schleierige, diffuse Lungeneintrübung bds. am 6. Lebenstag. b Bronchopulmonale Dysplasie Stadium III. Neugeborenes mit Langzeitbeatmung am 16. Lebenstag. Grobnetzige Lungenstruktur bds. mit multiplen pseudozystischen Strukturen (,SchwammMuster"). c Bronchopulmonale Dysplasie Stadium IV. Excessive Lungenüberblähung, besonders der Unterlappen. Grobstreifige, fibrotische Veränderungen in den para- und subhilären Abschnitten, rechts ausgeprägter als links. Relative Mikrokardie. d Bronchopulmonale Dysplasie Stadium III. - Verbreiterung des Interstitium mit Proliferation von Fibroblasten. Ausgedehnte Mikroatelektasen. Präazinäres Gefäß mit ausgeprägter Vasokonstriktion und perivaskulärem Ödem. HE $\times 120$

Das Stadium IV der BPD ist in der Regel nach 4 Lebenswochen erreicht. Es ist röntgenmorphologisch ausgezeichnet durch eine Vergrößerung und teilweise auch Rückbildung der pseudozystischen Strukturen; zusätzlich finden sich streifenförmige, vornehmlich perihilär lokalisierte Verdichtungen sowie eine Überblähung, vornehmlich in den Unterlappen (Abb. 16c).

Histomorphologisch ist die bronchopulmonale Dysplasie charakterisiert durch Metaplasien des Alveolarepithels, der Bronchialmukosa und der Bronchiolen, emphysematöse Alveolarbezirke mit sie umgebenden Atelektasen sowie durch eine erhebliche Verbreiterung des Interstitium mit ausgeprägter Fibroblastenproliferation (Bonikos et al. 1976; OpPERMANN et al. 1977; ReID 1979) (Abb. 16d).

Neuere Untersuchungen mittels postmortaler Pulmonalisangiogramme haben gezeigt, daß es bei Patienten mit bronchopulmonaler Dysplasie auch zu Strukturalterationen im pulmonalen Gefäßbett kommt. Im Niveau der Subsegmental- und Prälobular-Arterien ist eine regionale Gefäßrarefizierung nachweisbar, darüberhinaus finden sich abrupte Kalibersprünge in peripheren Pulmonalarterienästen wie bei einer pulmonalen Hypertension und ausgeprägte bronchiale Kollateralen (OPPERMANN 1983; TOMASHEFSKI et al. 1984) (Abb. 17a/b).

Das Stadium I der bronchopulmonalen Dysplasie ist vom Atemnotsyndrom im Stadium I nicht zu unterscheiden. 

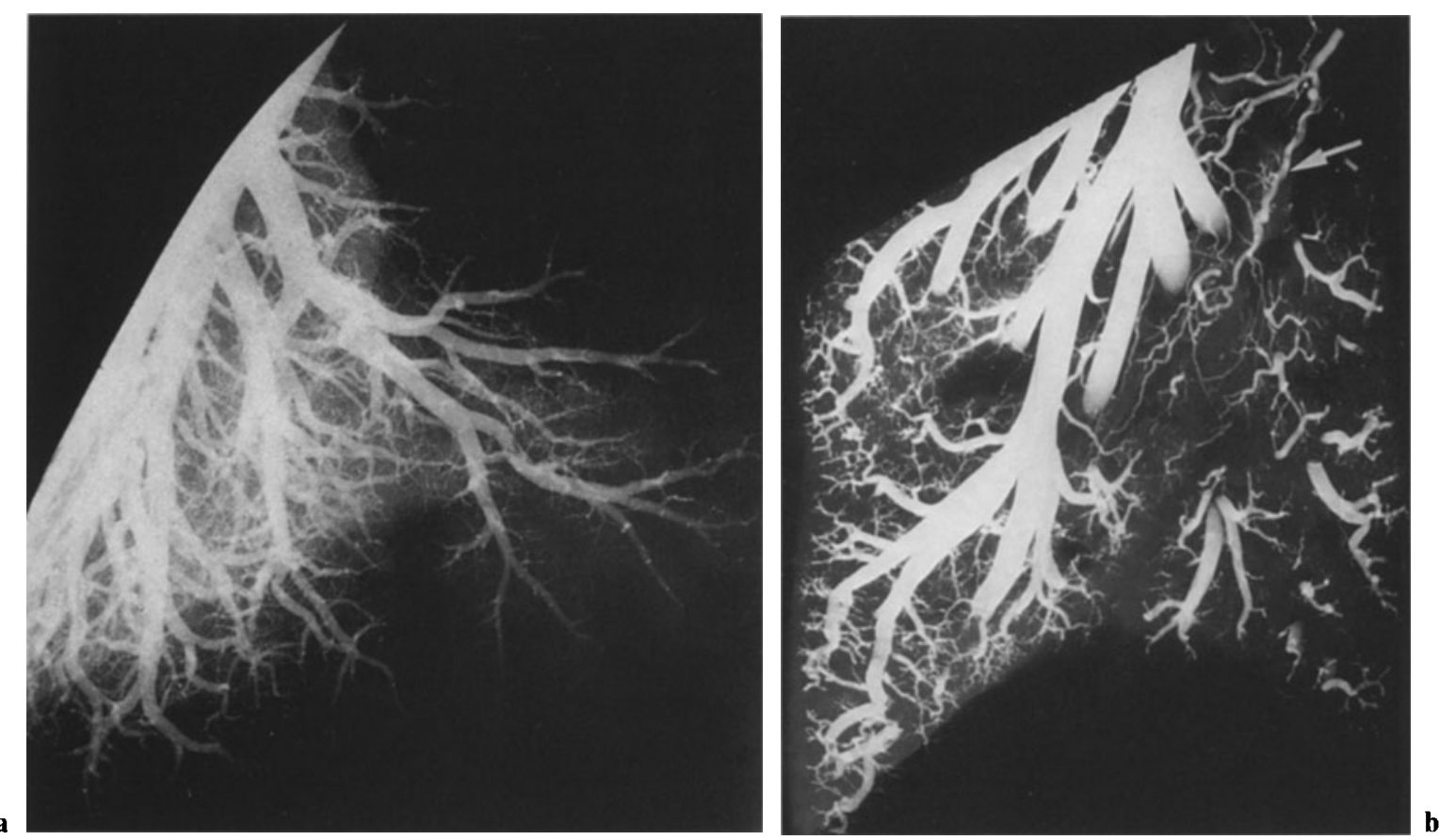

Abb. 17. a Postmortales Lungenangiogramm eines im Alter von 2 Wochen verstorbenen Patienten mit bronchopulmonaler Dysplasie. Medio-basaler Lungenabschnitt in Frontalprojektion (3fache Vergrößerung). Deutliche Rarefizierung peripherer Pulmonalarterienäste. Geschlängelter Verlauf einiger peripherer Lungenarterien. b Angiographischer Befund (postmortales Angiogramm) bei bronchopulmonaler Dysplasie Stadium II. Frontalschnitt des rechten Unterlappens (3fache Vergrößerung). Ausgeprägte Bronchialarterienfüllung (s. $P f e i l$ ). Die lochartigen Defektbildungen in der Lunge entsprechen fokalen Emphysemen

Das Stadium II der bronchopulmonalen Dysplasie muß abgegrenzt werden gegen ein pulmonales Ödem anderer Genese und gegen eine Hyperinfusion. -

Die wichtigste Differentialdiagnose zum Stadium III der bronchopulmonalen Dysplasie ist ein ausgedehntes persistierendes pulmonales interstitielles Emphysem. Eine Unterscheidung ist im Nativbild oft schwierig und kann nur mittels eines Ventilations- und Perfusionsszintigramms getroffen werden (LeONIDAS et al. 1978). Weitere Differentialdiagnosen im Stadium III der bronchopulmonalen Dysplasie sind eine Lungenvenenfehlmündung mit venöser Obstruktion, eine kongenitale pulmonale Lymphangiektasie und eine Mekoniumaspiration. Ein Wilson-Mikity-Syndrom läßt sich durch die Anamnese ausschließen, das Hamman-RichSyndrom ist nur im Spätstadium (Stadium IV) der bronchopulmonalen Dysplasie zu berücksichtigen. Der jüngste in der Literatur beschriebene Fall war 7 Wochen alt (IvEMARK u. WALLGREN 1962).

\section{Pleuraerkrankungen im Neugeborenenalter}

Erkrankungen des Pleuralraumes als eigenständiges Krankheitsbild sind in der Neugeborenenperiode ausgesprochen selten.

In der Regel treten Pleuraergußbildungen im Gefolge oder als Begleitsymptom anderer Grunderkrankungen auf, so z.B. bei einer perinatalen Pneumonie, im Rahmen eines Hydrops fetalis, bei kongenitalen Herz- und Gefäßanomalien, bei einer Polyzythämie, bei einer polyzy- 
stischen Nierenerkrankung vom infantilen Typ wie auch als ein Symptom eines Ullrich Turner Syndroms (OpPERmanN et al. 1982, S. 109). Darüberhinaus kann eine Pleuraergußbildung artefiziell nach Gefäßkatheterisierung (sog. Infuso-Thorax) entstehen (FRISCH u. SCHABEL 1979; KNIGHT et al. 1974; QuERFELD et al. 1984) oder sich auf dem Boden einer Thrombose der Vena cava superior bei längerfristiger parenteraler Ernährung über einen Jugulariskatheter entwickeln (KRAMER et al. 1981).

\section{Hydrothorax}

Der Hydrothorax ist definiert als eine intrapleurale Flüssigkeitsansammlung, deren Inhalt nicht aus Chylus, Sanguis oder Pus besteht. Ein primärer (kongenitaler) Hydrothorax ist von einem sekundären zu unterscheiden, welcher in der Regel artefiziell entsteht. Die letztere Form ist immer nur einseitig lokalisiert, während der kongenitale Hydrothorax uni- und bilateral auftreten kann (Berger 1968; DietzsCH u. Berger 1970; Frisch u. Schabel 1979; QuerFeld et al. 1984; Swischuk 1980, S. 153). Der kongenitale Hydrothorax stellt für das Neugeborene immer eine bedrohliche Situation dar, weil er unmittelbar post partum oder in den ersten Lebensstunden zu einer respiratorischen Insuffizienz führt (GIEDION 1965; OPPERMANN et al. 1984). Hierbei bestimmt nicht nur das Ausmaß der Flüssigkeitsansammlung die Gefahr einer bedrohlichen respiratorischen Insuffizienz sondern auch der Ausprägungsgrad der oft assoziierten Lungenhypoplasie (Frisch u. SCHABel 1979; OpPermanN et al. 1982, S. 109; OPPERMANN et al. 1984). Bei einem ausgeprägten kongenitalen Hydrothorax kann nur eine sofortige Thorakozentese zu einer ausreichenden Entfaltung der Lungen führen, um eine genügende Oxygenierung zu gewährleisten. -

Ursächlich werden für den Hydrothorax diskutiert kongenitale Defekte des Ductus thoracicus, eine Ruptur intrathorakaler Lymphgefäße durch Druckschwankungen sub partu, Geburtstraumata und Entwicklungsanomalien im Thorakalbereich des lymphatischen Systems (Berger 1968; Dietzsch u. Berger 1970; MCKendry et al. 1957; Oppermann et al. 1982, S. 109; WAGNER u. ZWEYMÜLLER 1973).

Der Entwicklung eines sekundären Hydrothorax (iatrogener Infuso-Thorax) geht in der Regel eine Gefäßkatheterisierung mit Gefäßperforation voraus (KNIGHT et al. 1974; QUERFELD et al. 1984).

Röntgenologisch stellt sich ein Hydrothorax bei starker bilateraler Ausprägung in Form einer ,weißen Lunge“ dar, innerhalb derer nur zentral Teile des Tracheo-Bronchialsystems belüftet sind. Hierbei besteht eine maximale Inspirationsstellung im Gegensatz zur ,weißen Lunge" beim Atemnotsyndrom Stadium IV. Die ventralen Rippenenden der ersten Rippenpaare sind nach kranial aufgebogen (sog. „Krabbenfußzeichen“ nach Giedion 1965) (Abb. 18). Das Aufwärtsbiegen der ersten Rippenpaare ist vermutlich durch die extreme Inanspruchnahme der Atemhilfsmuskulatur bedingt, die das Neugeborene in eine Lordosestellung bringt (OPPERMANN et al. 1982, S. 109).

Bei weniger starker Ausprägung imponiert der Hydrothorax - wie auch andere Pleuraergußformen - als mantelförmige basale Ergußverschattung.

Der bilaterale Hydrothorax muß differentialdiagnotisch abgegrenzt werden gegen eine verzögerte Resorption fetaler Lungenflüssigkeit, gegen ein Atemnotsyndrom Stadium IV sowie gegen eine primäre Lungenatelektase, bei der sich eine mittlere Inspirationsstellung findet und eine bilaterale Lungenaplasie, die meistens assoziierte Fehlbildungen aufweist. Der unilaterale Hydrothorax ist abzugrenzen gegen ein flüssigkeitsgefülltes, kongenitales lobäres Emphysem, gegen eine kongenitale Zwerchfellhernie mit noch unbelüfteten Darmschlingen, gegen einen intrathorakalen Tumor und einen Hämothorax. Eine unilaterale Atel- 


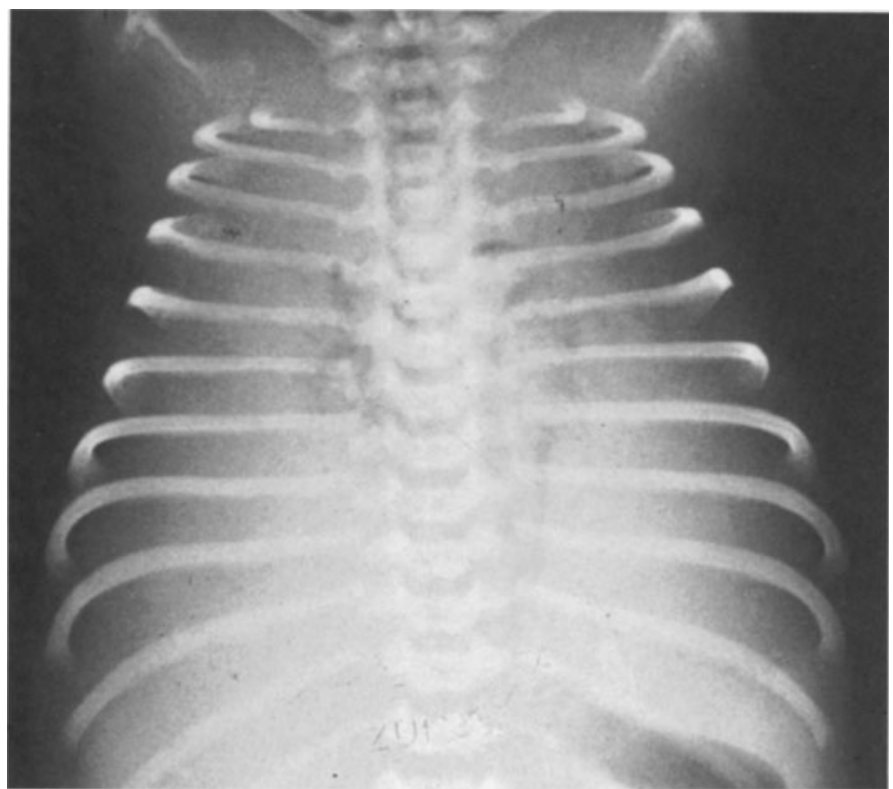

Abb. 18. Bilateraler, kongenitaler Hydrothorax. Der Thorax ist homogen veschattet, nur zentral geringe Luft. Herz, Lungen und Zwerchfell nicht abgrenzbar. Rippen in maximaler Inspirationsstellung. (Für die freundliche Überlassung des Röntgenbildes danke ich Herrn Prof. Dr. A. Giedion, Zürich)

ektase ist vom einseitigen Hydrothorax durch die in der Regel vorhandene Mediastinalverziehung leicht zu unterscheiden.

\section{Chylothorax}

Beim Chylothorax ist in Analogie zum Hydrothorax eine kongenitale, primäre Form von einer sekundären Form zu unterscheiden. Der Chylothorax nimmt unter den Pleuraerkrankungen des Neugeborenen insofern eine Sonderstellung ein, als die chylöse Flüssigkeit bei der primären Form zunächst extrapleural lokalisiert ist und erst später durch Ruptur der Pleura mediastinalis in den Pleuraraum eindringt (sekundäre Form) (KUNDERT u. WILLICH 1969; WILLICH u. KUNDERT 1971).

Dieses Verhalten erklärt auch die besondere Röntgensymptomatologie bei der kongenitalen Form des Chylothorax. Der Pathomechanismus, welcher zur Entwicklung eines primären Chylothorax führt, ist bis heute nicht eindeutig geklärt. In vereinzelten Fällen konnten sich geburtstraumatisch ausgelöste Lymphgefäßverletzungen und/oder Anomalien, bzw. Entwicklungsstörungen der intrathorakalen Lymphgefäße nachweisen lassen (AvERY et al. 1981, S. 197; Kundert u. Willich 1969; RandolPh u. Gross 1975; Tischer 1967; YanCy u. SPOCK 1967). Sekundär kann ein Chylothorax nach einer Thorakotomie oder als Folgesymptom eines erhöhten intrapulmonalen Innendruckes entstehen (HOLM u. SöDERLUND 1975). Als seltene, aber lebensbedrohliche Ursache eines sekundären Chylothorax beschrieben Kramer et al. (1981) eine Thrombose der Vena cava superior bei Frühgeborenen, die über längere Zeit mittels Jugulariskatheter ernährt wurden.

Die unterschiedliche Lokalisation der Chylusflüssigkeit beim primären Chylothorax im Gegensatz zum sekundären bedingt eine differente Röntgensymptomatologie. Der kongenitale (primäre) Chylothorax ist retropleural gelegen und zeichnet sich durch einen besonders 
hohen Fettgehalt aus. Bei ihm lassen sich nach WILlICH u. KUNDERT (1971) folgende Symptome nachweisen:

Die Chylusergußlamelle verbreitert sich bei aufrechter Position des Patienten nach kranial, sog. ,paradoxes Ergußverhalten“. In Rückenlage oder bei Kopf-Tief-Lage des Patienten wird die Ergußlamelle nach kaudal breiter (Abb. 19). Der kleine und große Lappenspalt sind beim primären Chylothorax nicht obligat verbreitert, die Sinus phrenicocostales sind oft ergußfrei.

Der sekundäre Chylothorax stellt sich auf Grund seiner intrapleuralen Lokalisation wie andere Pleuraergußformen als homogene oder mantelförmige Verschattung dar, seltener auch als subpulmonale Ergußansammlung (OPPERMANN et al. 1982, S. 112; WAGNER u. ZWEYMÜLLER 1973; WILliCH u. KuNDERT 1971).

Der primäre Chylothorax läßt sich bei Beachtung der angeführten Kriterien gut von den anderen Pleuraergußformen abgrenzen. Der sekundäre Chylothorax unterscheidet sich röntgenologisch nicht von anderen Pleuraergußbildungen.

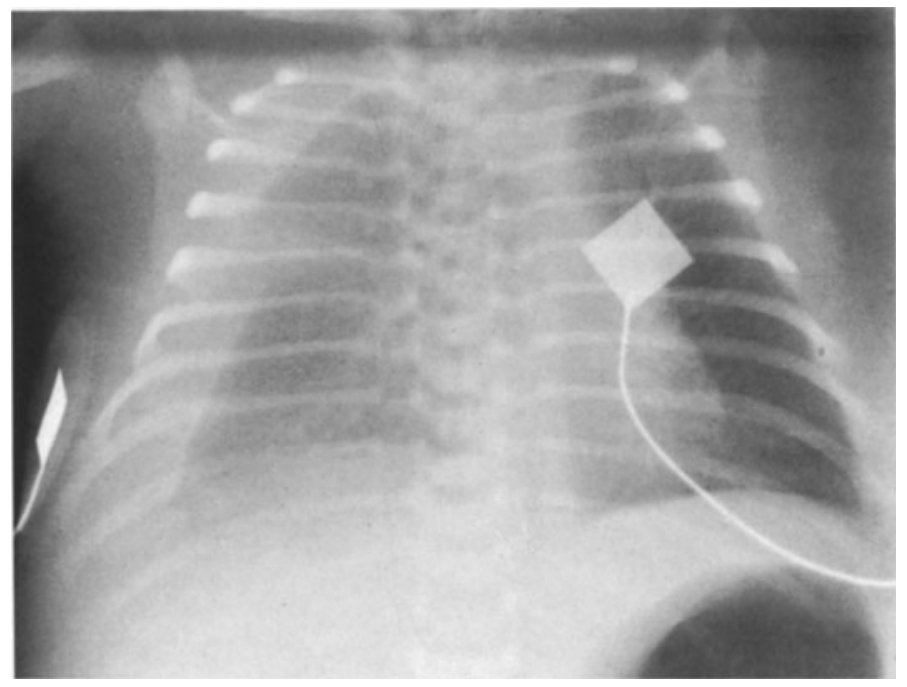

Abb. 19. Kongenitaler, unilateraler Chylothorax. - Rechtsseitige Pleuraergußverschattung mit Verbreiterung der Ergußlamelle nach caudal (Aufnahme in Rückenlage des Patienten)

\section{Hämothorax}

Der Hämothorax kommt im Neugeborenenalter nur extrem selten vor, er ist von anderen Pleuraergußbildungen nach röntgenmorphologischen Kriterien nicht zu differenzieren. Nahezu immer findet sich eine einseitige Ergußverschattung, wobei die linke Seite bevorzugt betroffen ist. Die sporadisch in der Literatur beschriebenen Fälle lassen eine Prädominanz des männlichen Geschlechtes erkennen. In der Pathogenese des Hämothorax spielt die wichtigste Rolle ein Vitamin K1-Mangel (Morbus hämorrhagicus neonatorum) (AARON u. DooHEN 1970; Josten u. Haupt 1956; Weill et al. 1965).

Weitere Ursachen für einen neonatalen Hämothorax sind geburtstraumatisch bedingte Rippenfrakturen oder Rippenfrakturen im Rahmen einer Osteogenesis imperfecta sowie pleurale Gefäßverletzungen (Giedion 1965; OppermanN u. Wille 1980; SChUKowski 1903), ferner wurde ein Hämothorax nach Ruptur eines Aneurysma des Ductus arteriosus Botalli sowie nach einer Perforation des linken Vorhofes im Rahmen einer Herzkatheterisierung beobachtet (Dippel et al. 1973; OPPERMANN U. WiLle 1980). 
Als „kuriose“ Ursache für die Entstehung eines Hämothorax beschrieben GwINN u. LEE 1974 eine intrauterine Transfusion. Auch eine Assoziation einer kongenitalen Zwerchfellhernie mit einem Hämothorax wurde beobachtet (StOKer u. Pуко 1978).

Die Röntgensymptome des Hämothorax entsprechen denen anderer pleuraler Ergußbildungen - mit Ausnahme des primären Chylothorax - (Abb. 20). Die Diagnose läßt sich nur durch eine Thorakozentese verifizieren, die zugleich als therapeutische Maßnahme fungiert (OPPERMANN u. Wille 1980).

Die Differentialdiagnose zum Hämothorax umfaßt eine massive Lungenblutung, ein Pleuraempyem, ein Hydrothorax sowie eine kongenitale Zwerchfellhernie vom Spättyp.

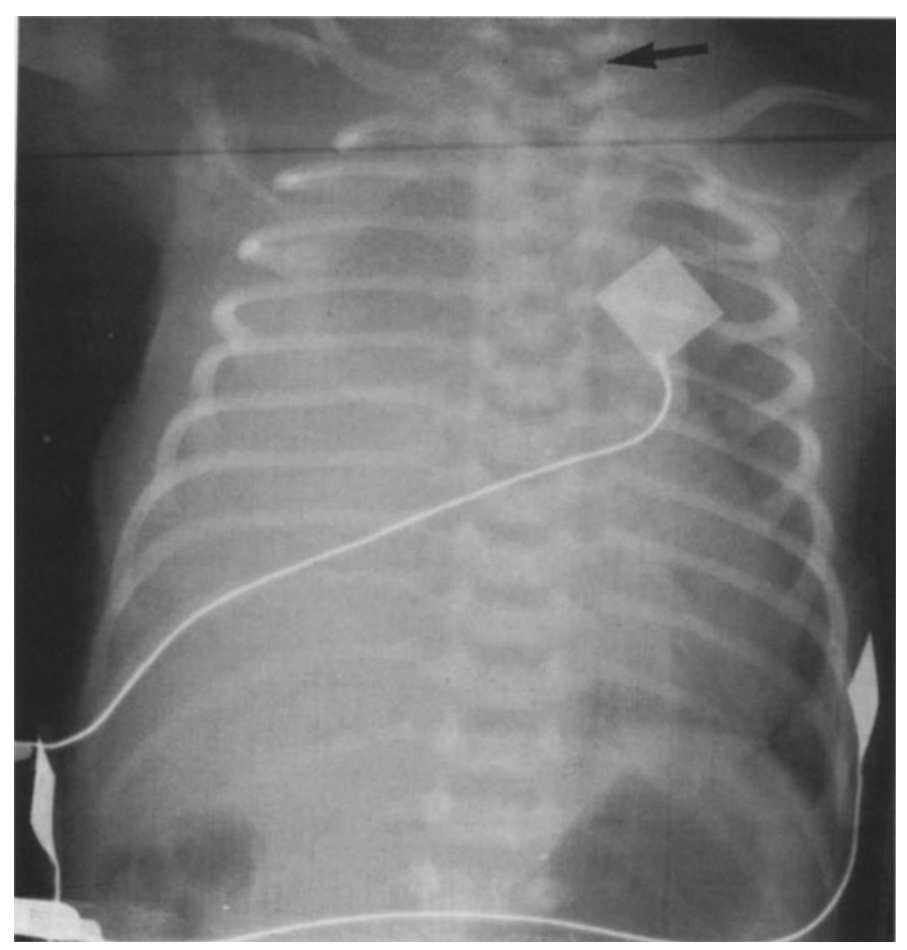

Abb. 20. Hämothorax bei verspätet auftretender rechtsseitiger Zwerchfellhernie am 4. Lebenstag. Fehlende Abgrenzbarkeit der rechten Zwerchfellhälfte. Massive Ergußverschattung rechts mit Abdrängung des Mediastinums nach links. Nur noch geringe Belüftung im rechten Oberlappen. Klavikulafraktur rechts. Fehlposition des zentralen Venenkatheters

\section{Lungenfehlbildungen}

\section{Lungenagenesie, Lungenaplasie und Lungenhypoplasic}

Das totale Fehlen einer oder beider Lungenanlagen wird als Lungenagenesie bezeichnet. Hingegen findet sich bei der Lungenaplasie rudimentäres, aber funktionsloses Lungengewebe. Der Begriff der Lungenhypoplasie beinhaltet das Vorhandensein einer kompletten Lungenanlage, die aber - bezogen auf das Gestationsalter des Föten bzw. des Neugeborenen - zu klein ist. 
Lungenagenesie und Lungenaplasie sind seltene Anomalien. Die Lungenhypoplasie kommt häufiger vor, sie wird meistens in Assoziation mit anderen Fehlbildungen infolge fetaler Entwicklungsstörungen beobachtet. Die Lungenagenesie bzw. -aplasie und Lungenhypoplasie kommen ein- und beidseitig vor. Bei der einseitigen Form besteht keine Seitenprädilektion.

Die Ätiologie der unilateralen Form dieser Fehlbildungen ist nicht geklärt. Zirkulationsstörungen während der organogenetischen Periode der Fetalzeit werden vermutet (BOYDEN 1955; Emery u. Mithal 1960; Reid 1977). Lungenagenesie, -aplasie und Lungenhypoplasie sind immer verbunden mit einer ipsilateralen Pulmonalarterienagenesie bzw. -hypoplasie.

Assoziierte - meistens komplexe Herz- und Gefäßfehlbildungen - werden vor allem bei rechtsseitiger Lokalisation der Agenesie, Aplasie und Hypoplasie beobachtet. Gleichzeitig können Wirbelanomalien, Nierenfehlbildungen und auch Anomalien im Gastrointestinaltrakt bestehen (Avery et al. 1981, S. 171; BOYden 1955; MENDELSOHN u. HutCHIN 1977; OpPeRMANN et al. 1982, S. 105; YAGHMAI 1970).

Die Lungenhypoplasie wird besonders im Zusammenhang mit einer kongenitalen Zwerchfellhernie beobachtet (AREECHON u. REID 1963; BERdon et al. 1968; KitAGaWA et al. 1971; Wiseman u. MCPhERSON 1977). Der Ausprägungsgrad der Lungenhypoplasie deutet auf den Zeitpunkt der intrauterinen Manifestation der Zwerchfellhernie hin. Je früher die Herniation auftritt, um so stärker ist die Anzahl der Bronchialäste, der Alveolen und der Gefäßäste reduziert (Kitagawa et al. 1971; Wiseman u. MCPherson 1977). Eine besonders gefürchtete Komplikation der Lungenhypoplasie ist die Entwicklung einer pulmonalen Hypertonie, die zu einem Rechts-Links-Shunt führt (NAEYE et al. 1976). Interessanterweise entwickelt sich beim Vorliegen einer Zwerchfellhernie die Lungenhypoplasie nicht nur auf der Hernienseite sondern auch auf der kontralateralen Seite. Hypoplastische Lungen neigen generell unter mechanischer Beatmung leicht zur Entwicklung eines Pneumothorax. Die Prognose gilt besonders dann als ungünstig, wenn das Barotrauma auf der Gegenseite der Hernie auftritt (Fliegel u. KaUfmann 1972).

Auch bei der bilateralen Form der Lungenagenesie bzw. -aplasie und Lungenhypoplasie ist keine spezifische Ätiologie bekannt. Der Ausprägungsgrad dieser Anomalie hängt davon $a b$, in welcher jeweiligen intrauterinen Zeitphase die Entwicklung des Lungengewebes gestört war (BOYDEn 1955; EMERY u. Mithal 1960).

Die Lungenagenesie und -aplasie sind meistens mit anderen schweren Fehlbildungen, wie z.B. einer Ösophagusatresie, kombiniert (DeBuse u. MorrIs 1972). Bei der bilateralen Lungenhypoplasie ist eine primäre von einer sekundären Form zu unterscheiden. Als Ursache für die Entstehung einer primären bilateralen Lungenhypoplasie wird eine fetale Hypoxie und eine verminderte Prolinsynthese bei einer gleichzeitigen Nierenfehlentwicklung diskutiert (Avery et al. 1981, S. 171; Hislop et al. 1979; SwischuK et al. 1979).

Nach SwISCHUK lassen sich als Ursachen für eine sekundäre bilaterale Lungenhypoplasie eine extrathorakale, thorakale und intrathorakale Kompression der Lungen unterscheiden.

Die extrathorakale Kompression kann verursacht werden durch ein Oligohydramnion mit gleichzeitiger Nierenerkrankung (Potter-Syndrom), durch ein Oligohydramnion ohne assoziierte Nierenfehlentwicklung und durch eine chronische Zwerchfellelevation infolge eines Aszites, intraabdominaler Tumoren oder eines membranösen Zwerchfells. -

Als Ursache für eine thorakale Kompression der Lungen kommen vor allem Thoraxdysplasien in Frage (z.B. asphyxierende Thoraxdysplasie, Achondroplasie, Achondrogenesis etc.). Außerdem können auch neuromuskuläre Erkrankungen, z.B. eine myotone Dystrophie oder Myasthenie, eine thorakale Kompression hervorrufen. -

Die intrathorakale Lungenkompression wird induziert durch eine Zwerchfellhernie oder Zwerchfellaplasie, aber auch durch einen kongenitalen Hydrothorax, Chylothorax sowie 


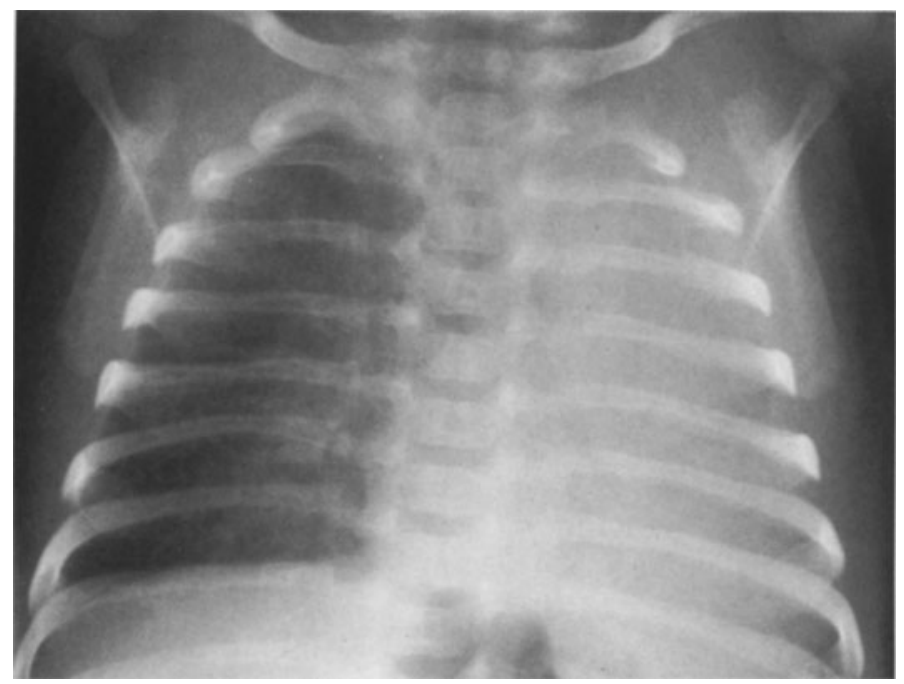

Abb. 21. Lungenhypoplasie. 4 Wochen altes Neugeborenes mit Lungenhypoplasie links. Totale linksseitige Thoraxverschattung mit Linksverlagerung des Herzens und Gefäßbandes

durch intrathorakale Tumoren (Oppermann et al. 1982, S. 105; Perlman u. Levin 1974; SwISCHUK et al. 1979).

Im Thoraxnativbild läßt sich eine Lungenagenesie nicht von einer Lungenaplasie unterscheiden. Nur mittels einer Tracheo-Bronchographie ist eine Differenzierung zwischen diesen beiden Fehlbildungen möglich. Zusätzlich kann Lungenperfusionsszintigraphie oder Pulmonalisangiographie zur Differenzierung zwischen Lungenaplasie und -agenesie herangezogen werden (Oppermann et al. 1982, S. 105; Pendarvis u. Swischuk 1969) (Abb. 22a).

Die einseitige Lungenagenesie bzw. -aplasie stellt sich als dichte homogene Verschattung dar, gleichzeitig ist das Mediastinum zur kranken Seite hin verzogen. Die kontralaterale, gesunde Lungenhälfte ist in der Regel überbläht und herniert über das vordere obere Mediastinum zur kranken Seite. Bedingt durch ein vermehrtes Herzminutenvolumen ist die Gefäßzeichnung auf der gesunden Seite verstärkt. Nicht in jedem Fall einer Lungenagenesie bzw. -aplasie ist auch der knöcherne Anteil des Hemithorax auf der betroffenen Seite verkleinert (Avery et al. 1981, S. 171; Daves u. Walsh 1970; Yaghmai 1970).

Besteht nur eine lobäre Agenesie bzw. Aplasie, zeigt der betroffene Hemithorax in der sagittalen Projektionsebene noch eine geringe Strahlentransparenz. Im transversalen Strahlengang läßt sich retrosternal eine bandförmige, dem Sternum parallel verlaufende Verdichtung nachweisen, welche das Korrelat von Fett und Bindegewebe an Stelle des fehlenden Lungengewebes darstellt (CREMin u. BASs 1975; OPPERMANN et al. 1982, S. 105).

Eine hypoplastische Lunge stellt sich im Thoraxnativbild mit normaler Transparenz und einer normalen oder nur diskret verminderten Lungengefäßzeichnung dar (OPPERMANN u. Wille 1977; Oppermann et al. 1982, S. 105; SwischUK et al. 1979) (Abb. 21).

Die bilaterale Lungenagenesie wird im Thoraxnativbild erkennbar an kleinen Thoraxhälften - bezogen auf das Alter des Kindes -, die total luftleer sind bis auf die im Trachealstumpf gelegene Luft (AvERY et al. 1981, S. 171).

Bei der bilateralen Lungenhypoplasie sind ebenfalls beide Lungenhälften klein und relativ hell. Bei nur geringer Ausprägung der Lungenhypoplasie läßt sich die Diagnose oft erst aus dem Verlauf heraus stellen (OPPERMANN et al. 1982, S. 105).

Die unilaterale Lungenagenesie ist differentialdiagnostisch $\mathrm{zu}$ unterscheiden von einer einseitig verzögerten Resorption fetaler Lungenflüssigkeit, von einer unilateralen Atelektase und von einem Pleuraerguß. 
$\mathbf{a}$
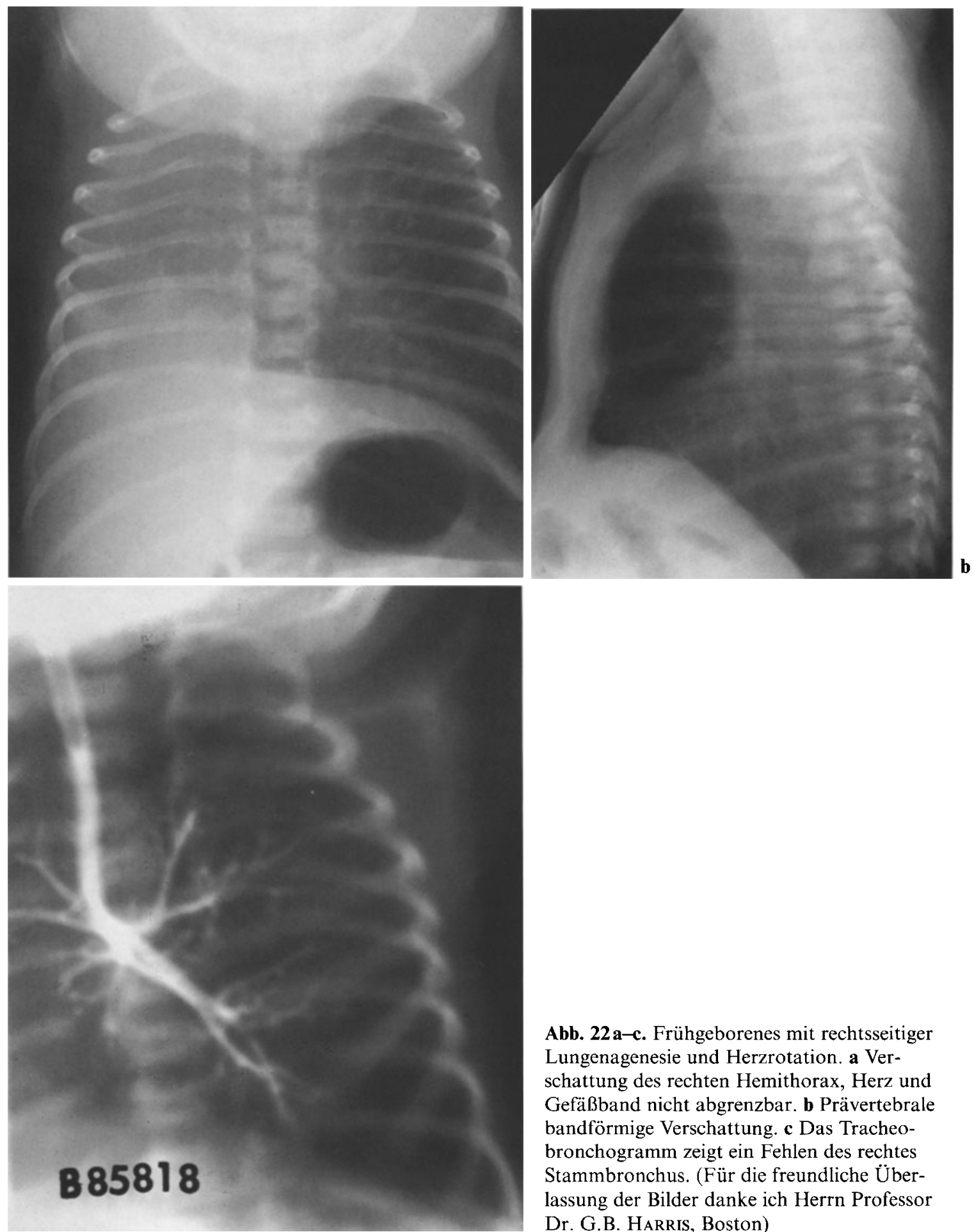

Abb. 22a-c. Frühgeborenes mit rechtsseitiger Lungenagenesie und Herzrotation. a Verschattung des rechten Hemithorax, Herz und Gefäßband nicht abgrenzbar. b Prävertebrale bandförmige Verschattung. c Das Tracheobronchogramm zeigt ein Fehlen des rechtes Stammbronchus. (Für die freundliche Überlassung der Bilder danke ich Herrn Professor Dr. G.B. Harris, Boston)

Bei der bilateralen Lungenagenesie müssen berücksichtigt werden ein Atemnotsyndrom Stadium IV, eine bilaterale Atelektase, eine massive Lungenblutung und ein Chylothorax. Die einseitige Lungenhypoplasie kann durch eine Thoraxskelettasymmetrie und durch Verdrehung der Aufnahme in den 1. oder 2. Schrägdurchmesser vorgetäuscht werden. 
Eine bilaterale Lungenhypoplasie ist abzugrenzen gegen eine zentrale oder periphere Atemstörung sowie ein Vitium cordis mit verminderter Lungenperfusion.

\section{Kongenitales lobäres Lungenemphysem}

Das kongenitale lobäre Lungenemphysem gehört zu den seltenen Ursachen der neonatalen Atemstörungen, häufiger manifestiert es sich erst im frühen Säuglingsalter, vornehmlich im Rahmen einer pulmonalen Infektion. - Die Ätiologie des kongenitalen lobären Emphysems ist multifaktoriell. Als Ursachen dieser Lungenanomalie sind bekannt eine Hypoplasie von Segmentbronchien und kongenitale Bronchusstenosen (BINSTADT et al. 1977; CAMPBELL 1969), sowie Gefäßanomalien mit Bronchusobstruktion (CoCHRAN et al. 1977; LeAPE et al. 1970; Pierce et al. 1970; Sulayman et al. 1975). - Auch Mediastinalzysten und andere Mediastinaltumoren führen über eine Bronchusobstruktion zur Entwicklung eines lobären Emphysems (Avery u. Fletcher 1974, S. 125; Cremin u. Movsowitz 1971; Hegenbarth et al. 1980; LEAPE u. LONGINO 1964; WeINGärTNER 1977). Sekundär kann in der Neonatalperiode oder später durch einen intraluminalen Schleimpfropf oder auch durch endobronchiales Granulationsgewebe, z.B. im Rahmen einer bronchopulmonalen Dysplasie, ein lobäres Lungenemphysem entstehen (COONEY et al. 1977; KEITH 1977).

Bei einer entsprechenden Größe führt das kongenitale lobäre Lungenemphysem sehr schnell zu einer bedrohlichen Ateminsuffizienz die eine Lobektomie des betroffenen Lungenlappens erforderlich macht (EHRENHART u. TABER 1953). Andererseits zeigen Einzelbeobachtungen, daß das kongenitale lobäre Lungenemphysem auch stationär bleiben und sich sogar zurückbilden kann (Roghair 1972; SHANNON et al. 1977).

Nach REID (1977) lassen sich histomorphologisch beim kongenitalen lobären Emphysem drei Formen unterscheiden. Beim gewöhnlichen Typ besteht eine Überdehnung der Alveolen und Bronchioli terminales, die aber in normaler Anzahl vorhanden sind. Bei der zweiten Form besteht eine übermäßige Anzahl der Bronchioli terminales und Alveolen (polyalveoläre Form), die dritte Form entspricht einem Mischtyp der vorgenannten Möglichkeiten (HeGENBARTH et al. 1980; HisLOP u. ReID 1970; RFID 1977).

Die röntgenologische Differenzierung der histomorphologisch unterschiedlichen Typen ist nicht möglich.

Das kongenitale lobäre Emphysem betrifft am häufigsten den linken Oberlappen, danach den Mittellappen und den rechten Oberlappen. In weniger als $1 \%$ der beobachteten Fälle konnte das lobäre Emphysem im Unterlappen oder bilateral nachgewiesen werden (CREMIN u. Movsowitz 1971; Floyd et al. 1963; Hendren u. MCKeE 1966).

Im Röntgenbild imponiert das lobäre Emphysem klassischerweise als ein überblähter Lungenlappen, der eine erheblich vermehrte Strahlentransparenz und eine deutlich verminderte Gefäßzeichnung aufweist. Die diesem Lappen benachbarten Lungenlappen sind kompressionsbedingt atelektatisch. Bei sehr starker Ausdehnung des lobären Emphysems kommt es zur Mediastinalverschiebung über das vordere obere Mediastinum zur Gegenseite (AvERY u. Fletcher 1974; CAMPBell 1969; Cremin u. Movsowitz 1971; Monin et al. 1979; WeinGÄRTNER 1977) (Abb. 23). Selten imponieren die überblähten Lungenlappen zunächst als dichte homogene Verschattung, die im Extremfall wie eine intrathorakale Raumforderung aussehen kann. Diese Verschattung ist durch Retention fetaler Lungenflüssigkeit distal der Bronchusobstruktion bedingt. So kann sich erst nach Absorption der fetalen Lungenflüssigkeit über das Lymphgefäßsystem und das venöse System das klassische Bild eines lobären Emphysems entwickeln (CORBETT u. WASHINGTON 1971; FAGAN u. SWISCHUK 1972; GrisCOM et al. 1969; Hitch et al. 1973; Zumbro et al. 1974). 


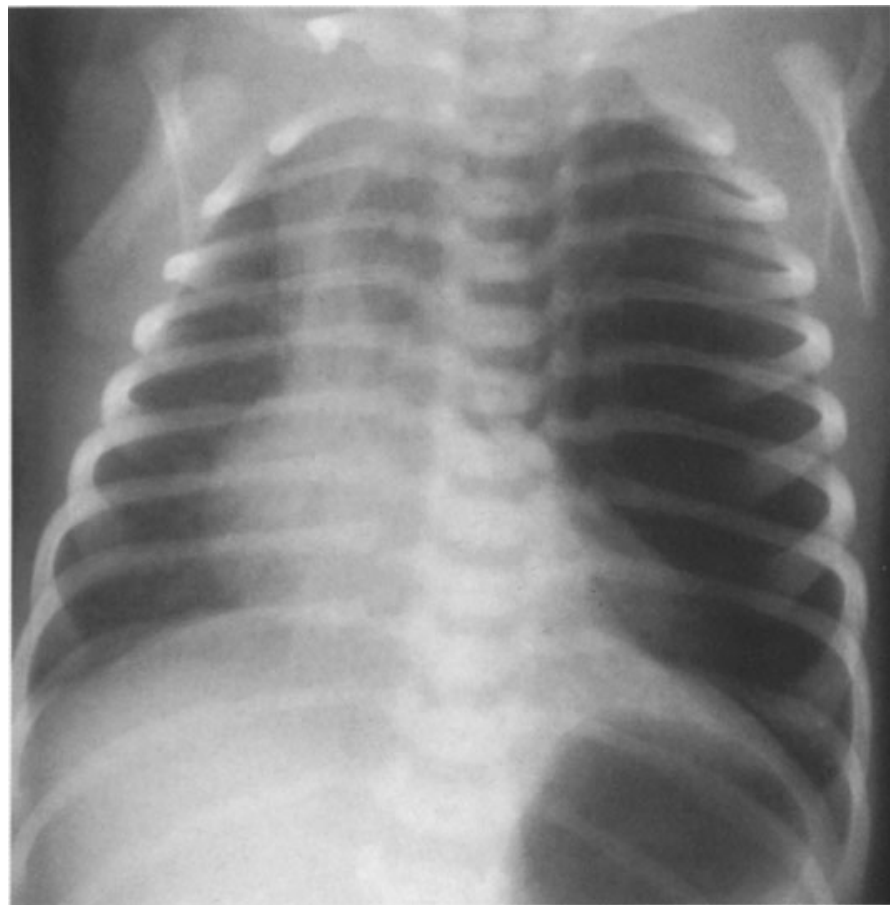

Abb. 23. 2 Tage altes Neugeborenes mit respiratorischer Insuffizienz bei kongenitalem lobären Lungenemphysem des linken Oberlappen. Vermehrte Transparenz des linken Oberlappens, Kompressionsatelektase des linken Unterlappens

Die Röntgensymptomatologie ist in der Regel so eindrucksvoll, daß weitere diagnostische Methoden wie Pulmonalisangiographie und Perfusionsszintigraphie nicht notwendig sind (Mauney u. Sabiston 1970; Neches et al. 1972). Im Ausnahmefall kann das kongenitale lobäre Emphysem mit einem Pneumothorax auf der befallenen Lungenseite einhergehen. Diese seltene Kombination läßt sich dann mutmaßen, wenn nach optimaler Drainage des Pneumothorax die betroffene Lungenseite unverändert überbläht bleibt (SwISCHUK 1980, S. 151).

Differentialdiagnostisch kommen bei einem kongenitalen lobären Lungenemphysem in erster Linie in Betracht eine kongenitale Lungenzyste, ein Pneumothorax, eine große Pneumatozele und ein kompensatorisches Lungenemphysem. Die erweiterte Differentialdiagnose hat eine zystisch-adenomatoide Malformation und eine Zwerchfellhernie in Betracht zu ziehen. Die letzten beiden Diagnosen lassen sich durch den Nachweis einer normalen bzw. pathologischen Abdominalbelüftung gegeneinander abgrenzen.

\section{Kongenitale Lungenzyste}

Die kongenitale Lungenzyste ist eine sehr seltene bronchopulmonale Fehlbildung, sie kann einseitig und beidseitig auftreten, ist meistens aber nur in einem Lungenlappen lokalisiert (Caffey 1953; Hegenbarth et al. 1980; Oppermann u. Wille 1977; Rehbein u. Röke 1960). Nach Rogers u. OSMER (1964) sind 66\% der Lungenzysten in den Unterlappen lokalisiert. Eine Assoziation von Lungenzysten mit zystischen Fehlbildungen in anderen Organen kommt nicht vor, auch ist keine familiäre Häufung oder eine Geschlechtsprädisposition bekannt. 
BAUM et al. beobachteten 1966 bei Patienten aus dem Jemen und Irak ungewöhnlich häufig kongenitale Lungenzysten, sie vermuten eine ethnische Besonderheit.

Ungewöhnlich ist auch die Kombination von kongenitalen Lungenzysten mit einer Dreilappung der linken Lunge und aberrierender systemischer arterieller Versorgung wie sie von SANE u. GiRdANY 1972 gemacht wurde. Eine anerkannte Klassifizierung der Lungenzysten gibt es bis heute nicht. Weder die Unterteilung in symptomatisch und asymptomatisch, wie sie von BRÜNNER et al. (1960) vorgenommen wurde, noch die Einteilung der Lungenzysten nach ihrem vornehmlichen histologischen Aufbau (MofFat 1960) oder die Klassifizierung nach solitärer oder multipler Manifestation (PoTTER 1961) haben sich durchgesetzt. Pathoanatomisch lassen sich bei den Lungenzysten drei unterschiedliche Formen voneinander differenzieren:

a) Lungenzysten mit Verbindung zum Bronchialsystem

b) Lungenzysten ohne Verbindung zum Bronchialsystem

c) Lungenzysten, die einen Ventilmechanismus aufweisen (Heymer 1963; KuRPAT u. Rothe 1974; SCHÜTZE et al. 1972).

Die Lungenzysten können bei Kommunikation mit dem Bronchialsystem und vor allem bei gleichzeitigem Vorliegen eines Ventilmechanismus eine beträchtliche Größe annehmen, so daß sie die angrenzenden Lungenabschnitte komprimieren und bei entsprechender Lokalisation auch zur Mediastinalabdrängung führen (KeUtel u. WiLliCh 1968; Oestreich 1973; ReHbeIN u. RöKE 1960; SCHÜTzE et al. 1972). Wenn zwischen Zysten und Bronchialsystem keine Verbindung besteht, sind die Lungenzysten mit Flüssigkeit oder mit Schleim gefüllt. - Von der Lokalisation her sind periphere von zentral gelegenen Lungenzysten zu unterscheiden. Die peripheren Zysten kommen wesentlich häufiger vor. Nach neueren Erkenntnissen sind die Lungenzysten nicht nur als isolierte Fehlbildung zu betrachten, sie sind vielmehr dem großen Spektrum der bronchopulmonalen Fehlbildungen zuzuordnen, zu denen auch die zystisch-adenomatoide Malformation sowie die intralobäre und extralobäre Sequestration gehören (CUliner 1968; RAMINOWSKy et al. 1979; KirKPATRICK 1980).

Der Entwicklung der Lungenzysten liegt pathogenetisch vermutlich eine fehlerhafte Aussprossung des ventralen Vorderdarmdivertikels zugrunde (AVERY et al. 1981, S. 164; REED u. Sobonya 1975; Kirk Patrick 1980). -

Histologisch sind die Lungenzysten aufgebaut aus Bronchialknorpel, glatter Muskulatur und Säulenepithel (Avery u. Fletcher 1981, S. 236; Caffey 1953; ReEd u. Sobonya 1975). -

Kongenitale Lungenzysten manifestieren sich in der Regel erst jenseits der Neugeborenenperiode, vornehmlich dann, wenn sich die Zyste infiziert (GWINN u. LeE 1970). Andererseits kann bei entsprechender Größe die Lungenzyste bereits in der Neonatalperiode rasch zu einer bedrohlichen Atemstörung führen (BEAU et al. 1969; Oestreich 1973).

Röntgenologisch stellt sich die Lungenzyste - sofern sie nicht schleim- oder flüssigkeitsgefüllt ist - als runder, scharf gegen die Umgebung abgegrenzter gefäßloser Bereich mit vermehrter Transparenz dar. Ihr Randsaum, der histologisch aus glatter Muskulatur, Bronchialknorpel und Respirationsepithel besteht, erscheint sehr dicht (AvERY u. FLETCHER 1981; ReEd u. SoBonya 1975; Young 1979) (Abb. $24 \mathrm{a}$, b). Oft ist die Lungenzyste auf dem Thoraxnativbild nicht sichtbar. So konnten OPSAHL u. BERMAN (1962) unter 25 klinisch symptomatischen Fällen mit einer Lungenzyste dieselbe nur 14mal im Thoraxbild nachweisen. Eine Unterscheidung zwischen kongenitaler Lungenzyste und einer sekundären, erworbenen Lungenzyste bzw. Pseudozyste (Pneumatozele), ist röntgenologisch nicht sicher möglich. Die Pseudozyste enthält im Gegensatz zur echten primären Zyste keine glatte Muskulatur und kein Bronchialknorpelgewebe (HARRIs 1977; Siegel u. MCCRACKEN 1979). Bei der solitären Lungenzyste kommt differentialdiagnostisch vor allem ein kongenitales lobäres Emphysem 

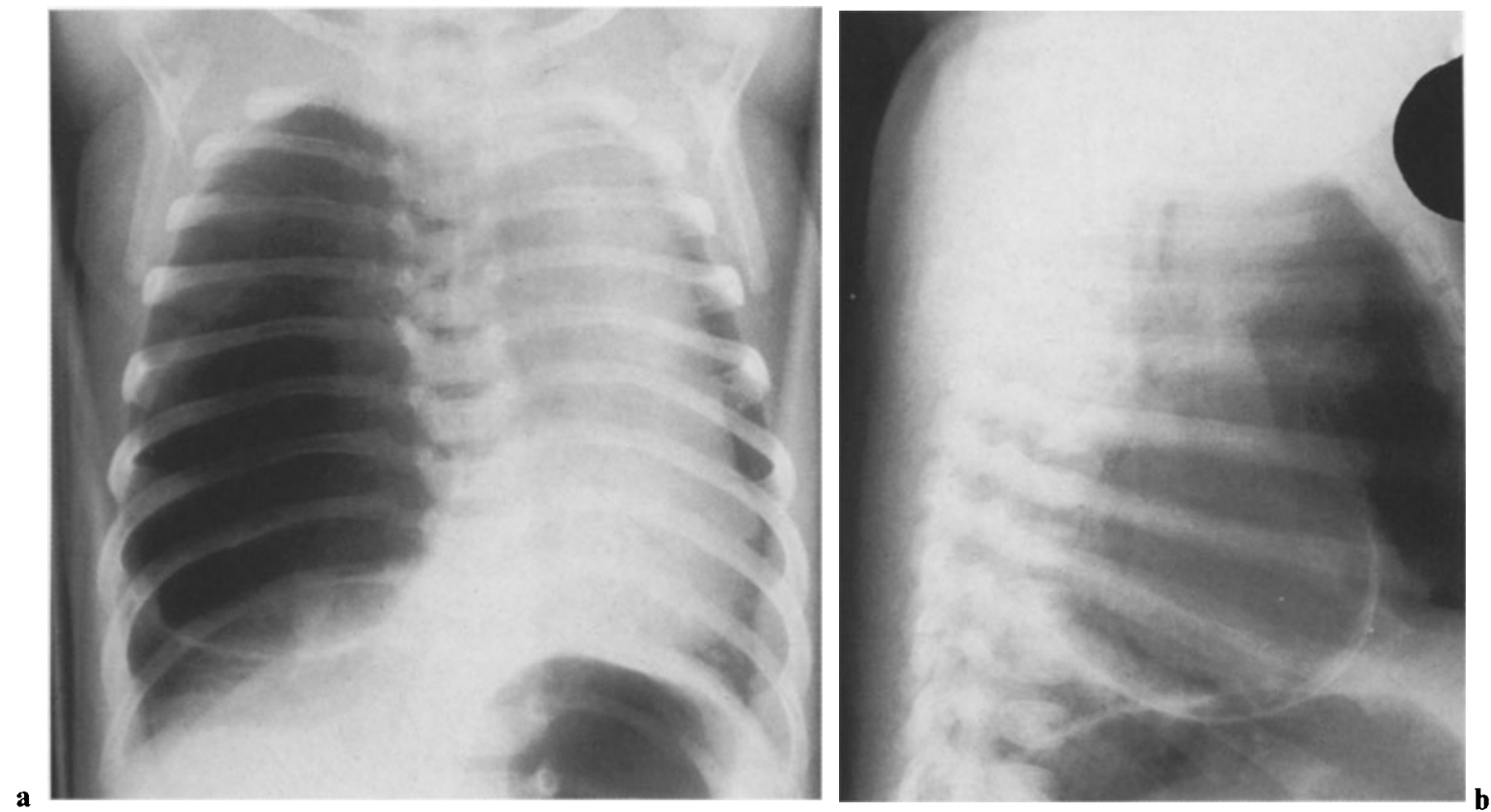

Abb. 24a, b. 4 Wochen altes Neugeborenes mit solitärer Lungenzyste im Mittellappen. Die Zyste komprimiert den rechten Unterlappen. Der rechte Lungenoberlappen ist kompensatorisch überbläht

in Betracht. Sind die Zysten multipel, ist an eine zystisch-adenomatoide Malformation zu denken.

Bei nicht sicher abgrenzbarem Zwerchfell und Nachweis zystoider Strukturveränderungen in einer Thoraxhälfte muß in der Neugeborenenperiode eine kongenitale Zwerchfellhernie ausgeschlossen werden (OPPERMANN et al. 1982, S. 94).

\section{Zystisch-adenomatoide Lungenmalformation}

Die zystisch-adenomatoide Lungenmalformation gehört zu den seltenen zystischen Fehlbildungen. Die Erstbeschreibung dieser Anomalie geht auf STOERK zurück. Er beobachtete einen im normalen Lungengewebe eingebettenen tumorösen Komplex von Zysten, die mit Respirations- und Plattenepithel ausgekleidet waren (STOERK 1897). Der zystisch-adenomatoiden Lungenmalformation liegt eine gestörte Kanalisation des Lungenmesenchyms und Kommunikation mit dem endodermalen Lungenanteil zugrunde. Daraus resultiert eine zystische Umstrukturierung mit überschießendem Wachstum (adenomatoides Wachstum) des terminalen Bronchialbaumes in dem betroffenen Lungenlappen. Die arterielle Versorgung der zystischen Areale erfolgt über die Pulmonalarterien (CH'IN u. TANG 1949; CraIGet al. 1956; Kuittken u. Reiner 1962; Madewell et al. 1975; Merenstein 1969; Wille u. Wurster 1974). Die betroffenen Lungenlappen sind in ihrem Gewicht und Volumen vergrößert. Eine Seitenprädilektion besteht nicht, auch ist keine Geschlechtsprädisposition bekannt (MERENSTEIN 1969; SANE u. Girdany 1972; WeXleR u. Dapena 1978).

Die Ätiologie dieser Fehlentwicklung ist nicht geklärt. Bei etwa $25 \%$ der bisher beschriebenen Patienten mit zystisch-adenomatoider Lungenmalformation besteht in der Anamnese ein Polyhydramnion, ca. 33\% der Patienten haben Anasarka. Die letzteren entwickeln sich 
vermutlich durch eine venöse Abflußbehinderung infolge der zystisch-tumorösen Raumforderung (Ch'in u. TANG 1949; Merenstein 1969). - Die zystisch-adenomatoide Malformation kommt mit gleicher Häufigkeit in beiden Lungen vor, die Oberlappen scheinen bevorzugt befallen (Craig et al. 1956; Merenstein 1969; Madewell et al. 1975; Sane u. Girdany 1972).

Die zystische Umstrukturierung der betroffenen Lungenabschnitte ist nicht einheitlich. STOCKER et al. (1978) unterteilen drei Typen bzw. Formen der zystisch-adenomatoiden Malformation. Die erste Form, die am häufigsten vorkommt, ist charakterisiert durch unterschiedlich große, ausgedehnte Zysten, die röntgenologisch dem kongenitalen lobären Lungenemphysem sehr ähnlich sind. Bei der zweiten Form, die bei etwa $40 \%$ aller betroffenen Patienten beobachtet wird, finden sich multiple, dünnwandige, nahezu uniforme Zysten von max. $2 \mathrm{~cm}$ Durchmesser. Bei der dritten Form präsentiert sich die zystisch-adenomatoide Malformation als eine tumoröse Masse mit multiplen winzigen Zysten, die makroskopisch als solide imponieren (STOCKER et al. 1978).

Die zystisch-adenomatoide Lungenmalformation kann bei einem entsprechenden Ausprägungsgrad bereits in der Neugeborenenperiode als schwere Atemstörung imponieren, häufiger manifestiert sie sich aber jenseits der Neugeborenenperiode. Die Resektion der von der zystisch-adenomatoiden Fehlbildung betroffenen Lungenabschnitte sollte in jedem Fall erfolgen, auch dann, wenn keine unmittelbare respiratorische Insuffizienz besteht (SCHAPIRO u. Evans 1972; WiLle u. WurSTER 1974).

Im Neugeborenenalter stellt sich diese Fehlbildung röntgenologisch meistens als einseitige expansive Weichteilmasse mit multiplen, zum Teil flüssigkeitsgefüllten und teilweise luftgefüllten zystischen Arealen unterschiedlicher Größe dar, meistens mit Tiefstand des gleichseitigen Zwerchfells und Abdrängung des Mediastinum zur Gegenseite (CraIg et al. 1956; HorCHER et al. 1979; Merenstein 1969; Sane u. Girdany 1982; Tucker et al. 1977; Wexler u. DAPENA 1978). Je älter der Patient ist, um so mehr finden sich luftgefüllte Zysten, weil diese über die Kohnschen Poren durch die angrenzenden Lungenanteile zunehmend belüftet werden (OPPERMANN et al. 1982, S. 98) (Abb. 25a, b). -

Bei thoraxwandnahen zystisch umstrukturierten Lungenarealen kann die Diagnose auch sonographisch gestellt werden. Bereits intrauterin ist der sonographische Nachweis der zystisch-adenomatoiden Lungenmalformation gelungen. Nach DiwaN et al. (1983) ist die Symptomentrias mütterliches Hydramnion, fetale Anasarka und der Nachweis eines zystischen oder soliden intrathorakalen Tumors beim Föten dringend verdächtig auf das Vorliegen einer zystisch-adenomatoiden Malformation.

In der Differenzierung zum kongenitalen lobären Emphysem hilft das Computertomogramm, wobei sich beim kongenitalen Lobäremphysem eine dünnere Wandstruktur der zystischen Veränderungen findet als bei der adenomatoiden Malformation (HARTENBERG u. BREWER 1983; SILVERMAN 1985). Die Differentialdiagnose der zystisch-adenomatoiden Lungenmalformation umfaßt Pneumatozelen (Pseudozysten), multiple Lungenabszesse, z.B. im Rahmen einer Staphylokokken-Pneumonie und eine kongenitale Zwerchfellhernie, vornehmlich eine Bochdaleksche Hernie. Bei der letzteren findet sich aber im Gegensatz zur adenomatoiden Malformation ein pathologisches Abdominalbelüftungsmuster. Weiterhin ist eine konge-

Abb. 25. a $18 \mathrm{~h}$ altes Neugeborenes mit zystisch-adenomatoider Lungenmalformation. Multiple, großzystische Areale im linken Hemithorax, massive Mediastinalabdrängung nach rechts. Abdominalbelüftung normal! (Für die freundliche Überlassung des Bildes danke ich Herrn Professor Dr. J.A. KirkPATrick, Boston) b 17 Tage altes Neugeborenes mit zystisch-adenomatoider Lungenmalformation der rechten Lunge. Im rechten Oberlappen - und deutlicher im rechten Unterlappen - mehrere pseudozystische Strukturen 


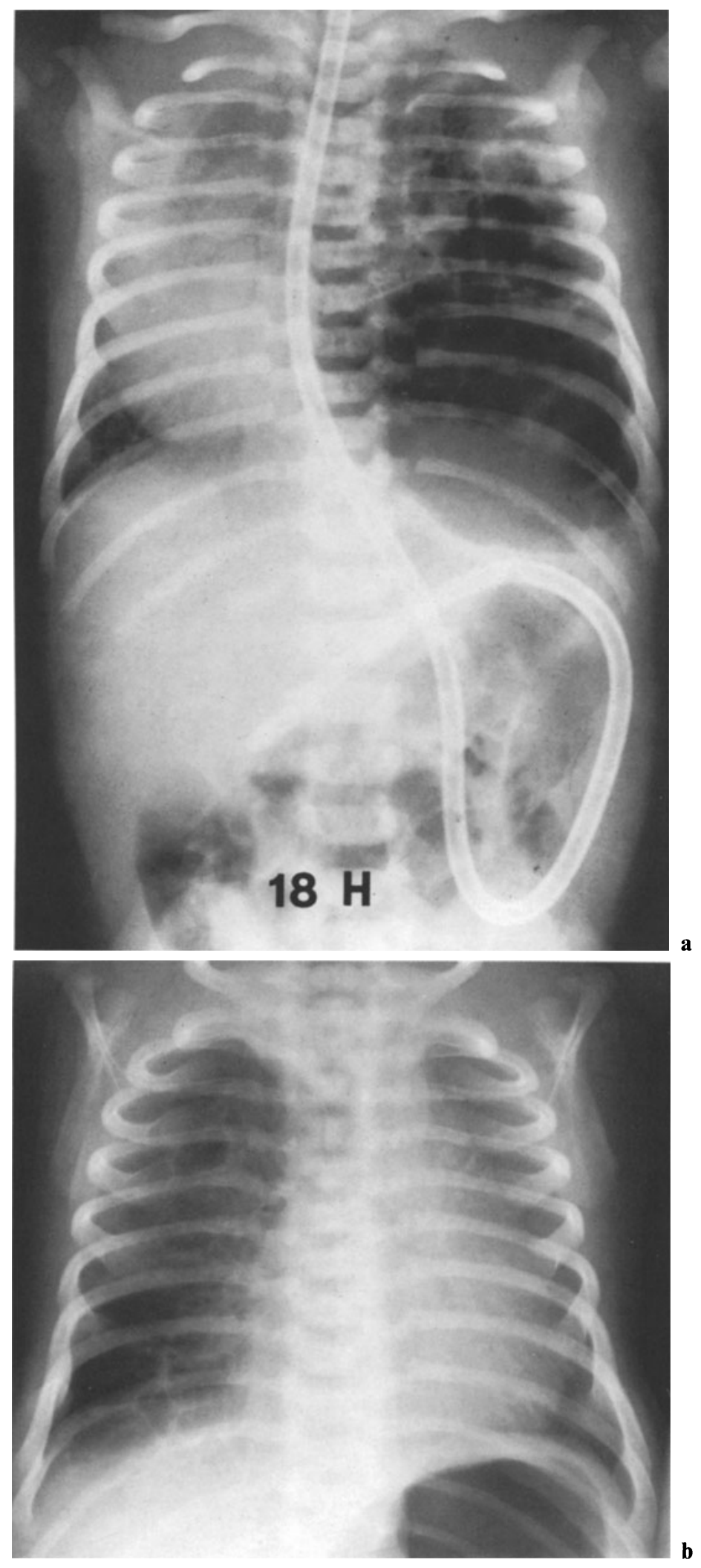


nitale Wabenlunge - eine zystische Fehlbildung des Lungenparenchyms - gegen die adenomatoide Malformation abzugrenzen (DENES et al. 1974; Doesel 1968; GroHMANn u. RiedeberGER 1966; SCHÜTZE et al. 1972). Die kongenitale Wabenlunge manifestiert sich aber nahezu nie in der Neugeborenenzeit, sie bleibt in der Regel über mehrere Jahre klinisch stumm (Brands u. Everts 1979; Heymer et al. 1981; Keutel u. Willich 1968). Bei Lokalisation der zystisch-adenomatoiden Malformation in den Unterlappen ist differentialdiagnostisch auch an die im Neugeborenenalter allerdings sehr seltene pulmonale Sequestration zu denken (KirKPATRICK 1980; OpPERMANN et al. 1982, S. 98).

\section{Kongenitale pulmonale Lymphangiektasie}

Diese Malformation des pulmonalen Lymphgefäßsystems kommt ausgesprochen selten vor (Fronstin et al. 1967; O'Hara u. Libshitz 1968).

NoOnan (1970) unterscheidet drei verschiedene Typen dieser Anomalie. Bei der ersten Form findet sich die pulmonale Lymphangiektasie im Rahmen einer generalisierten Lymphangiektasie. Diese Form macht zunächst klinisch keine pulmonale Symptomatik, vielmehr imponieren diese Patienten durch eine eiweißverlierende Enteropathie. - Die zweite Form der pulmonalen Lymphangiektasie ist gekennzeichnet durch Assoziation mit Herzfehlern, so z.B. mit einer totalen Lungenvenenfehlmündung Typ III, einem hypoplastischen Linksherzsyndrom und einer Pulmonalvenenatresie. Die dritte Form der pulmonalen Lymphangiektasie stellt eine isolierte Differenzierungsstörung der pulmonalen Lymphgefäße dar. Nach den Untersuchungen von LAURENCE (1955 und 1959) ist anzunehmen, daß es bei dieser Form der pulmonalen Lymphangiektasie in einer frühembryonalen Phase zu einem Stillstand der Entwicklung der pulmonalen Lymphgefäße kommt, so daß dilatierte und obstruierte Lymphgefäße bis in die Neonatalperiode hinein persistieren. Die isolierte pulmonale Lymphangiektasie führt in der Regel bereits perinatal oder etwas später zu einer respiratorischen Insuffizienz durch die sekundäre Beeinträchtigung des kardiovaskulären Systems (Brown u. Reidborg 1967; Ekelund et al. 1966; Felman et al. 1972; Schmidt-Redemann et al. 1980; Weigel u. Mentzel 1974).

In einer von FronstiN et al. (1967) vorgenommenen retrospektiven Analyse an 32 Patienten mit isolierter pulmonaler Lymphangiektasie ergab sich, daß 21 von diesen bereits innerhalb der ersten 48 Lebensstunden gestorben waren. Das mit dieser Fehlbildung am längsten überlebende Kind wurde 5 Jahre alt.

Die Röntgensymptomatologie der dilatierten pulmonalen Lymphgefäße ist charakterisiert durch grobnetzige Verdichtungen der Lungensepten mit Verbreiterung des Lungeninterstitium, besonders in den Perihilärabschnitten, aber weit bis in die Peripherie hineinreichend.

Da die Lymphgefäße in ihrer Verteilung parallel zu den bronchovaskulären Strukturelementen verlaufen, kann eine vermehrte Gefäßzeichnung vorgetäuscht werden. Neben den grobnetzigen Strukturveränderungen finden sich gleichzeitig noduläre Verdichtungen, die das Korrelat kollabierter Alveolen sind (Abb. 26). Diese werden von zystoiden Aufhellungszonen umgeben, welche überdehnten Bronchioli terminales und Ductuli alveolares entsprechen. Insgesamt stellen sich die Lungen als erheblich überbläht dar, was eine Differenzierung der pulmonalen Lymphangiektasie gegenüber dem idiopathischen Atemnotsyndrom erleichtert (Brown u. Reidbord 1967; Hernandes et al. 1980; Shannon et al. 1974; Theros 1967). Die Kombination einer kongenitalen pulmonalen Lymphangiektasie mit einem Chylothorax ist extrem selten (LANNING et al. 1978).

Differentialdiagnostisch sind vor allem ein Atemnotsyndrom Stadium II, eine totale Lungenvenenfehlmündung Typ III und eine bronchopulmonale Dysplasie im Stadium III 
in Erwägung zu ziehen, darüberhinaus auch ein Mikity-Wilson-Syndrom. Die letzten beiden Erkrankungen lassen sich durch anamnestische Daten ausschließen.

Schwierig kann auch die Abgrenzung gegen eine perinatale interstitielle Pneumonie sein. Schließlich kann eine diffuse pulmonale Angiomatose das Bild einer pulmonalen Lymphangiektasie imitieren (Holden u. AleXander 1970).

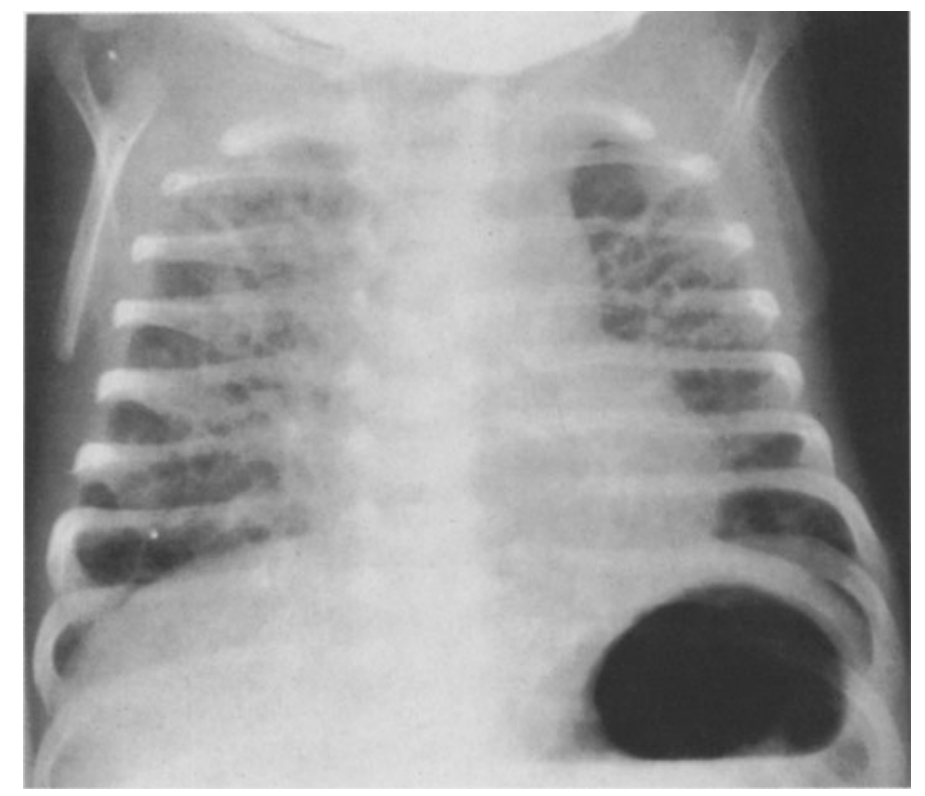

Abb. 26. 22 Tage altes Neugeborenes mit progredienter respiratorischer Insuffizienz bei kongenitaler pulmonaler Lymphangiektasie. Grobretikuläre, partiell noduläre, diffuse Zeichnungsvermehrung in beiden Lungen. (Für die freundliche Überlassung des Bildes danke ich Herrn Professor Dr. W. SchUSTER, UniversitätsKinderklinik Gießen)

\section{E. Zwerchfellanomalien}

\section{Kongenitale Zwerchfellhernien}

Kongenitale Zwerchfellhernien sind Folgezustände einer gestörten Zwerchfellentwicklung.

Nach der Lokalisation der Hernien unterscheidet man die am häufigsten vorkommende postero-laterale Form (Bochdaleksche Hernie) von der parasternalen (Morgagnische Hernie) und retrosternalen Form (Larreysche Hernie). Die Bochdaleksche Hernie, die durch das Trigonum lumbocostale in den Thoraxraum eventeriert, tritt vornehmlich linksseitig auf (Gross 1953; Hüner u. Mahmoudi 1970; Irle et al. 1969; Konrad u. Fahmy 1959; Kozlowski u. Glasson 1980; Pietsch u. Ungeheuer 1960; Wiseman u. McPherson 1977). Dagegen sind die Morgagnische Hernie (COMER u. ClagetT 1966; Korobkin et al. 1973; Thomas u. Clitherow 1977) und die Larreysche Hernie (Davies et al. 1977; Grundner 1974) überwiegend rechts lokalisiert. - In Einzelfällen können die Zwerchfellhernien auch beidseitig auftreten (AvNET 1962; CONDE et al. 1979; LEVY et al. 1969; RoBINSON et al. 1980). Als Sonderform einer kongenitalen Zwerchfellhernie, die sich im Neugeborenenalter manifestiert, ist die sog. Spätform bzw. verzögert auftretende Form einer Zwerchfellhernie (late- 
onset-Hernie) bekannt (FaurĖ et al. 1971; Glasson et al. 1975; KenNy 1977; KirChNer et al. 1975; SIEGEL et al. 1981; Young 1978).

In der Neugeborenenperiode haben vornehmlich die Bochdaleksche Hernie und die verzögert auftretende Form einer Bochdalekschen Hernie Bedeutung, während die Morgagnische und Larreysche Hernie in der Regel erst im späteren Säuglings- oder Kleinkindesalter meistens als Zufallsbefund entdeckt werden, da sie über lange Zeit symptomlos bleiben können.

Pathogenetisch liegt der Entwicklung einer kongenitalen Bochdalekschen Zwerchfellhernie ein fehlerhafter Verschluß der Foramina pleuroperitonealea und eine mangelhafte muskuläre Durchsetzung des betroffenen Zwerchfellanteils zugrunde (ENGELManN 1975; Gross 1953; IRLE et al. 1969; ReED u. LANG 1969; TöNDURY 1967).

Die Bochdaleksche Hernie führt in der Regel unmittelbar post partum zu einer lebensbedrohlichen respiratorischen Insuffizienz. Der Ausprägungsgrad der die Bochdaleksche Hernie oft begleitenden Lungenhypoplasie erlaubt einen Rückschluß auf den intrauterinen Zeitpunkt der Herniation. Tritt die Hernienbildung zum Zeitpunkt der Bronchialaufzweigung auf, d.h. um die 10.-14. Gestationswoche, entwickelt sich sowohl auf der Hernienseite eine ausgeprägte Lungenhypoplasie wie auch auf der Gegenseite, bedingt durch Mediastinalverdrängung mit Interferenz des Lungenwachstums. Entwickelt sich dagegen die Herniation nach Abschluß der Ausbildung der Bronchien und terminalen Luftwege, ist der Hypoplasiegrad der Lungen wesentlich geringer (Berdon et al. 1968; Wiseman u. MCPHERSON 1977).

OHI et al. (1976) konnten tierexperimentell den wachstumshemmenden Effekt auf das Alveolarwachstum durch langdauernde Lungenkompression nachweisen. Die der Zwerchfellhernie assoziierte Lungenhypoplasie kann darüberhinaus dadurch kompliziert sein, daß der fetale Kreislauf persistiert, sich eine pulmonale Hypertonie und nachfolgend ein RechtsLinks-Shunt entwickeln (BERDON et al. 1968; Haller et al. 1976; Hislop u. Reid 1976; LEVY et al. 1977; NAEYE et al. 1976). Eine weitere Komplikation der Lungenhypoplasie besteht darin, daß hypoplastische Lungen unter Beatmung sehr leicht zur Ruptur und damit zur Entwicklung extraalveolärer Luftansammlungen neigen. Nach FliEgel u. KaufmanN (1972) ist die Prognose besonders dann als nahezu infaust anzusehen, wenn sich unter Beatmung ein Pneumothorax auf der Gegenseite der Hernie entwickelt.

Weitere den Zwerchfellhernien assoziierte Fehlbildungen sind kardiovaskuläre Anomalien (Brundelet u. SuCKSDORFF 1964; GreenwOOD et al. 1976), zystische Fehlbildungen (CAmpBell u. RAFFENSBERGer 1972; EKKelKamp u. Vos 1980), eine pulmonale Sequestration (WaLTHER 1975), Skelettanomalien (MCCREDI et al. 1978), Spaltbildungen im Bereich des Thorax und der vorderen Bauchwand mit gleichzeitigen Skelettfehlbildungen (DAvies et al. 1977; TOYama 1972) sowie eine Schilddrüsenaplasie (GRUNDNER 1974).

Der Entstehungsmechanismus einer verzögert auftretenden kongenitalen Bochdalekschen Hernie ist nicht geklärt. Bei diesen Patienten bestehen im Thoraxbild zunächst normal abgrenzbare Zwerchfellschenkel und erst nach einigen Lebenstagen läßt sich eine Herniation nachweisen. Man vermutet, daß bei der Hernienentwicklung auf der rechten Seite die Leber und bei Hernierung auf der linken Seite entsprechend die Milz zunächst eine Verlagerung von Magen-Darmanteilen in den Thorakalraum verhindern, mit Zunahme des intraabdominalen Drucks dann aber doch eine Herniation einsetzt (FAuRÉ et al. 1971; GLASSON et al. 1975; KenNy 1977; KirCHNER et al. 1975; SiEgel et al. 1981; Young 1978).

Interessanterweise wird diese sich verzögert entwickelnde Hernienform auch im Zusammenhang mit einer perinatalen B-Streptokokkenpneumonie beobachtet. Eine Erklärung für dieses Phänomen gibt es nicht (MCCARTEN et al. 1981; NiELSEN et al. 1980).

Röntgenologisch stellt sich die Bochdaleksche Hernie bei linksseitiger Lokalisation unmittelbar post partum als weichteildichte Verschattung des linken Hemithorax bei gleichzeitig fehlender Abgrenzbarkeit des Zwerchfellschenkels dar. Das Abdomen dieser Neugeborenen ist auffallend luftarm, oft ist nur der Magen als wenig lufthaltiges, in den Thorakalraum 
hinein verlagertes Gebilde erkennbar (Abb. 27a). Manchmal stellt sich in dem luftarmen Abdomen eine stehende, geblähte Sigmaschlinge dar. Dieselbe entsteht durch Luftübertritt aus den intrapleural gelegenen komprimierten Darmanteilen in das Sigma. Durch gleichzeitigen, streßbedingten Sphinkterkrampf wird ein Entweichen der Luft per anum verhindert (Nicolesches Zeichen). Mit physiologischerweise fortschreitender Belüftung der in den Thoraxraum eventerierten Darmanteile stellen sich diese dann als multiple, große, zystoide Areale dar (Abb. 27b).
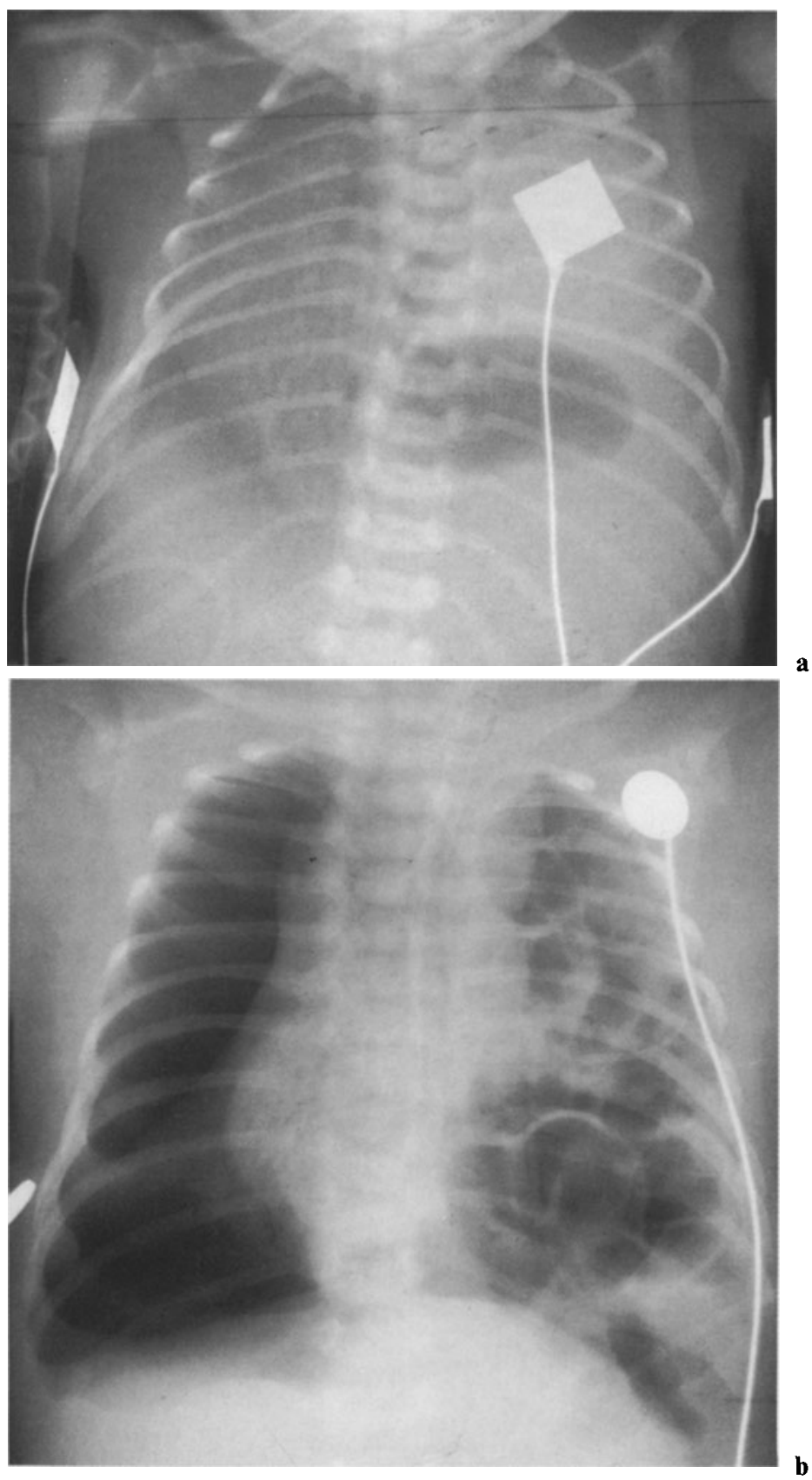

Abb. 27. a Bochdaleksche Hernie links. Fehlende Abgrenzbarkeit des linken Zwerchfellschenkels. Totale Verschattung der linken Lunge, Abdrängung des Mediastinums nach rechts. Luftleeres Abdomen. b Ausgedehnte Bochdaleksche Hernie links. Die hernierten Darmschlingen nehmen den gesamten Hemithorax links ein. Ausgedehnter, rechtsseitiger Pneumothorax, wobei die rechte kollabierte Lunge deutlich sichtbar wird 
Bei rechtsseitigem Auftreten der Bochdalekschen Hernie läßt sich oft zusätzlich die fehlende Abgrenzbarkeit des Leberschattens an typischer Stelle nachweisen (,Absent liver sign“) (Riggs u. Herschmann 1970). Die Verlagerung der Leber in den Thoraxraum ist sehr leicht sonographisch zu diagnostizieren, außerdem durch eine umbilikale Phlebographie und indirekt auch eine Fehlposition des Nabelvenenkatheters (Sagel u. Ablow 1970; Taber et al. 1973).

Die verzögert auftretende Form der Bochdalekschen Hernie stellt sich meistens in Form einer plötzlich auftretenden einseitigen thorakalen Verschattung dar - bei unmittelbar post partum nachweislich noch normalem Thoraxbefund - (Abb. 28a, b).

Die Morgagnische und Larreysche Hernie sind anterior und retro-, bzw. parasternal gelegen. Sie stellen sich im sagittalen Thoraxbild röntgenologisch als weichteildichte Verschattung in Projektion auf den Herzzwerchfellwinkel dar. Im seitlichen Strahlengang ist der vordere Anteil des betroffenen Zwerchfellschenkels nicht abgrenzbar, die Hernie selbst gibt sich als retro- bzw. parasternale Verdichtungsfigur zu erkennen.

Bei nur sehr kleiner Morgagnischer Hernie kann diese röntgenologisch in Form einer „hirtenstabähnlichen“ Aufhellungsfigur imponieren, welche durch thorakal prolabiertes properitoneales Fettgewebe verursacht wird (LANUZA 1971).

Bei bilateraler Lokalisation der antero-medialen Hernien können Herz und der sie überlagernde Thymus soweit nach kranial abgedrängt werden, daß eine Kardiomegalie, manchmal auch eine „Schneemannsilhouette“ des Herz und Gefäßbandes vorgetäuscht werden (RoBINson et al. 1980). Im Extremfall reicht die Herniation bis in den Perikardialsack (GwINN u. LeE 1973; Wallace 1977; Wilson et al. 1947).

Die bei der kongenitalen Zwerchfellhernie zu berücksichtigenden Differentialdiagnosen richten sich nach der Hernienlokalisation. Gegen die Bochdaleksche Hernie sind vor allem ein flüssigkeitsgefülltes kongenitales lobäres Lungenemphysem, ein kongenitaler Hydro- und Chylothorax sowie ein Hämatothorax abzugrenzen. Die erweiterte Differentialdiagnose umfaßt die zystisch-adenomatoide Lungenmalformation, das Pleuraempyem und einen intrathorakalen Tumor sowie die äußerst seltene Zwerchfellaplasie. -

Die retro- und parasternalen Hernien sind abzugrenzen gegen tumoröse Prozesse im vorderen unteren Mediastinum, so z.B. die sehr seltene Perikardzölomzyste.

\section{Akzessorisches Zwerchfell}

Das akzessorische Zwerchfell ist eine ausgesprochen seltene Anomalie, die vermutlich keine isolierte Fehlbildung darstellt, sondern eine Form der Hypogenese der rechten Lunge (FELSON 1972). Unterstützt wird diese Annahme dadurch, daß das akzessorische Zwerchfell sehr oft assoziiert ist mit einer Hypoplasie des rechten Ober- und Mittellappens, einer anormalen systemischen Blutversorgung sowie einer fehlerhaften venösen Lungendrainage (FELSON 1972; GWINN et al. 1974; IKEDA et al. 1972; WILLE et al. 1975).

Auch die Kombination eines akzessorischen Zwerchfells mit einem Vorhofdefekt wurde beschrieben (TOMiSAWA et al. 1974). KanANOGLU u. TUNCBILEK berichten über einen Fall mit einem linksseitig lokalisierten akzessorischen Zwerchfell.

Das akzessorische Zwerchfell entspricht einer muskulärbindegewebigen Membran, welche ventral vom normalen Zwerchfellschenkel entspringt, im dorsalen Anteil als Duplikatur nach postero-lateral verläuft und in Höhe der 5. bis 7. Rippe ansetzt (Hashida u. Sherman 1961; Kananoglu u. Tuncbilek 1978; Nigogosyan u. Ozarda 1961; Wille et al. 1975). 

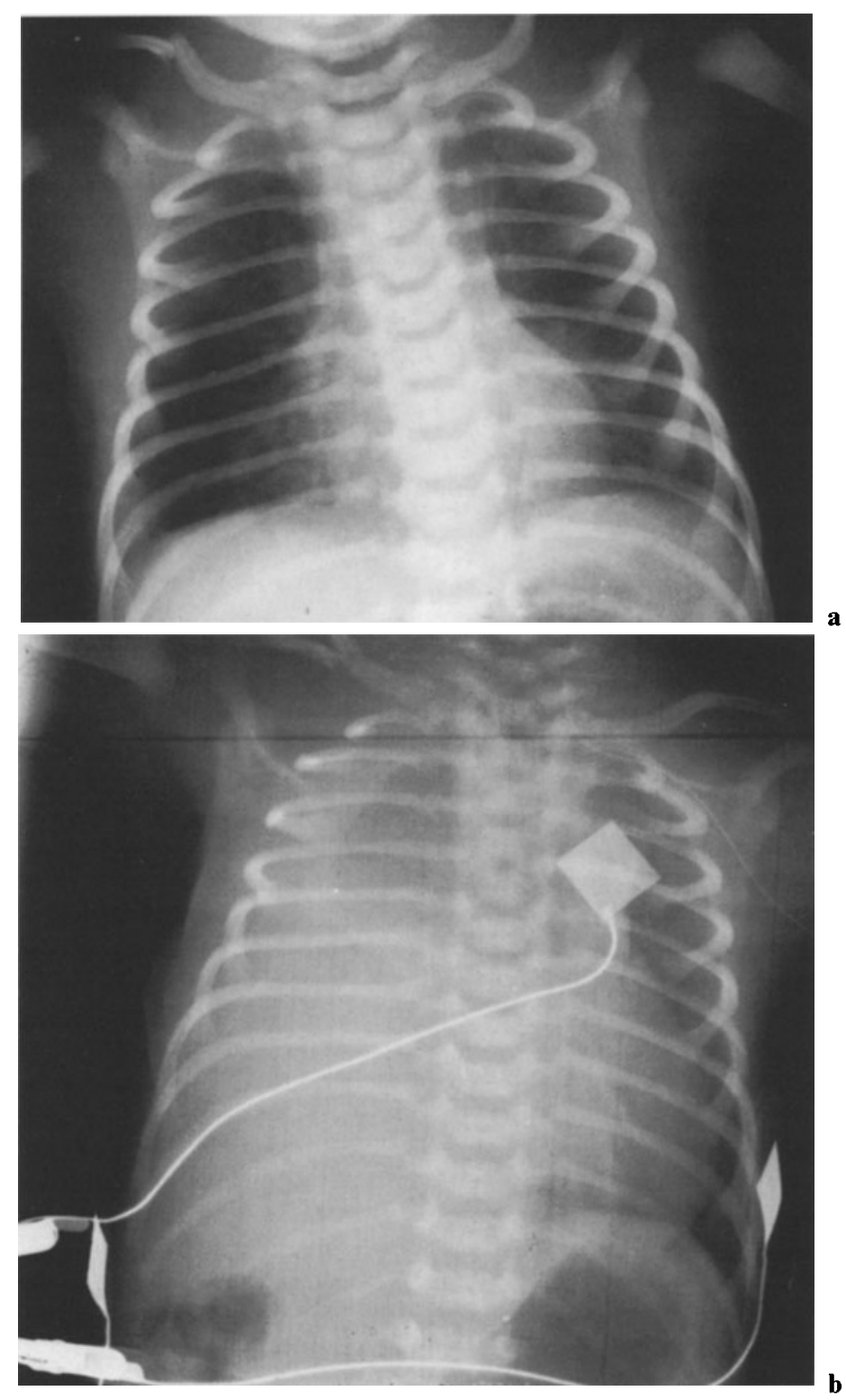

Abb. 28a, b. Neugeborenes mit verzögert auftretender Zwerchfellhernie (Bochdaleksche Hernie) rechts. a Normaler Thoraxbefund am 1. Lebenstag. Rechtsseitige Klavikulafraktur. b Verschattung des rechten Unterund Mittelfeldes, Zwerchfellschenkel rechts nicht mehr abgrenzbar. - „Absent-liver-sign“

Die Entstehung des akzessorischen Zwerchfells wird auf einen unvollständigen Deszensus des Septum transversum zurückgeführt (WILLE et al. 1975).

Im Thoraxbild stellt sich das akzessorische Zwerchfell nicht direkt dar. Auf diese Anomalie hinweisende Symptome im sagittalen Thoraxbild sind ein verkleinerter Hemithorax, eine Transparenzminderung desselben, vornehmlich medial, eine Unschärfe von Herz- und Mediastinalbegrenzung und eine Verlagerung des Herz und Gefäßbandes zum akzessorischen Zwerchfell hin. In der seitlichen Projektion grenzt sich retrosternal und parallel zu diesem verlaufend eine breite, bandförmige Verdichtung ab, die nach dorsal hin konkavbogig scharf abgegrenzt ist. Diese Verdichtung entspricht nicht dem akzessorischen Zwerchfell, sie ist 
vielmehr das Korrelat extrapleuralen Fettgewebes, das den Raum der hypoplastischen Lungenanteile einnimmt (CREMIN u. Bass 1975; Davis u. Allen 1968; Felson 1970) (Abb. 29a, b). Differentialdiagnostisch ist in erster Linie an eine Lungenhypoplasie sowie an eine partielle Oberlappen- und Mittellappenatelektase zu denken. Weniger wahrscheinlich im Neugeborenenalter ist eine pulmonale Sequestration (OPPERMANN et al. 1982, S. 127).

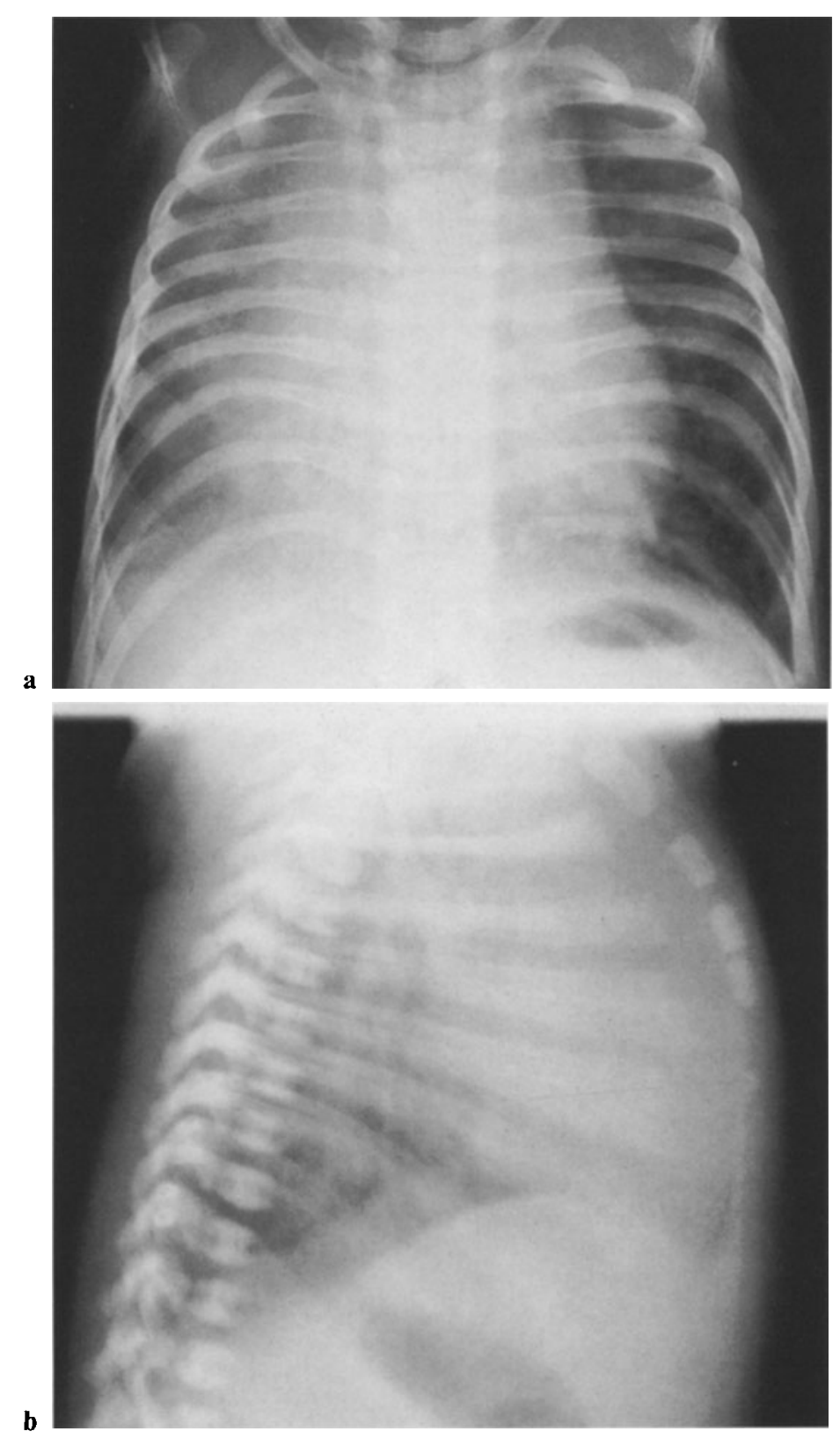

Abb. 29a, b. 4 Monate alter männlicher Säugling mit akzessorischem Zwerchfell rechts. a Subtotale schleierige Eintrübung des rechten Hemithorax. b Retrosternal bandförmige weichteildichte Verschattung 


\section{Zwerchfellagenesie}

Die schwerste Form einer fetalen Entwicklungsstörung des Zwerchfells stellt die Agenesie dar. Diese kann uni- und bilateral auftreten. Die Ätiologie dieser extrem seltenen Anomalie ist nicht bekannt. Sie wird im Rahmen eines familiären rezessiv-autosomalen Erbleiden, aber meistens sporadisch beobachtet (PASSARGE et al. 1968). FeINGOLD berichtete 1971 über einen Patienten mit einer kongenitalen Rötelnerkrankung und einem membranösen Zwerchfell ohne muskuläre Elemente (FEINGOLD 1971). Die Röntgensymptome der Zwerchfellagenesie entsprechen denen einer kongenital uni-, bzw. bilateralen Zwerchfellhernie.

\section{Literatur}

Aaron BL, Doohen DJ (1970) Spontaneous hemothorax in the newborn. Ann Thorac Surg 9:258

Ablow RC (1971) Radiologic diagnosis of the newborn chest. In: Current problems in pediatrics 1 . Year Books Medical Publ, Chicago, p 12

Ablow RC, Orzalesi MM (1971) Localized roentgenographie pattern of hyaline membrane disease: evidence that the upper lobes of human lung mature earlier than the lower lobes. AJR 112:23

Ablow RC, Driscoll SG, Effmann EL, Gross I, Jolles CJ, Warshaw JB (1976) Comparison of early-onset group B streptococcal neonatal infection and the respiratory distress syndrome of the newborn. NEJM 294:65

Ablow RC, Gross I, Effmann EL, Uauy R, Driscoll $S$ (1977) The radiographic features of early onset group B streptococcal neonatal sepsis. Radiology 124:777

Adamson TM, Boyd RDH, Normand ICS, Reynolds EOR, Shaw JL (1969) Hemorrhagic pulmonary edema in the newborn ("massive pulmonary hemorrhage"). Lancet $1: 494$

Aherne W, Dawkins MJR (1964) The removal of fluid from the pulmonary airways after birth in the rabbit, and the effect on this of prematurity and pre-natal hypoxia. Biol Neonate 7:214

Ahvenainen EK, Call JD (1952) Pulmonary hemorrhage in infants. Am J Pathol 28:1

Anderson RW, Strickland MB (1971) Pulmonary complications of oxygen therapy in the neonate. Arch Pathol 91:506

Areechon W, Reid L (1963) Hypoplasia of lung with congenital diaphragmatic hernia. $\mathrm{Br}$ Med J $1: 230$

Arth C, Schmidt B von, Grossman M, Schachter J (1978) Chlamydial pneumonitis. J Pediatr 93:447

Avery ME (1968) The lung and its disorders in the newborn infants. Saunders, Philadelphia, p 190

Avery ME, Clements JA (1963) Pulmonary surfactant and atelectasis. Physiol Physicians 1:1

Avery ME, Fletcher BD (1974) The lung and its disorders in the newborn infant, 3rd edn. Saunders, Philadelphia London Toronto, p 125, 236

Avery ME, Fletcher BA (1981) The lung and its dis- orders in the newborn infants. Saunders, Philadelphia, p 164

Avery ME, Gatewood OB, Brumley G (1966) Transient tachypnea of the newborn; possible delayed resorption of fluid at birth. Am Dis Child $111: 380$

Avery ME, Fletcher BD, Williams RGC (1981) The lung and its disorders in the newborn infant, 4 th edn. Saunders, Philadelphia London Toronto, p 171, 197, 203, 271, 284, 312

Avnet NL (1962) Roentgenologic features of congenital bilateral anterior diaphragmatic eventration. AJR 88:743

Bale JF, Walkins M (1978) Fulminant neonatal haemophilus influenzae pneumonia and sepsis. J Pediatr 92:233

Bancalari E, Abdenour GE, Feller R, Gannon J (1979) Bronchopulmonary dysplasia: Clinical presentation. J Pediatr 95:819

Banerjee CK, Girling DJ, Wigglesworth JS (1972) Pulmonary fibroplasia in newborn babies treated with oxygen and artifical ventilation. Arch Dis Child 47:509

Barnes ND, Glover WJ, Hull D, Milner AD (1969) Effects of prolonged positive pressure ventilation in infancy. Lancet 2:1096

Barth K, Schnauffer L, Kaufmann HJ (1976) Case report: giant idiopathic thymomegaly. Pediatr Radiol 4:117

Baum GL, Racz I, Bubis JJ, Molho M, Shapiro BL (1966) Cystic disease of the lung. Am J Med $40: 578$

Bauman WA, Nadelhaft J (1958) Chest radiography of newborns. A planned study of 104 patients including clinico-pathologic correlation of the respiratory distress syndrome. Pediatrics 21:813

Baumgärtner W, Calker H van, Eisenberg W (1980) Konnatale Tuberkulose. Monatsschr Kinderheilkd 128:563

Bawkin H, Bawkin RM (1935) Body build in infants: VI. Growth of the cardiac silhouette and the thoraco-abdominal cavity. Am J Dis Child 49:861

Bean WJ, Jordan RB, Gentry H, Nice CM (1969) 
Fissure lines in the pediatric roentgenogram. AJR 106:109

Beau A, Prévot J, Azambourg JP (1969) Acute respiratory distress and bronchogenic cyst in the newborn infant. Ann Chir Infant 10:495

Beem M, Saxon E (1977) Respiratory tract colonization and a distinctive pneumonia syndrome in infants infected with chlamydia trachomatis. NEJM 296:306

Benirschke KK (1960) Routes and types of infection in the fetus and newborn. Am J Dis Child 99:714

Berdon WE, Baker DH (1966) Radiology of the newborn. Pediatr Clin North Am 13:1017

Berdon WE, Baker DH, James LST (1965) The ductus bump (a transient physiologic mass in chest roentgenograms of newborn infants). AJR 95: 91

Berdon WE, Baker DH, Amoury R (1968) The role of pulmonary hypoplasia in the prognosis of newborn infants with diaphragmatic hernia and eventration. AJR 103:413

Berg TJ, Pagtakhan RD, Reed MH, Langston C, Chernick V (1975) Bronchopulmonary dysplasia and lung rupture in hyaline membrane disease: Influence of continuous distending pressure. Pediatrics $55: 51$

Berger G (1968) Zur Differentialdiagnose des Atemnotsyndroms im Neugeborenenalter unter besonderer Berücksichtigung des Hydrothorax. Monatsschr Kinderheilkd 116:507

Binstadt DH, Williams HJ, Jarvis CW (1977) Bronchial stenosis and segmental emphysema in a neonate. J Can Assoc Radiol 28:297

Blystad W, Landing B, Smith C (1951) Pulmonary hyaline membranes in newborn infants. Pediatrics $8: 5$

Boisset GF (1972) Subpleural emphysema complicating staphylococcal and other pneumonias. $\mathbf{J}$ Pediatr $81: 259$

Bomsel F, Couchard M, Henry E (1951) Respiratory distress in the newborn: Radiological approach, differential diagnosis. J Belg Radiol 63:89

Bomsel F, Couchard M, Larroche JC, Magder L (1975) Diagnostic radiologique de l'hemorrhagie pulmonaire massive du nouveau-né. Ann Radiol (Paris) $18: 419$

Bonikos DS, Bensch KG, Northway WM, Edwards DK (1976) Bronchopulmonary dysplasia: The pulmonary pathologic sequel of necrotizing bronchiolitis and pulmonary fibrosis. Hum Pathol $7: 643$

Boothby CB, De Sa DJ (1973) Massive pulmonary hemorrhage in the newborn: changing pattern. Arch Dis Child 48:21

Boyden EA (1955) Developmental anomalies of the lungs. Am J Surg 89:79

Boyden EA (1965) The terminal air sacs and their blood supply in a 37 - day infant lung. Am J Anat 116:413

Brands W, Evertz K (1979) Röntgenologische As- pekte der Zystenlunge beim Neugeborenen. RÖFO 130:153

Brown MD, Reidborg HE (1967) Congenital lymphangiectasis. Am J Dis Child 114:654

Brown ER, Stark A, Sosenko I, Lawson EE, Avery ME (1978) Bronchopulmonary dysplasia: Possible relationship to pulmonary edema. J Pediatr 92:982

Brünner S, Poulsen PT, Vesterdal J (1960) Cysts of the lung in infants and children. Acta Paediatr 49:39

Brundelet PJ, Sucksdorff J (1964) The cardiovascular component of congenital diaphragmatic hernia. Acta Paediatr 53:221

Burnard ED, Grattan-Smith P, Dicton-Warlow CG, Graunang A (1965) Pulmonary insufficiency in prematurity. Aust Paediatr J 7:12

Burney B, Smith WL, Franken EA, Klatte EC (1978) Chest film diagnosis of patent ductus arteriosus in infants with hyaline membrane disease. AJR $130: 1149$

Buse PJ de, Morris G (1972) Bilateral pulmonary agenesia, oesophageal atresia and the first archsyndrome. Thorax 28:256

Caffey J (1953) On the natural regression of pulmonary cysts during early infancy. Pediatrics 11 : 48

Caffey J (1978) Pediatric x-Ray diagnosis 7 th edn. Year Book Medical Publ, Chicago, p 511

Campbell DP, Raffensperger JG (1972) Congenital cystic disease of the lung masquerading as diaphragmatic hernia. J Thorac Cardiovasc Surg 64:592

Campbell PE (1969) Congenital lobar emphysema. Aust Paediatr J 5:226

Capitanio MA, Kirkpatrick JA Jr (1966) Pneumocystis carinii pneumonia. AJR 97:174

Cheeseman SH, Hirsch MS, Keller EW, Keim DE (1977) Fatal neonatal pneumonia caused by echovirus type 9. Am Dis Child 131:1169

Ch'in KY, Tang MY (1949) Congenital adenomatoid malformation of one lobe of lung with general anasarca. Arch Pathol 48:221

Clark JM, Lambertson CJ (1971) Pulmonary oxygen toxicity. Pharmacol Rev 23:37

Cleveland RH, Todres ID (1981) Patterns of evolution of X-ray changes in respiratory distress syndrome. Helv Paediatr Acta [Suppl] 34:43

Coceani F, Olley PM, Lock JE (1980) Prostaglandins, ductus arteriosus, pulmonary circulation: current concepts and clinical potential. Eur J Clin Pharmacol 18:75

Cochran ST, Gyepes MT, Smith LE (1977) Obstructions of the airways by the heart and pulmonary vessels in infants. Pediatr Radiol 6:81

Cole VA, Normand ICS, Reynolds EOR, Rivers RPA (1973) Pathogenesis of hemorrhagic pulmonary edema and massive pulmonary hemorrhage in the newborn. Pediatrics 51:175

Comer TP, Clagett OT (1966) Surgical treatment of 
hernia of the foramen of Morgagni. J Thorac Cardiovasc Surg 12:149

Conde J, Mendoza E, Rafel E, Parra DM (1979) Congenital bilateral posterolateral and anterior diaphragmatic defects. J Pediatr Surg 14:185

Cooney DR, Menke JA, Allen JE (1977) Acquired lobar emphysema, a complication of respiratory distress in premature infants. J Pediatr Surg 12:897

Corbett DP, Washington JE (1971) Respiratory obstruction in the newborn and excess pulmonary fluid. AJR 112:18

Couchard M, Polge J, Bomsel F (1974) Hyaline membrane disease; diagnosis, radiological observation, treatment, and complications. A radiological study of 589 cases. Ann Radiol 17:669

Craig JM, Kirkpatrick JA, Neuhauser EBD (1956) Congenital cystic adenomatoid malformation of the lung in infants. AJR 76:516

Cramblett HG, Haynes RE, Azimi PH, Hilty MD, Wilder MH (1973) Nosocomial infection with echovirus type II in handicapped and premature infants. Pediatrics $51: 603$

Cremin BJ, Bass EM (1975) Retrosternal density: a sign of pulmonary hypoplasia. Pediatr Radiol $3: 145$

Cremin BJ, Movsowitz H (1971) Lobar emphysema in infants. Br J Radiol 44:692

Cronan JJ, Ablow RC (1981) Radiological case of the month. Am J Dis Child 135:369

Culiner MM (1968) Intralobar bronchial cystic disease: The sequestration complex and cystic bronchiectasis. Dis Chest 53:462

Daves ML, Walsh JA (1970) Minihemithorax. AJR 109:528

Davies GM, Reid L (1970) Growth of the alveoli und pulmonary arteries in childhood. Thorax 25:669

Davies MRQ, Rode H, Cywes S (1977) Thoracoschisis associated with an ipsilateral distal phocomelia and an anterolateral diaphragmatic hernia. J Pediatr Surg 12:755

Davis WS, Allen RP (1968) Accessory diaphragm. Radiol Clin North Am 5:253

Dénes J, Lukacs VF, Léb J, Cholnoky P (1974) Angeborene polyzystische Lunge, ein lobäres Emphysem vortäuschend. Z Kinderchir 14:333

Desmond MM, More J, Lindley JE, Brown CA (1957) Meconium staining of the amniotic fluid. A marker of fetal hypoxia. Obstet Gynecol 9:91

Dietzsch HJ, Berger G (1970) Röntgenschaukasten: Zur Differentialdiagnose des Röntgensymptoms „Weißer Thorax" beim Neugeborenen. Kinderärztl Prax 38:137

Dippel WF, Doty DB, Ehrenhaft JL (1973) Tension hemothorax due to patent ductus arteriosus. $\mathrm{N}$ E J M 288:353

Diwan RV, Brennan JN, Philipson EH (1983) Ultrasonic prenatal diagnosis of type III congenital cystic adenomatoid malformation of lung. J Clin Ultrasound $11: 218$
Dixon BK, Houston CS (1978) Radiographic exhibit; fatal neonatal pulmonary candidiasis. Radiology $129: 132$

Doesel H (1968) Bronchographische Befunde bei angeborenen Fehlbildungen des Bronchialsystems und der Lunge im Kindesalter. RÖFO 109: 759

Donald I, Steiner RE (1953) Radiography in the diagnosis of hyaline membrane disease. Lancet 2 : 846

Doppman JL, Geelhoed GW, DeVita VT (1975) Atypical radiographic features in pneumocystis carinii pneumonia. Radiology 114:39

Dunken J (1927) Mediastinale Pneumatozele nach Pneumonie bei einem Säugling. Z Kinderheilkd 43:339

Easa D (1978) Coagulation abnormalities associated with localized hemorrhage in the neonate. $J$ Pediatr 92:989

Ebel KLD (1980) Zur Röntgenuntersuchung des Thymus im Kindesalter. Radiologe 20:379

Ebel KD, Fendel H (1967) The roentgen changes of pneumocystis pneumonia and their anatomical basis. Progr Pediatr Radiol 1:177

Edwards DK (1979) Radiographic aspects of bronchopulmonary dysplasia. J Pediatr 95:823

Edwards DK, Dyer WM, Northway WH Jr (1977) Twelve years experience with bronchopulmonary dysplasia. Pediatrics 59:839

Edwards DK, Colby TV, Northway WH (1979) Radiographic-pathologic correlation in bronchopulmonary dysplasia. J Pediatr 95:834

Edwards DK, Higgins ChB, Gilpin EA (1981) The cardiothoracic ratio in newborn infants. AJR 136:907

Ellis K, Nadelhaft J (1957) Roentgenographic findings in hyaline membrane disease infants weighting 2000 grams and over. AJR 78:444

Ellison RC, Peckham GI, Lang P, Talner NS, Lerer TJ, Lin L, Dooley NJ, Nadas AS (1983) Evaluation of the preterm infant for patient ductus arteriosus. Pediatrics $71: 364$

Ehrenhart JL, Taber RE (1953) Progressive infantile emphysema in infancy; surgical emergency. $\mathrm{J}$ Thorac Surg 26:1

Ehrenkranz RA, Ablow RC, Warshaw JB (1978) The complication of oxygen use in the newborn infant. Clin Perinatol 5:437

Ekelund H, Palmstierna S, Östberg G (1966) Congenital pulmonary lymphangiectasis. Acta Paediatr Scand $55: 121$

Ekkelkamp S, Vos A (1980) A newborn with congenital diaphragmatic hernia and congenital cystic adenomatoid malformation of the lung. $\mathrm{Z} \mathrm{Kin-}$ derchir $31: 65$

Emery JL, Mithal A (1960) The number of alveoli in the terminal respiratory unit of man during late intrauterine life and childhood. Arch Dis Child 35: 544

Engelmann C (1975) Zu den Fehlbildungen des 
Zwerchfells und der Lunge. Z Erkr Atmungsorgane 142:164

Esterly JR, Oppenheimer EH (1966) Massive pulmonary hemorrhage in the newborn. I. Pathologic considerations. J Pediatr 69:3

Fagan CJ, Swischuk LE (1972) The opaque lung in lobar emphysema. AJR 144:300

Falkenbach KH, Bachmann KD, O'Loughlin BJ (1961) Pneumocystis carinii pneumonia. AJR $85: 706$

Fauré C, Sauvegrain J, Bomsel F (1971) Hernie congénitale du diaphragme droit avec coupole diaphragmatique en place normale à la naissance. Ann Radiol (Paris) 14:305

Fawcitt J, Lind J, Wegelius C (1960) The first breath. Acta Paediatr Scand [Suppl 123] 49:5

Feingold M (1971) Aplasia of the diaphragm. Pediatrics $47: 601$

Felman AH, Rhatigan RM, Pierson KK (1972) Pulmonary lymphangiectasia: Observations in 17 patients and proposed classification. AJR 116:548

Felson B (1970) Pulmonary agenesis and related anomalies. Semin Roentgenol 7:17

Fletcher BD, Sachs BF, Kotas RV (1970) Radiologic demonstration of postnatal liquid in the lungs of newborn lambs. Pediatrics 46:252

Fliegel CP, Kaufmann HJ (1972) Problems caused by pneumothorax in congenital diaphragmatic hernia. Ann Radiol 15:159

Floyd FW, Repici A, Gibson ET, Mc George CA (1963) Bilateral congenital lobar emphysema surgically corrected. Pediatrics $31: 87$

Fox WW, Gewitz MH, Dinwiddie R, Drummond WH, Peckham GJ (1977) Pulmonary hypertension in the perinatal aspiration syndromes. Pediatrics $59: 205$

Frisch H, Schabel F (1979) Der Hydrothorax in der Neonatalperiode. Monatsschr Kinderheilkd $127: 207$

Frommell GT, Rothenberg R, Wang S, McIntosh K (1979) Chlamydial infection of mothers and their infants. J Pediatr 95:28

Fronstin MH, Hooper GS, Besse BE, Ferreri S (1967) Congenital pulmonary cystic lymphangiectasis. Am J Dis Child 114:330

Giedion A (1965) Beidseitiger Hydrothorax als Ursache schwerster initialer Atemnot des Neugeborenen. RÖFO 102:29

Giedion A, Haefliger H, Dangel P (1973) Acute pulmonary $\mathrm{X}$-ray changes in hyaline membrane disease treated with artificial ventilation and positive end-expiratory pressure (PEEP). Pediatr Radiol $1: 145$

Glasson MJ, Barter W, Cohen DH (1975) Congenital left posterolateral diaphragmatic hernia with previously normal chest x-ray. Pediatr Radiol 3:201

Goldman HS, Scarpelli EM (1981) Pattern of clearance of fetal pulmonary fluid from the newborn lung (Abst.) AJR 135:863

Gooding CA, Gregory GA (1971) Roentgenographic analysis of meconium aspiration of newborns. Radiology 100:131

Greenwood RD, Rosenthal A, Nadas AS (1976) Cardiovascular abnormalities associated with congenital diaphragmatic hernia. Pediatrics 57:92

Gregg RH, Bernstein J (1961) Pulmonary hyaline membranes and the respiratory distress syndrome. Am J Dis Child 102:871

Gregory GA, Gooding CA, Phibbs RH, Tooley WH (1974) Meconium aspiration in infants - a prospective study. J Pediatr 85:848

Griscom NT, Harris GBC, Wohl MEB, Vawter GF, Eraklis AJ (1969) Fluid-filled lung due to airway obstruction in the newborn. Pediatrics $43: 383$

Griscom NT, Wohl MEB, Kirkpatrick JA (1978) Lower respiratory infections: how infants differ from adults. Radiol Clin North Am 26:367

Grohmann W, Riedeberger J (1966) Lungenzysten. Z Ärztl Fortbild (Jena) 60:1-171

Gross RE (1953) The surgery of infancy and childhood. Saunders, Philadelphia, p 428

Grossmann H, Winchester PH, Auld PA (1970) Simultaneous frontal and lateral chest roentgenograms on low birth weight infants. AJR 108:550

Gruenwald P (1958) The significance of pulmonary hyaline membrane in newborn infants. JAMA 166:621

Grundner HG (1974) Doppelseitige parasternale Zwerchfellhernie mit Schilddrüsenaplasie bei einem Säugling. RÖFO 120:362

Gwinn JL, Lee FA (1970) Congenital pulmonary cysts. Am J Dis Child 119:341

Gwinn JL, Lee FA (1973) Radiological case of the month. Am J Dis Child 125:539

Gwinn JL, Lee FA (1974) Radiological case of the month: Intrauterine transfusion of donor blood into right thorax of fetus. Am J Dis Child 128: 521

Gwinn JL, Lee FS, Fagan CJ, Swischuk LE (1974) Radiological case of the month: right upper and middle lobar agenesis with accessory diaphragm. Am J Dis Child 128:367

Haller JA jr, Signer RD, Golladay ES, Inon AE, Harrington DP, Shermeta DW (1976) Pulmonary and ductal hemodynamics in studies of simulated diaphragmatic hernia of fetal and newborn lambs. J Pediatr Surg 11:675

Halliday HL, McClure G, Mc Reid M (1981) Transient tachypnea of the newborn: two distinct clinical entities? Arch Dis Child 56:322

Hammersen G, Bartholomé K, Oppermann HC, Wille L, Lutz P (1977) Group B streptococci : A new threat to the newborn. Eur J Pediatr 126:189

Harris H (1977) Pulmonary pseudocysts in the newborn infant. Pediatrics 59:199

Harris GBC (1981) Persönliche Mitteilung

Harrod JR, Heureux PL, Wagensteen OD, Hunt CE (1974) Long-term follow up of severe respiratory distress syndrome treated with IPPB. J Pediatr $84: 277$ 
Hartenberg MA, Brewer WH (1983) Cystic adenomatoid malformation of the lung: Identification by sonography. AJR 140:693

Hashida Y, Sherman FE (1961) Accessory diaphragm associated with neonated respiratory distress. J Pediatr 59:529

Hathaway WE (1970) Coagulation problems in the newborn infant. Pediatr Clin North Am 17:929

Hegenbarth R, von der Hardt H, Zimmermann H (1980) Zur röntgenologischen Differentialdiagnose der einseitigen Lungenüberblähung im Neugeborenen- und Säuglingsalter. Röntgenblätter $33: 539$

Hendren H, McKee DM (1966) Lobar emphysema of infancy. J Pediatr Surg 1:24

Hernandes RJ, Stern AM, Rosenthal A (1980) Pulmonary lymphangiectasis in Noonan syndrome. AJR 134:75

Heymann MA, Rudolph AM (1972) Effects of congenital heart disease on fetal and neonatal circulation. Prog Cardiovasc Dis 15:115

Heymer A (1963) Klinik der zystischen Lungenerkrankungen. Langenb Arch Klin Chir 304: 348

Heymer R, Benz-Bohm G, Heimann G (1981) Die kongenitale Wabenlunge beim Kind - ein radiologischer Zufallsbefund. RÖFO 135:381

Higgins CB, Rausch J, Friedmann WF, Hirschklau MJ, Kirkpatrick SE, Goergen TG, Reinke RT (1977) Patent ductus arteriosus in preterm infants with idiopathic respiratory distress syndrome. Radiology 123:189

Highman JH (1969) Staphylococcal pneumonia and empyema in childhood. AJR 106:103

Hilton S, Edwards DK, Hilton JW (1984) Practical pediatric radiology. Saunders, Philadelphia London Toronto

Hinds EA, Linkner LM, Clud DT, Trump DS (1970) Ectopic thymic tissue of the neck. J Pediatr Surg $5: 460$

Hislop A, Reid L (1970) New pathologic findings in emphysema of childhood. I. Polyalveolar lobe with emphysema. Thorax 25:682

Hislop A, Reid L (1973) Pulmonary arterial development during childhood: branching pattern and structure. Thorax 28:129

Hislop A, Reid L (1976) Persistent hypoplasia of the lung after repair of congenital diaphragmatic hernia. Thorax $31: 450$

Hislop A, Hey E, Reid L (1979) The lungs in congenital bilateral renal agenesis and dysplasia. Arch Dis Child 54:32

Hitch DC, Minor GR, Mitchell AR, Keats TE (1973) Dilated lymphatics in congenital lobar emphysema. J Thorac Cardiovasc Surg 66:127

Hobson D, Rees E (1977) Chlamydia infection in neonates. NEJM 296:398

Hodgman JE, Mikity VG, Tatter D, Cleland RS (1969) Chronic respiratory distress in the premature infants, Wilson-Mikity syndrome. Pediatrics $44: 179$
Hoffmann RR, Campbell RE, Decker JP (1974) Fetal aspiration syndrome: clinical roentgenologic and pathologic features. AJR 122:90

Holden KR, Alexander F (1970) Diffuse neonatal hemangiomatosis. Pediatrics 46:411

Holm AL, Söderlund S (1975) Experience of postoperative chylothorax in children. Pediatr Radiol 4:10

Horcher E, Helmer F, Felsenreich G (1979) Kongenitale zystische Adenomatose beim Neugeborenen: Vortäuschung einer Zwerchfellhernie. Z Kinderchir 26:197

Howatt WF, Avery ME, Humphreys PW, Normand ICS, Reid L, Strang LB (1965) Factors affecting pulmonary surface properties in the fetal lamb. Clin Sci 29:239

Hüner H, Mahmoudi I (1970) Die ,Zwerchfellhernien" als Ursache lebensbedrohlicher Zustände der Neugeborenenperiode. Geburtshilfe Frauenheilkd 4:327

Humphreys PW, Normand ICS, Reynolds EOR, Strang LB (1967) Pulmonary lymph flow and the uptake of liquid from the lungs of the lamb at the start of breathing. J Physiol (Lond) 193:1

Huxtable KA, Tucker AS, Wedgwood RJ (1964) Staphylococcal pneumonia in childhood. Am J Dis Child 108:262

Ikeda $T$, Ishihara T, Yoshimatsu H, Kikuchi K, Yamazaki S, Hatakeyma T, Murakami M, Kobayashi K (1972) Accessory diaphragm associated with congenital posteriolateral diaphragmatic hernia, aberrant systemic artery to the right lower lobe, and anomalous pulmonary vein. Review and report of a case. J Thorac Cardiovas Surg 64: 18

Irle U, Oelsnitz G vd, Schwede N, Willich E (1969) Zwerchfellbrüche beim Kind. Fortschr Med $31: 1-270$

Ivemark BI, Wallgren CG (1962) Diffuse interstitial pulmonary fibrosis (Hamman-Rich-Syndrome) in infancy. Acta Paediat Scand [Suppl] 135:97

Jones RWA, Pickering D (1977) Persistent ductus arteriosus complicating the respiratory distress syndrome. Arch Dis Child 52:274

Joshi VV, Escobar MR, Stewart L, Bates RD (1973) Fatal influenza $A 2$ viral pneumonia in a newborn infant. Am J Dis Child 126:839

Josten EA, Haupt H (1956) Hämothorax bei einem Neugeborenen. Kinderärztl Prax 24:204

Kabelka M, Sintakova B, Zitkova M (1977) Dysontogenic accessory lobe of the thymus; a new clinical entity? Z Kinderchir 20:116

Kananoglu A, Tuncbilek E (1978) Accessory diaphragm in the left side. Pediatr Radiol 7:172

Karlberg P (1960) The adaptive changes in the immediate postnatal period, with particular reference to respiration. J Pediatr 56:585

Karlberg P, Cherry RB, Escardó FE, Koch G (1962) Respiratory studies in newborn infants II. Pulmonary ventilation and mechanics of breathing in 
the first minutes of life, including the onset of respiration. Acta Paediatr $51: 121$

Kaufmann HJ (1962) Über eine neue Form von Lungenfibrose bei Frühgeborenen. ROFO 97:434

Keith HH (1977) Congenital lobar emphysema. Pediatr Ann 6:34

Kemp FH, Morley HMC, Emrys-Roberts E (1948) A sail-like triangular projection from the mediastinum: A radiographic appearance of the thymus gland. Br J Radiol 21:618

Kenny JD (1977) Right-sided diaphragmatic hernia of delayed onset in the newborn infants. South Med J 70 (3): 373

Kerstan J, Schmidt DST (1977) Aneurysma des Ductus arteriosus beim Neugeborenen. Monatsschr Kinderheilkd 125:888

Keutel J, Willich E (1968) Röntgenologische Differentialdiagnostik zystischer und lokalisierter Lungenaufhellungen im Säuglings- und Kindesalter. RÖFO 109:291

Kirchner SG, Burko H, O’Neill JA (1975) Delayed radiographic presentation of congenital right diaphragmatic hernia. Radiology 155:155

Kirkpatrick JA jr (1980) Pulmonary development: Postnatal considerations. Postgraduate Course in Pediatric Radiology Boston, No 3-5

Kirks DR, McCook TA, Serwer GA, Newland Oldham $\mathrm{H}$ jr (1980) Aneurysm of the ductus arteriosus in the neonate. AJR 134:573

Kitagawa M, Hislop A, Boyden EA, Reid L (1971) Lung hypoplasia in congenital diaphragmatic hernia. A quantitative study of airway, artery and alveolar development. Br J Surg 58:342

Knapp K (1967) Aortenknopf beim Neugeborenen als Zeichen eines ,zirkulatorischen Distress“. Z Kinderchir 5:180

Knight L, Tobin J jr, L'Heureux Ph (1974) Hydrothorax: A complication of hyperalimentation with radiologic manifestations. Radiology 111:693

Konrad RM, Fahmy AR (1959) Angeborene Zwerchfellhernien und Zwerchfellprolapse im Kindesalter. Arch Klin Chir 291:253

Korobkin MT, Miller SW, Lorimier AA de, Gordon LS, Palubinskas AJ (1973) Hepatic herniation through the Morgagni foramen. Am J Dis Child $126: 217$

Köteles GY (1982) X-ray diagnosis in neonates. Akadémia Kiadó, Budapest, p 53, 57, 64

Kozlowski K, Glasson MJ (1980) Geometrical features of the Bochdalek congenital diaphragmatic hernia. RÖFO 133:2

Kramer SS, Taylor GA, Garfinkel DJ, Simmons MA (1981) Lethal chylothoraces due to superior vena caval thrombosis in infants. AJR 137:559

Krous HF, Dietzmann D, Ray CG (1973) Fatal infections with echovirus types 6 and II in early infancy. Am J Dis Child 126:842

Kuhn AP, Fletcher BD, Lemos MRA de (1969) Roentgen findings in transient tachypnea of the newborn. Radiology 92:751
Kuhn JP, Lee SB (1973) Pneumatoceles associated with escherichia coli pneumonias in the newborn. Pediatrics $51: 1008$

Kundert JG, Willich E (1969) Der idiopathische Chylothorax im Säuglings- und frühen Kindesalter. Dtsch Med Wochenschr 23:1221

Kurpat D, Rothe G (1974) Zystische Lungenveränderungen. Z Erkr Atmungsorgane 140:170

Kwittken H, Reiner L (1962) Congenital cystic adenomatoid malformation of the lung. Pediatrics 30:759

Lanning P, Similä S, Suramo I, Paavilainen T (1978) Lymphatic abnormalities in Noonan's syndrome. Pediatr Radiol 7:106

Laurence KM (1955) Congenital pulmonary cystic lymphangiectasis. J Pathol Bacteriol 70:325

Laurence KM (1959) Congenital pulmonary cystic lymphangiectasis. J Clin Pathol 12:62

Lanuza A (1971) The sign of the cane. Radiology $101: 293$

Leape LL, Longino LA (1964) Infantile lobar emphysema. Pediatrics $34: 246$

Leape LL, Ching N, Holder TM (1970) Lobar emphysema and patent ductus arteriosus. Pediatrics $46: 97$

Leonidas JC, Moylan FMB, Kahn PC, Ramenofsky ML (1978) Ventilation - perfusion scans in neonatal regional pulmonary emphysema complicating ventilatory assistance. AJR $131: 243$

Leonidas JE, Hall RT, Beatty EC, Fellows RA (1977) Radiographic findings in early-onset neonatal group B streptococcal septicemia. Pediatrics (Suppl) 59:1006

Levy JL, Guynes WA, Louis JE, Linder LH (1969) Bilateral congenital diaphragmatic hernias through the foramina of Bochdalek. J Pediatr Surg 4:557

Lilien LD, Harris VJ, Phildes RS (1977) Significance of radiographic findings in early-onset group $B$ streptococcal infection. Pediatrics $60: 360$

Loher E, Giedion A (1971) Radiological aspects of massive hemorrhage in the newborn. Report of three surviving cases. Ann Radiol 14:147

Luddy RE, Champion LAA, Schwartz AD (1977) Pneumocystis carinii pneumonia with pneumatocele formation. Am J Dis Child 131:470

Macias EG, Eller JJ, Huber TW, Abraham G, Diserens HW, Crawford ST (1974) Immunofluorescence of tracheal secretions in neonatal syphilis. Pediatrics 53:947

Madewell JE, Stocker JT, Korsower JM (1975) Cystic adenomatoid malformation of the lung; morphologic analysis. AJR 124:436

Mauney MF, Sabiston DC (1970) The role of pulmonary scanning in the diagnosis of congenital lobar emphysema. Am Surg 36:20

McCarten K, Rosenberg HK, Borden SP, Mandell GA (1981) Delayed appearance of rigt diaphragmatic hernia associated with group B streptococcal infection in newborns. Radiology 139:385 
McCredi J, Reid IS (1978) Congenital diaphragmatic hernia associated with homolateral upper limb malformation; a study of possible pathogenesis in four cases. J Pediatr 92:762

McKendry JB, Lindsay WL, Gerstein MC (1957) Congenital defects of lymphatics in infancy. Pediatrics 19:21

Mendelsohn G, Hutchin GM (1977) Primary pulmonary hypoplasia. Am J Dis Child 131:1220

Merenstein GB (1969) Congenital cystic adenomatoid malformation of the lung. Am J Dis Child 118:772

Mikity VG, Hodgman JE, Tatter D (1967) The radiologic findings in delayed pulmonary maturation in premature infants. Prog Pediatr Radiol 1:149

Miller BW, Orris HW, Taus HH (1947) Friedländer's pneumonia in infancy. J Pediatr $31: 521$

Milner AD, Saunders RA, Hopkin IE (1978) Effects of delivery by caesarean section on lung mechanism and lung volume in the human neonate. Arch Dis Child 53:545

Mithal A, Emery JL (1961) Postnatal development of alveoli in premature infants. Arch Dis Child $36: 449$

Moës CAF, Sondheimer HM, Keith JD, Bloom KR, Gilday DL, Rowe RD (1978) The chest roentgenogram in congenital heart disease. In: Keith JD, Rowe RD, Vlad P (eds) Heart disease in infancy and childhood, 3rd ed. Macmillian, New York Toronto London, $\mathrm{p} 45$

Moffat AD (1960) Congenital cystic disease of the lungs and its classification. J Pathol Bact 79:361

Monin P, Didier F, Vert P, Prevot J, Plenat F (1979) Giant lobar emphysema - neonatal diagnosis. Pediatr Radiol 8:259

Moore PH, Brogdon BG (1962) Granulomatosis infantiseptica. Radiology $79: 415$

Moss AJ, Emmanoulides G, Duffie ER (1963) Closure of the ductus arteriosus in the newborn infant. Pediatrics $32: 25$

Moylan FMB, Kramer SK, Todres IS, Shannon DC (1976) Bronchopulmonary dysplasia and mechanical ventilation of RDS. Pediatr Res 10:465

Mulvey RB (1963) The thymic "wave" sign. Radiology $81: 834$

Nadas AS, Fyler DC (1972) Pediatric cardiology, 3rd ed. Saunders, Philadelphia London Toronto, p 34

Nadelhaft J, Ellis K (1957) Roentgen appearances of the lungs in 1000 apparently normal full term newborn infants. AJR 78:440

Naeye RL, Shochat SJ, Whitman V, Maisels MJ (1976) Unsuspected pulmonary vascular abnormalities associated with diaphragmatic hernia. Pediatrics 58:902

Nash G, Blennerhassett JB, Pontoppidan H (1967) Pulmonary lesions associated with oxygen therapy and artificial ventilation. N E J M 276:368

Neches WH, Williams RL, Mc Namara DG (1972) Pulmonary angiographic findings in infantile lobar emphysema. Am J Dis Child 123:171
Neuhauser EBD, Griscom NT (1967) Aspiration pneumonitis in children. Progr Pediatr Radiol $1: 265$

Nicole R (1965) Das stehende, geblähte Sigma als typisches Symptom beim angeborenen Zwerchfelldefekt des Neugeborenen. Radiol Clin Biol $34: 273$

Nielsen HC, Cloherty H, Harris GBC (1980) Group B streptococcal infection with delayed onset right diaphragmatic hernia (DH): Correlation of clinical course and radiographic findings. Pediatr Res $14: 516$

Nigogosyan G, Ozarda A (1961) Accessory diaphragm: A case report. AJR 85:309

Noonan JA, Walters LR, Reeves JT (1970) Congenital pulmonary lymphangiectasis. Am J Dis Child $120: 314$

Northway WH, Rosan RC (1968) The radiographic features of pulmonary oxygen toxicity in the newborn: Bronchopulmonary dysplasia. Radiology $91: 49$

Northway WH jr, Rosan RC, Porter DY (1967) Pulmonary disease following respiratory therapy of hyaline-membrane disease: Bronchopulmonary dysplasia. N E J M 276:357

Obladen M (1979) Tracheale Phospholipid-Zusammensetzung und Atemnotsyndrom des Neugeborenen. Fortschr Med 97:403

Oestreich AE (1973) Air-fluid level detection in neonatal lung cyst identification. Pediatr Radiol $1: 244$

Oetgen WJ (1979) Chlamydial pneumonia of infancy vs Wilson-Mikity-syndrome. Pediatrics 64:119

O'Hara AE, Libshitz HI (1968) Congenital pulmonary lymphangiectasis. AJR 103:119

Ohi R, Suzuki H, Kato T, Kasai M: Development of the lung in fetal rabbits with experimental diaphragmatic hernia. (1976) J Pediatr Surg 11 955

Olley PM, Coceani F (1981) Prostaglandins and the ductus arteriosus. Annu Rev Med 32:375

Oppermann HC (1983) Die Lungengefäßstruktur bei der bronchopulmonalen Dysplasie - Angiographische Studien -. Habilitationsschrift, RuprechtKarls-Universität Heidelberg

Oppermann HC, Wille L (1977) Röntgenologie pulmonal bedingter Lungenveränderungen bei Neuund Frühgeborenen. Pädiatr Prax 18:569

Oppermann HC, Wille L (1980) Hemothorax in the newborn. Pediatr Radiol 9:129

Oppermann HC, Wille L (1982) Bronchopulmonale Dysplasie. In: Oppermann HC, Wille L, Ulmer HE (Hrsg) Der Neugeborenen-Thorax. Springer, Berlin Heidelberg New York, S. 74

Oppermann HC, Wille L, Bleyl U, Obladen M (1977) Bronchopulmonary dysplasia in premature infants - a radiological and pathological correlation. Pediatr Radiol 5:137

Oppermann HC, Wille L, Ulmer HE (1980) Zur Problematik der Röntgendiagnose des persistieren- 
den Ductus Botalli bei Frühgeborenen mit Atemnotsyndrom. Wissensch Inform (Milupa) 613:69

Oppermann HC, Wille L, Ulmer HE (1982) Der Neugeborenen-Thorax. Springer, Berlin Heidelberg New York, S 5, 47, 80, 91, 98, 105, 109, 127

Oppermann HC, Ulmer HE, Wille L (1983) Radiographic assessment of patent ductus arteriosus in preterm infants. Pediatr Cardiol (Suppl II) 4:43

Oppermann HC, Ulmer HE, Wille L (1984) Die Atemnot des Neugeborenen aus radiologischer Sicht. Monatsschr Kinderheilkd 132:378

Oppermann HC, Wiens A, Wiens ST, Wille L (1986) Ist die röntgenmorphologische Stadieneinteilung der bronchopulmonalen Dysplasie nach Northway noch sinnvoll? In: Hohenauer L (Hrsg) Pädiatrische Intensivmedizin VII. Thieme, Stuttgart, New York, p 21

Opsahl T, Berman EJ (1962) Bronchogenic mediastinal cysts in infants. Case report and report and review of the literature. Pediatrics $30: 372$

Outerbridge EW, Stern L (1972) Developmental follow-up of artificially ventilated infants with neonatal respiratory failure. Pediatr Res 6:152

Parker JC, Brown AL, Harris LE (1968) Pulmonary hemorrhage in newborn. Mayo Clin Proc 43: 465

Passarge E, Halsey H, German J (1968) Unilateral agenesis of the diaphragm. Humangenetik 5:226

Patriquin H, Lebowitz R, Perreault G, Yousefzadeh $D$ (1980) Neonatal candidiasis: Renal and pulmonary manifestations. AJR 135:1205

Patriquin HB, Beauregard G, Dunbar JS (1976) The right pleuromediastinal reflection in children. $\mathrm{J}$ Can Assoc Radiol 27:9

Pendarvis B, Swischuk LE (1969) Lung scanning in the assessment of pulmonary disease in children. AJR 107:313

Perlman M, Levin M (1974) Fetal pulmonary hypoplasia, anuria and oligohydramnios; clinicopathologic observations and review of the literature. Am J Obstet Gynecol 118:1119

Peterson HG, Pendleton ME (1955) Contrasting roentgenographic pulmonary patterns of the hyaline membrane and fetal aspiration syndromes. AJR 74:800

Peuckert W, Huys J, Pringsheim W, Reinwein H (1981) Chlamydien-Pneumonie im jungen Säuglingsalter. Monatsschr Kinderheilkd 129:575

Philip AGS (1975) Oxygen plus pressure plus time: The etiology of bronchopulmonary dysplasia. Pediatrics $55: 44$

Philip AGS, Larson EJ (1973) Overwhelming neonatal infection with ECHO 19 virus. J Pediatr 82:391

Pierce WS, Paredes CG de, Friedman S, Waldhausen JA (1970) Concomitant congenital heart disease and lobar emphysema in infants; incidence, diagnosis, and operative management. Ann Surg $172: 951$

Pietsch J, Ungeheuer E (1960) Die angeborenen
Zwerchfellhernien, ihre frühe Erkennung und Behandlung. Kinderärztl Prax 1:22

Polansky SM, Frank A, Ablow RC, Effmann EL (1978) Congenital tuberculosis. AJR 130:994

Ponhold W (1981 a) Die radiologische Symptomatik der respiratorischen Anpassungsstörung (,,transiente Tachypnoe") und ihre Differentialdiagnose. Röntgenblätter 34:375

Ponhold W (1981 b) Die Lungenblutung des Neugeborenen im Thoraxröntgen und ihre Differentialdiagnose. Radiologe $21: 455$

Ponhold W (1982) Häufigste Ursachen, Komplikationen und Differentialdiagnose neonataler Atemstörungen im Röntgenbild. Pädiatr Pädol 17:715

Potter EL (1961) Pathology of the fetus and infant Year Book, Chicago

Pusey VA, Mac Pherson RI, Chernick V (1969) Pulmonary fibroplasia following prolonged artificial ventilation of newborn infants. Can Med Assoc J 100:451

Querfeld U, Sandbrink H, Oppermann HC (1984) Iatrogener Hydrothorax bei einem Frühgeborenen und seine Behandlung. Monatsschr Kinderheilkd 132:186

Radkowski MA, Kranzler JK, Beem MO, Tipple MA (1981) Chlamydia pneumonia in infants: Radiography in 125 cases. AJR 137:703

Raminosky ML, Leape LL, Mc Cauley RGK (1979) Bronchogenic cyst. J Pediatr Surg 14:219

Randolph JG, Gross RE (1975) Congenital chylothorax. Arch Surg 74:405

Reed JC, Sobonya RE (1975) Congenital lung cyst. Radiology 177:315

Reed JO, Lang EF (1959) Diaphragmatic hernia in infancy. AJR 82:437

Rehbein F, Röke T (1960) Lufthaltige Lungenzysten beim Säugling und Kleinkind. Monatsschr Kinderheilkd 108:422

Reid L (1977) The lung: its growth and remodeling in health and disease. AJR 129:777

Reid L (1979) Bronchopulmonary dysplasia - pathology. J Pediatr 95:836

Reynolds EOR (1970) Hyaline membrane disease. Am J Obstet Gynecol 106:780

Rhodes PG, Hall RT, Leonidas JC (1975) Chronic pulmonary disease in neonates with assisted ventilation. Pediatrics 55:788

Riggs W, Herschman AA (1970) Absent liver sign in congenital diaphragmatic hernia. South Med J $63: 265$

Rimmer S, Fawcitt J (1982) Delayed clearance of pulmonary fluid in the neonate. Arch Dis Child $57: 63$

Robinson AE, Gooneratne NS, Blackburn WR, Brogdon BG (1980) Bilateral antero-medial defect of the diaphragm in children. AJR 135:301

Rogers LF, Osmer JC (1964) Bronchogenic cyst: Review of 46 cases. A J R 91:273

Roghair GD (1972) Nonoperative management of lo- 
bar emphysema. Long-term follow-up. Radiology $102: 125$

Roos R, Peller P, Fendel H, Linderkamp O, Belohradsky BH (1979) Radiologische Befunde bei Neugeborenen mit B-Streptokokken-Sepsis. Herzgröße, Lungenbefunde und ihre klinische Bedeutung. Klin Pädiatr 191:305

Rowe S, Avery ME (1966) Massive pulmonary hemorrhage in the newborn. II. Clinical considerations. J Pediatr 69:12

Rudolph AJ, Smith CA (1960) Idiopathic respiratory distress syndrome of the newborn. J Pediatr 57:905

Rutishauser M, Rouen G, Wyler F (1977) Aneurysm of the nonpatent ductus arteriosus in the newborn. Acta Paediatr Scand 66:649

Saade M, Whitten DM, Necheles TF, Leape L, Darling D (1976) Posterior mediastinal accessory thymus. J Pediatr 88:71

Sagel SS, Ablow RC (1970) The use of umbilical venography for the diagnosis of congenital rightsided diaphragmatic hernia. Radiology $91: 797$

Saigal S, Wison R, Usher R (1977) Radiological findings in symptomatic neonatal plethora resulting from placental transfusion. Radiology 125:185

Sane SM, Girdany BR (1972) Cysts and neoplasms in the infant lung. Semin Roentgenol 7:122

Saunders RA, Milner AD (1978) Pulmonary pressure/volume relationships during the last phase of delivery and the first postnatal breaths in human subjects. J Pediatr 93:667

Scarpelli EM, Condorelli S, Cosmi EV (1975) Lamb fetal pulmonary fluid. - I. Validation and significance of method for determination of volume and volume change. Pediatr Res 9:190

Schaffer AM, Avery ME (1977) Diseases of the newborn, 4th edn. Saunders, Philadelphia London Toronto, p 116

Schapiro RL, Evans ET (1972) Surgical disorders causing neonatal respiratory distress. AJR 114:305

Schmidt-Redemann B, Pringsheim W, Böhm N, Schaupeter W (1980) Hämodynamik bei kongenitaler pulmonaler Lymphangiektasie. Klin Pädiatr $192: 342$

Schröder H, Paust H (1979) B-Streptokokken als häufigste Erreger der Neugeborenen-Sepsis. Monatsschr Kinderheilkd 127:720

Schütze U, Vogt-Moykopf I, Krieg M (1972) Lungenzysten und kongenitale Lungenemphyseme im Säuglings- und Kindesalter. Dtsch Med Wochenschr 97:1-462

Schukowski W (1903) Ein Fall von Hämothorax nicht traumatischen Ursprungs bei einem Neugeborenen. Jb Kinderheilkd 58:319

Schumacher G, Klein U, Locher D (1978) Röntgenuntersuchung des Herzens. In: Schumacher G, Bühlmeyer K (Hrsg) Diagnostik angeborener Herzfehler. Perimed, Erlangen, S 61

Seyberth HW (1986) Neue Aspekte zur Pathogenese des persistierenden Ductus arteriosus beim Frühgeborenen. Monatsschr Kinderheilkd 134:432

Shackelford GD, McAlister WH (1976) The aberrantly positioned thymus: a cause of mediastinal or neck masses in children. AJR 120:291

Shanklin DR, Wolfson SL (1967) Therapeutic oxygen as a possible cause of pulmonary hemorrhage in premature infants. N E J M 277:833

Shannon DC, Todres ID, Moylan FMB (1977) Infantile lobar hyperinflation; expectant treatment. Pediatrics 59:1012

Shannon MP, Grantmyre EB, Reid WD, Wotherspoon AS (1974) Congenital pulmonary lymphangiectasis, Report of two cases. Pediatr Radiol 2:235

Shepard FM, Johnston RB, Klatte EC, Burko H, Stahlman MT (1968) Residual pulmonary findings in clinical hyaline-membrane disease. $\mathrm{N} \mathrm{E}$ J M 279:1063

Siassi B, Blanco C, Cabel LA, Coran AG (1976) Incidence and clinical features of patent ductus arteriosus in low-birth-weight infants. A prospective analysis of 150 consecutively born infants. Pediatrics $57: 347$

Sicgel JD, McCracken GH (1979) Neonatal lung abscess. Am J Dis Child 133:947

Siegel MJ, Shackelford GD, Mc Alister WH (1981) Left-sided congenital diaphragmatic hernia: Delayed presentation. AJR 137:43

Silverman FN (1985) Caffey's Pediatric X-Ray diagnosis, 8th edn. Year Book, Chicago, p 1143

Singleton EB (1967) Respiratory distress syndrome. Prog Pediatr Radiol 1:108

Slovis ThL, Shankaran S (1980) Patent ductus arteriosus in hyaline membrane disease: Chest radiography. AJR 135:307

Sone S, Higashihara T, Morimoto S, Yokota K, Ikezoe J, Masoaka A, Monden Y, Kagotani T (1980) Normal anatomy of thymus and anterior mediastinum by pneumomediastinography. AJR 134:81

Speer M, Rosan RC, Rudolph AJ (1978) Clinical notes: Haemophilus influenzae infection in the neonate mimicking respiratory distress syndrome. J Pediatr 932:295

Stickney RH, Bjelland JC, Capp MP, Harrison RR, Hansen R (1978) Chlamydia trachomatis, a cause of an infantile pneumonia syndrome. AJR $131: 914$

Stocker JT, Drake RM, Madewell JE (1978) Cystic and congenital lung disease in the newborn. Perspect Pediatr Pathol 4:93

Stocks J, Godfrey S (1976) The role of artificial ventilation, oxygen, and CPAP in the pathogenesis of lung damage in neonates: Assessment by serial measurements of lung function. Pediatrics $57: 352$

Stoerk O (1897) Über eine angeborene blasige Mißbildung der Lunge. Wien Klin Wochenschr 10: 25

Stoker JA, Pyko BE (1978) Congenital hernia of right 
side of diaphragm associated with hemothorax. J Am Optom Assoc 77:789

Strang L (1963) Respiratory distress in newborn infants. Br Med Bull 19:45

Strang LB (1977) Neonatal respiration. Physiological and clinical studies. Blackwell, Oxford London Edinburgh Melbourne, p 73

Sulayman R, Thilenius O, Replogle R, Arcilla RA (1975) Unilateral emphysema in total anomalous pulmonary venous return. J Pediatr 87:433

Sundell H, Garrott J, Blankenship W, Shepard F, Stahlman M (1971) Studies on infants with type II respiratory distress syndrome. J Pediatr 78:754

Swischuk LE (1970) Transient respiratory distress of the newborn - TRND: a temporary disturbance of a normal phenomenon. AJR 108:557

Swischuk LE (1971) Anterior tracheal indentation in infancy and early childhood: Normal or abnormal? AJR 95:125

Swischuk LE (1980) Radiology of the newborn and young infant, 2nd edn. Williams and Wilkins, Baltimore London, p 64, 71, 151, 153, 167

Swischuk LE, Hayden CN (1983) The trachea in children. Semin Roentgenol XVIII (1):7

Swischuk LE, Richardson CJ, Nichols MM, Ingman MJ (1979) Primary pulmonary hypoplasia in the neonate. J Pediatr 95:753

Swischuk LE, Hayden CK, Richardson CJ (1981) Neonatal opaque right lung: Delayed fluid resorption. Radiology $141: 671$

Taber P, Gyepes MT, Lackey DA (1973) Malposition of umbilical vascular catheters in the diagnosis of congenital diaphragmatic hernia. Radiology 109:413

Tausend ME, Stern WZ (1965) Thymic patterns in the newborn. AJR 95:125

Taybi H (1971) Roentgen evaluation of cardiomegaly in the newborn period and early infancy. Pediatr Clin North Am 18:1031

Taylor F jr, Abrams M (1966) Effect of surface active lipoprotein on clotting and fibrinolysis, and of fibrinogen surface tension of surface active lipoprotein with a hypothesis on the pathogenesis of pulmonary atelectasis and hyaline membrane in respiratory distress syndrome of the newborn. Am J Med 40:346

Taylor PM, Allen AC, Stinson DA (1971) Benign unexplained respiratory distress of the newborn infant. Pediatr Clin North am 18:975

Tchou CS, Fletcher BD, Franke P, Outerbridge EW, Dunbar JS (1972) Asymmetric distribution of the roentgen pattern in hyaline membrane disease. $\mathrm{J}$ Can Assoc Radiol 23:85

Theros EG (1967) Case of the month from the AFIP. An exercise in radiologic-pathologic correlation. Radiology 89:524

Thibeault DW, Emmanouilides GC, Nelson RJ, Lachman RS, Rosengart RM, Oh W (1975) Patent ductus arteriosus complicating the respirato- ry distress syndrome in preterm infants. J Pediatr $86: 120$

Thomas GC, Clitherow NR (1977) Herniation through the foramen Morgagni in children. $\mathrm{Br}$ J Surg 64:215

Thomas SF, Dutz W, Khodadad EJ (1966) Pneumocystis carinii pneumonia (plasma cell pneumonia) AJR 98:318

Tipple MA, Beem MO, Saxon EM (1979) Clinical characteristics of the afebrile pneumonia associated with chlamydia trachomatis infection in infants less than 6 months of age. Pediatrics 63:192

Tischer W (1967) Der Chylothorax im ersten Trimenon. Z Kinderchir 5:43

Töndury G (1967) Über die Entwicklung und Anatomie des Zwerchfells beim Menschen. Arch Klin Chir 319:722

Tomashefski JF jr, Oppermann HC, Vawter GF, Reid LM (1984) Bronchopulmonary dysplasia: A morphometric study with emphasis on the pulmonary vasculature. Pediatr Pathol 2:469

Tomisawa M, Goto M, Kimpara K, Onouchi Z, Oga K (1974) Accessory diaphragm; report of a case associated with atrial septal defect. J Pediatr Surg $9: 223$

Toyama WM (1972) Combined congenital defects of the anterior abdominal wall, sternum, diaphragm, pericardium, and heart: A case report and review of the syndrome. Pediatrics 50:778

Trompeter R, Yu VYH, Aynsley-Green A, Roberton NRC (1975) Massive pulmonary hemorrhage in the newborn infant. Arch Dis Child 50:123

Tucker ThT, Smith WL, Smith JA (1977) Fluid-filled cystic adenomatoid malformation. AJR 129:323

Tyler DC, Murphey J, Cheney FW (1978) Mechanical and chemical damage to lung tissue caused by meconium aspiration. Pediatrics $62: 454$

Ulmer HE (1982) Erkrankungen des Herzens und der großen Gefäße. In: Oppermann HC, Wille L, Ulmer HE (Hrsg) Der Neugeborenen-Thorax. Springer, Berlin Heidelberg New York, S 131

Vessal K, Post C, Dutz W, Bandarizadeh B (1974) Pneumocystis carinii pneumonia. AJR 120:254

Visintine AM, Oleske JM, Nahmias AJ (1977) Listeria monocytogeneses infection in infant and children. Am J Dis Child 131:393

Wagner IU, Zweymüller E (1973) Chylothorax und Hydrothorax beim Neugeborenen. Bruns' Beitr Klin Chir 220:588

Wallace DB (1977) Radiographic exhibit; intrapericardial diaphragmatic hernia. Radiology 122:596

Walther A (1975) Ungewöhnlicher radiologischer Befund bei rechtsseitiger Zwerchfellhernie und Sequestration des rechten Lungenunterlappens. $\mathrm{Z}$ Kinderchir 16:97

Weigel W, Mentzel H (1974) Die angeborene Lymphangiektasie der Lunge. Monatsschr Kinderheilkd $122: 85$

Weill J, Baruch M, LeBalle J-Ch, Sternberg M (1965) 
Hémothorax du nouveau-né. Arch Fr Pediatr $22: 888$

Weingärtner L (1977) Das kongenitale lobäre Emphysem. Pädiatr Pädol 12:33

Weingärtner L, Reiss HJ, Knolle H (1968) Die interstitielle mononucleäre, herdförmige, fibrosierende Pneumonie (Wilson-Mikity-Syndrom) - keine ausschließliche Erkrankung Frühgeborener. Monatsschr Kinderheilkd 116:581

Weisenbach J, Schultz K, Sarlós P, Noth A (1982) Über die Röntgendiagnostik der Meconiumaspiration. Klin Pädiatr 194:100

Wesenberg RL (1973) The newborn chest. Harper \& Row, New York Evanston San Francisco, p 71,119

Wesenberg RL, Graven SN, McCabe EB (1971) Radiological findings in wet lung disease. Radiology 98:69

Wesenberg RL, Rumack CM, Lubchenco LO, Wirth FH, McGuinness GA, Tomlinson AL (1977) Thick blood syndrome. Radiology 125:181

Wexler HA, Dapena MV (1978) Congenital cystic adenomatoid malformation. Radiology 126:737

Wille L, Wurster K (1974) Congenital cystic adenomatoid pulmonary hamartoma in a newborn infant. Z Kinderheilkd 117:205

Wille L, Holthusen W, Willich E (1975) Accessory diaphragm. Pediatr Radiol 4:14

Willich E (1967a) The roentgenologic appearance of pulmonary listeriosis. Progr Pediatr Radiol 1:160

Willich E (1967b) A new pulmonary manifestation of listeriosis in newborn babies. Ann Radiol $10: 285$

Willich E, Kundert JG (1971) Chylothorax in the newborn. Radiological features. Ann Radiol $14: 155$

Wilson AK, Rumel WR, Ross OL (1947) Peritoneopericardial diaphragmatic hernia; report of a case in a newborn infant. AJR 57:42

Wilson M, Mikity VG (1960) A new form of respira- tory distress in premature infants. Am J Dis Child 99:489

Wiseman NE, McPherson RI (1977) Acquired congenital diaphragmatic hernia. J Pediatr Surg $12: 657$

Wittenborg MH, Gyepes MT, Crocker D (1967) Tracheal dynamics in infants with respiratory distress, stridor, and collapsing trachea. Radiology $88: 653$

Wohlfeld GM (1965) Hyaline membrane disease. AJR 93:425

Wolfson SL, Frech R, Hewitt C, Shanklin DR (1969) Radiographic diagnosis of hyaline membrane disease. Radiology 93:339

Wood BP (1979) Infantile chlamydia trachomatis pneumonia: Radiographic features. Ann Radiol $22: 213$

Wung JT, Koons AH, Driscoll JM, James LS (1979) Changing incidence of bronchopulmonary dysplasia. J Pediatr 95:845

Yaghmai I (1970) Agenesis of the lung. AJR 108:564

Yancy WS, Spock A (1967) Spontaneous neonatal pleural effusion. J Pediatr Surg 2:313

Young LW (1978) Radiological case of the month: Postnatal appearance of diaphragmatic hernia. Am J Dis Child 132:1137

Young LW (1979) Radiological case of the month, congenital cyst of the lung. Am J Dis Child 133:81

Young R, Pochaczevsky R, Pollak L, Bryk D (1973) Cervicomediastinal thymic cysts. AJR 117:855

Zach M, Ritschl E (1982) Das chlamydienbedingte subakute Pneumoniesyndrom junger Säuglinge. Pädiatr Prax 26:57

Zsebök Z (1958) Röntgenanatomie der Neugeborenen- und Säuglingslunge. Thieme, Stuttgart, p 17

Zumbro GL, Green DC, Brott W, Treasure RL (1974) Pulmonary lung sequestration with spontaneous intrapleural hemorrhage. J Thorac Cardiovasc Surg 68:673-674 